\title{
Magnetic model studies of the New York-Alabama Lineament and other magnetic anomalies in West Virginia
}

\author{
Tanner Anthony Sattler \\ West Virginia University
}

Follow this and additional works at: https://researchrepository.wvu.edu/etd

\section{Recommended Citation}

Sattler, Tanner Anthony, "Magnetic model studies of the New York--Alabama Lineament and other magnetic anomalies in West Virginia" (2000). Graduate Theses, Dissertations, and Problem Reports. 1098.

https://researchrepository.wvu.edu/etd/1098

This Thesis is protected by copyright and/or related rights. It has been brought to you by the The Research Repository @ WVU with permission from the rights-holder(s). You are free to use this Thesis in any way that is permitted by the copyright and related rights legislation that applies to your use. For other uses you must obtain permission from the rights-holder(s) directly, unless additional rights are indicated by a Creative Commons license in the record and/ or on the work itself. This Thesis has been accepted for inclusion in WVU Graduate Theses, Dissertations, and Problem Reports collection by an authorized administrator of The Research Repository @ WVU. For more information, please contact researchrepository@mail.wvu.edu. 


\title{
Magnetic Model Studies of the New York - Alabama Lineament and other magnetic anomalies in West Virginia
}

\author{
Tanner A. Sattler \\ Thesis submitted to the Eberly College of Arts and Sciences \\ at West Virginia University \\ in partial fulfillment of the requirements \\ for the degree of \\ Master of Science \\ in \\ Geology
}

Thomas H. Wilson, Ph.D., Chairperson
Helen Lang, Ph.D.
Robert Shumaker, Ph.D.
Department of Geology and Geography

Morgantown, West Virginia

2000

Keywords: Total Intensity Magnetics, Residual Magnetics, Magnetic Modeling, Structural Geology 


\title{
Magnetic Model Studies of the New York - Alabama Lineament and other magnetic anomalies in West Virginia
}

Tanner A. Sattler

\begin{abstract}
This study was undertaken to model possible origins of the magnetic anomalies in the central Appalachian foreland of West Virginia with aeromagnetic total intensity data. Analysis of the areal distribution of residual magnetic anomalies and modeling of of selected residual magnetic profiles were also undertaken. Basement crustal lithology and structure are thought to be responsible for the magnetic anomalies observed in West Virginia. The most prominent magnetic anomaly modeled in the study area is the New York - Alabama lineament (NY-Al). The NY-Al is a regional scale, linear magnetic high that lies along the east margin of the Rome trough in central West Virginia.

Preliminary model studies were undertaken of a local magnetic anomaly along the $\mathrm{NY}-\mathrm{Al}$ in the Gassaway District of Braxton and Clay counties of central West Virginia. Models of a NY-Al source revealed that the center of the magnetic bodies used to simulate the magnetic anomaly can be located no deeper than 20 kilometers below current sea level (at approximately mid-crustal depths as inferred from earlier gravity model studies). Models indicate that the dip of this zone could be anywhere from $32^{\circ} \mathrm{NW}$ to $27^{\circ} \mathrm{SE}$. The magnetic susceptibility has been modeled within the range of 0.0025 to $199.0 \mathrm{cgs}$ units, so that any known lithology could, in theory, be used to represent the NY-Al magnetic source body. The models of the NY-Al source body, however, use the average magnetic susceptibility of a basalt (consistent with the likely lithology of an intrusion along a transform fault zone).

Interpretations of residual aeromagnetic data (provided by AGI) reveal the presence of two categories of magnetic anomaly trends. Variations in the magnetic grain of the region are reflected in the form of alignment of residual magnetic anomaly highs and lows (ARMAHLs). Interruptions of anomaly trends are present in the form of the alignment of residual magnetic anomaly terminations (ARMATs). Selected anomalies (both ARMAHLS and ARMATs) are modeled to assess possible geological interpretations responsible for their formation. In addition, the ARMATs and ARMAHLs are superimposed upon inferred and known near surface structures for purposes of adding support to the theory of basement reactivation and subsequent formation of structures, such as the Gassaway dome.

Results from the modeling of the residual data reveal that a weathered basement deformation zone or simply basement topography may be used to represent the low amplitude, short wavelength anomalies occupying regions bounded by ARMATs. Regions characterized by relatively low amplitude anomalies within the Rome trough, could not be modeled as preferentially weathered areas of low susceptibility. Instead, residual magnetic anomalies in this area of the trough were successfully modeled by introducing thin sheets of relatively high susceptibility (interpreted as basalt flows) into the interior of the trough.
\end{abstract}




\section{Acknowledgements}

I would like to thank my advisory committee for their helpful advice and patience during this thesis process. Dr. Helen Lang has provided me with a great deal of useful information concerning basement and New York - Alabama lineament mineralogy issues, along with some much needed grammatical editing. I would also like to thank Dr. Robert Shumaker for his financial contribution from the Shumaker Fund, which allowed me to present the preliminary results of this project at the 1999 Geological Society of America National Meeting in Denver, Colorado. A special thank you is given to my advisor, Dr. Thomas Wilson, for his encouragement and commitment concerning the completion of this study.

I am also indebted to Applied Geophysics Incorporated and S. Parker Gay for their donation of the residual magnetic data and map.

I would like to thank two other non-committee members, Dr. Dick Smosna and Dr. Kathy Bruner, for their numerous employment leads and advice on life after WVU. To all the friends of BAGL, thanks for the good times and laughs! You have made my time here at WVU most memorable.

I would also like to acknowledge my parents, Bruce and Diane Sattler, for their unwavering devotion and support. Mom and Dad, thank you. To my new wife, Niki, thank you for having the stamina to move to Morgantown and putting up with me through the completion of my degree. 


\section{Table of Contents}

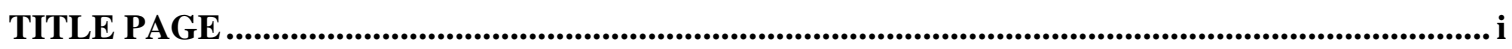

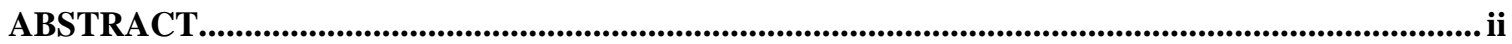

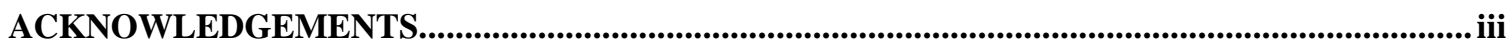

TABLE OF CONTENTS ........................................................................................................................ iv

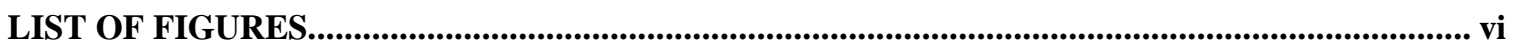

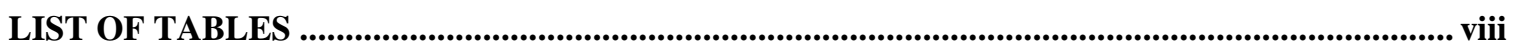

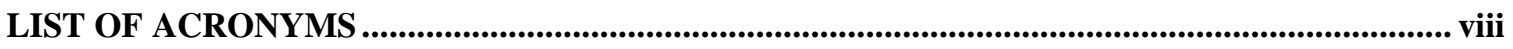

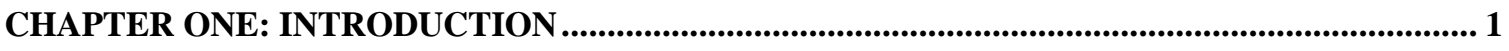

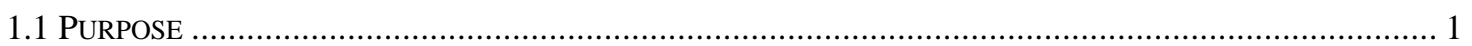

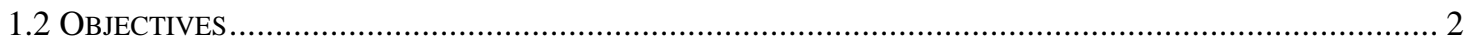

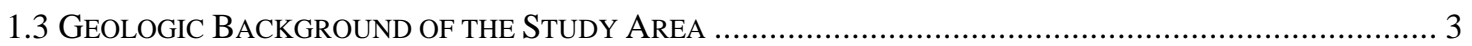

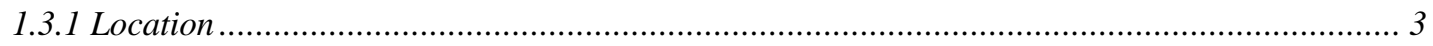

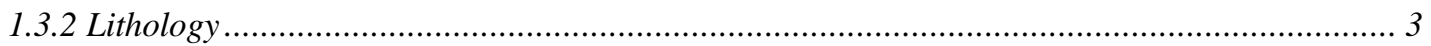

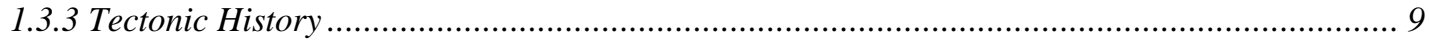

1.4 TOTAL-INTENSITY AND RESIDUAL AEROMAGNETIC DATA AND MAPS........................................... 10

1.4.1 Data from the Aeromagnetic Map of West Virginia (WVGES, 1978) .................................... 10

1.4.2 Data donated from Applied Geophysics Incorporated ..................................................... 13

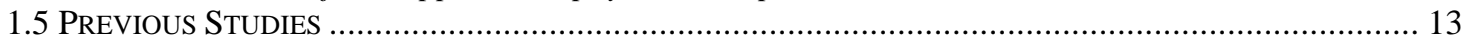

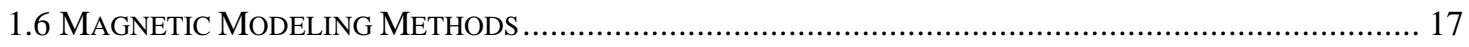

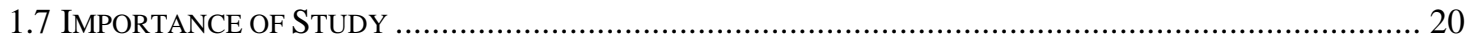

CHAPTER TWO: MODEL STUDIES OF THE GASSAWAY AREA USING WVGES (1978) AND

AGI AEROMAGNETIC DATA ................................................................................................. 22

2.1 Magnetic Modeling of GaSSAway AREA with WVGES (1978) DATA ........................................ 22

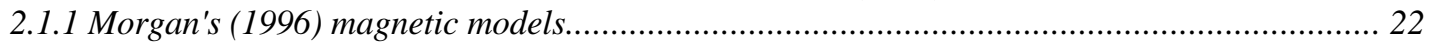

2.1.2 Incorporation of Morgan's (1996) models to the Gassaway Anomaly study ............................. 24

2.1.3 Models Cross Strike to the NY- Al with WVGES (1978) Data................................................. 26

2.1.3.1 Susceptibility trends of the Gassaway Magnetic Body ……………………………......................26

2.1.3.2 Depth to the Mid-Point of the Gassaway Magnetic Anomaly .........................................................29

2.1.3.3 Dipping Suture Zone Model for the Gassaway Anomaly .................................................................

2.1.4 Models Along-Strike to the NY-Al with WVGES (1978) Data ................................................ 35

2.2 Data AND MODEL COMPARISON OF WVGES (1978) DATA TO THE AGI DATA .............................. 37

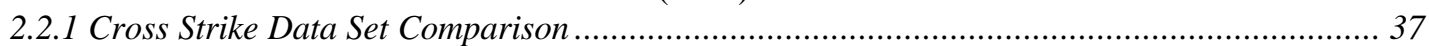

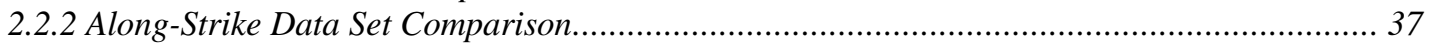

2.2.3 Data Set Comparison Summary ................................................................................ 41

CHAPTER THREE: MAGNETIC MODEL STUDIES ALONG THE NEW YORK -ALABAMA

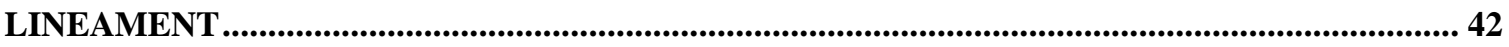

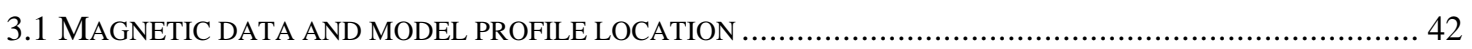

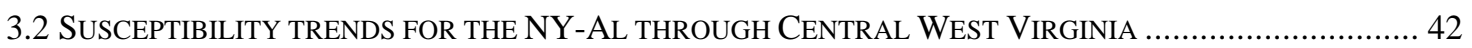

3.3 DePth to the Mid-Point of THE NY-Al through CENTRAL WeSt Virginia .............................. 45

3.4 Minimum Dip OF THE NY-Al THROUGH CENTRAL WeSt VirginiA ................................................ 45

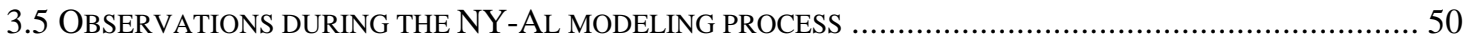


CHAPTER FOUR: RESIDUAL AEROMAGNETIC ANOMALIES AND CHARACTERISTICS OF

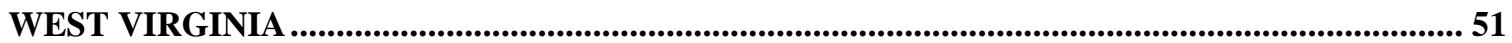

4.1 DESCRIPTION AND CRITERIA FOR FINDING ARMATS AND ARMAHLS IN THE RESIDUAL MAGNETIC

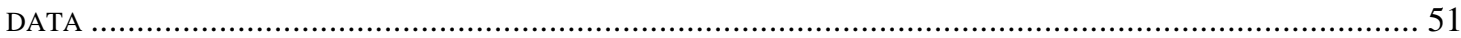

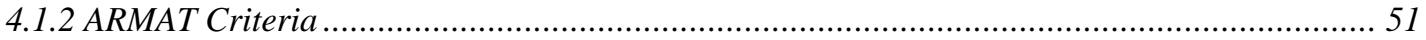

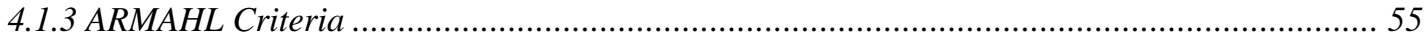

4.2 THE TRENDS IN THE RESIDUAL MAGNETIC WITHIN SOUTHERN WEST VIRGINIA.................................. 55

4.2.1 ARMAHL directional trends in residual aeromagnetic data in West Virginia ......................... 57

4.2.2 ARMAT directional trends in residual aeromagnetic data in West Virginia ............................ 57

4.2.3 Directional summary chart of ARMATs and ARMAHLs in southern West Virginia................. 60

4.3 THE RELATIONSHIP OF ARMATS AND ARMAHLS TO NEAR SURFACE STRUCTURES........................ 60

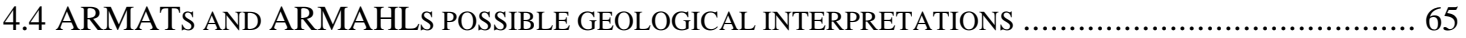

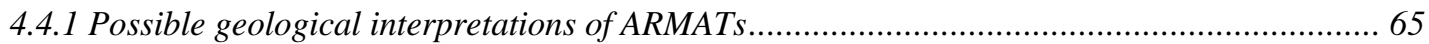

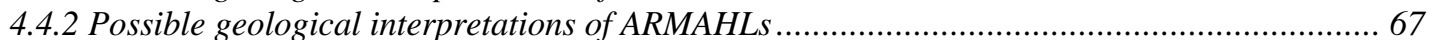

CHAPTER FIVE: RESIDUAL MAGNETIC MODEL STUDIES OF THE APPALACHIAN

PLATEAU, ROME TROUGH AND VALLEY AND RIDGE REGIONS OF WEST VIRGINIA..... 68

5.1 Magnetic Models near the Valley and Ridge Province of West Virginia ......................... 68

5.2 Magnetic Models of the Appalachian Plateau Rome trough Region in Central WeSt

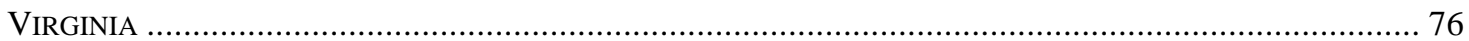

5.2.1 Incompatibility of Deformation Zone Models of the Rome trough ............................................. 76

5.2.2 Alternate models of the Rome trough of Central West Virginia ............................................ 81

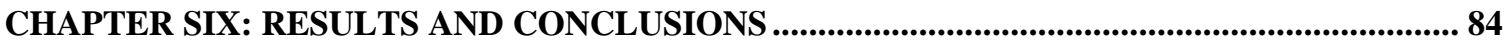

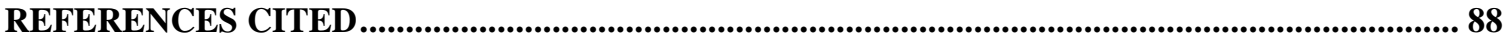




\section{List of Figures}

Figure 1: Study area located in central and southern West Virginia ................................ 4

Figure 2: Preliminary Gassaway study area location.................................................. 5

Figure 3: The location of basement drill holes in West Virginia...................................... 7

Figure 4: Total intensity versus residual magnetic data types ...................................... 11

Figure 5: Location map of cross strike and along-strike transects through the Gassway study area upon the total intensity aeromagnetics of West Virginia........................ 12

Figure 6: Location of AGI profile data ...................................................................... 14

Figure 7: Higher resolution residual data donated by AGI ............................................ 15

Figure 8: Basement topographic map of West Virginia.................................................. 18

Figure 9: The magnetic modeling procedure in MAGIXXL........................................ 19

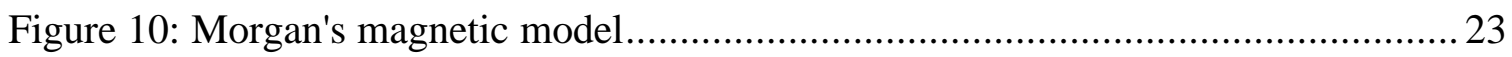

Figure 11: Incorporation of Morgan's (1996) model into this study ............................. 25

Figure 12: Rice's (1983) magnetic model across Central West Virginia ......................... 27

Figure 13: Magnetic susceptibility contrast range for the NY-Al source body in the

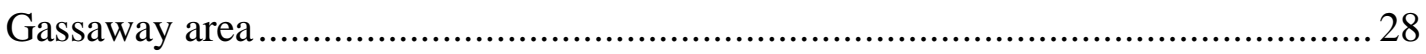

Figure 14: Depth to mid-point of NY-Al source body in Gassaway area......................... 30

Figure 15: Dipping bodies modeled along total intensity profile 2 ............................... 32

Figure 16: Dipping bodies modeled along total intensity profile 3 ……........................ 33

Figure 17: Dipping body models along total intensity profile 4..................................... 34

Figure 18: Vertical and dipping along-strike model s for the Gassaway anomaly ........... 36

Figure 19: Fault and lithology changes models for the Gassaway anomaly ..................... 38

Figure 20: WVGES compared to AGI total intensity data along profiles 2 and 3 ........... 39

Figure 21: WVGES compared to AGI total intensity data along profile 4 and along-strike

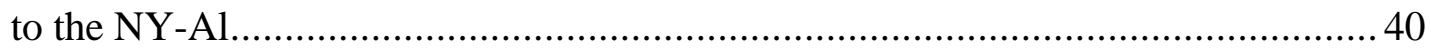

Figure 22: Magnetic susceptibility contrast along total intensity profile 6 ...................... 43

Figure 23: Minimum dip model along total intensity profile 7 ....................................... 46

Figure 24: Minimum dip of the NY-Al source body along total intensity profile 1......... 47

Figure 25: Minimum dip of NY-Al source body along total intensity profile 5 ............. 48

Figure 26: Minimum dip of the NY-Al source body along total intensity profile 6 ......... 49 
Figure 27: Example ARMATs and ARMAHLs shown within the AGI data set 52

Figure 28: ARMAHLs within the AGI data set................................................... 53

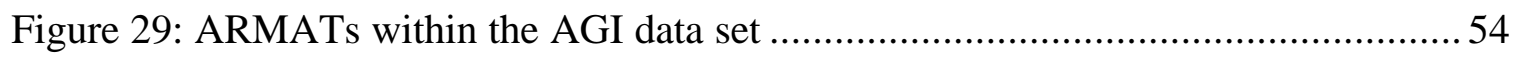

Figure 30: Magnetic regions based on residual magnetic anomalies..........................56

Figure 31: ARMAHL rose diagrams for magnetic regions......................................58

Figure 32: ARMAT rose diagrams for magnetic regions..................................... 59

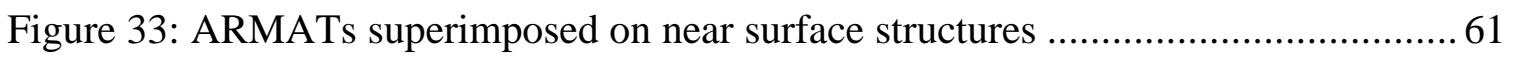

Figure 34: ARMAHLs superimposed on near surface structures.............................. 62

Figure 35: ARMAHLs superimposed on Yang's (1998) basement blocks ..................... 63

Figure 36: ARMATs superimposed on Yang's (1998) basement blocks ....................... 64

Figure 37: Conceptual model of the formation of residual magnetic highs and lows ...... 66

Figure 38: Two sets of ARMATs outlined on AGI's residual magnetic map .................69

Figure 39: Location of ARMATs in relationship to AGI profiles .............................. 70

Figure 40: Defomation zone models along residual profiles 8 and 9 ........................ 71

Figure 41: Basement topography residual models along profiles 8 and 9 ..................... 72

Figure 42: Variable zones of magnetic susceptibility models along residual profiles 8 and 9 75

Figure 43: Rome trough modeled along residual profile 1 exclusively as basement

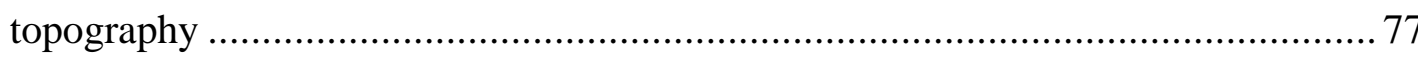

Figure 44: Attempts at a deformation zone model of profiles 1, 2, and 3 across the Rome

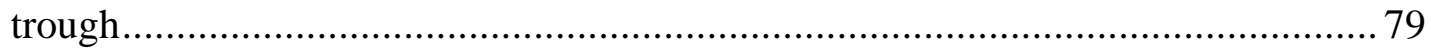

Figure 45: Thinning veneer model along profiles 1, 2, and 3 across the Rome trough .... 80

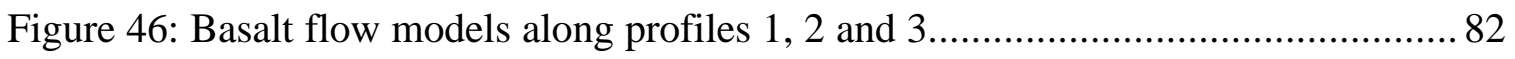

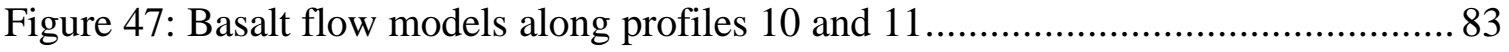




\section{List of Tables}

Table 1: A summary of examined basement core in West Virginia ............................. 6

Table 2: Magnetic Susceptibility of Common Rocks and Minerals .............................. 8

Table 3: Summary of Magnetic Susceptibility and Depth to Mid-Point for Profiles cross-

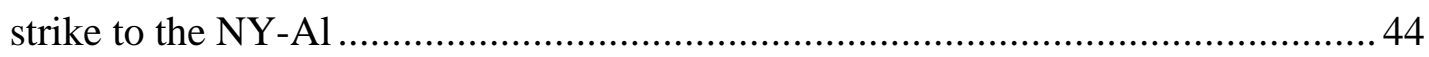

Table 4: Minimum Dip Estimates for the NY-Al Source Body ................................ 50

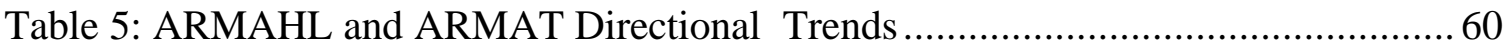

\section{List of Acronyms}

NY-Al............................................. Yew York - Alabama lineament ARMAHL...........................Alignment of Residual Magnetic Highs and Lows ARMAT...............................Alignment of Residual Magnetic Terminations 


\section{Chapter One: Introduction}

\subsection{Purpose}

This research effort was undertaken to evaluate the possible range of structures and lithologies that could give rise to the New York - Alabama magnetic lineament (NYAl) and other magnetic anomalies in central West Virginia. The initial modeling efforts conducted in this study were developed across the NY-Al near the town of Gassaway in Braxton County, West Virginia. These models utilized the total intensity aeromagnetic map of West Virginia produced by the United States Geological Survey and the West Virginia Geological and Economic Survey (1978). Many authors have suggested (King and Zietz (1978), King et al., (1998), Gay (1996), and German (1985)) that the origin of the NY-Al likely to be either a transform fault or sutures zone. This study has utilized source body shapes that suggest a suture zone or transform fault origin.

More recent vintage, higher resolution data was donated for use in this study by Applied Geophysics Incorporated (AGI) over central and southern West Virginia for use in this study. AGI's residual map reveals several patterns that appear to have some relationship to the structural framework of the Appalachian foreland. The trends and patterns observed in the residual anomaly map have been summarized in the form of alignments of residual magnetic anomaly terminations (ARMATs) and alignments of residual magnetic anomaly highs and lows (ARMAHLs) beyond the NY-Al. AGI also provided data in digital form along select profiles across various features observed in the residual anomaly map. 
The purpose of examining the ARMATs and ARMAHLs is to identify and evaluate the significance of shallow basement features and trends outside of the NY-Al. The trends in the residual magnetics may also help constrain the range of possible structural interpretations of the NY-Al. Also, trends in the ARMATs and ARMAHLs will be investigated for correlation to other structures thought to be basement controlled, such as the Burning-Mann lineament and Interior Fault within the Rome Trough of West Virginia.

\subsection{Objectives}

The objectives of this project are as follows:

- Present and discuss current interpretations of the origin and significance of the NYAl.

- Undertake detailed magnetic modeling of the Gassaway magnetic anomaly, a local magnetic anomaly along the NY-Al in West Virginia, using WVGES (1978) data and more recent higher resolution AGI magnetic data.

- Compare the AGI total intensity data to the WVGES (1978) total intensity data.

- Model the NY-Al along its entire length through West Virginia and evaluate possible depth, shape, and orientation changes in the magnetic source body along its length.

- Model a select number of observed ARMATs and ARMAHLs on either side of the NY-Al. 


\subsection{Geologic Background of the Study Area}

\subsubsection{Location}

The study area is broadly located in central and southern West Virginia, in the Appalachian Plateau physiographic province (Figure 1). A detailed study was conducted across the Gassaway magnetic anomaly located in the vicinity of Braxton and Clay counties, West Virginia (Figure 2).

\subsubsection{Lithology}

The lithology of the basement within West Virginia is generally presumed to be Grenville basement of eastern North America (Shumaker and Wilson, 1996). Basement core has been examined in 10 locations within western West Virginia, however, no basement core has been taken east of the NY-Al (King et al., 1998) within West Virginia. Table 1 summarizes (King et al. 1998) the deep well information along with basement lithology encountered in those wells, and deep well locations are shown on Figure 3. Heald (1981) described the Mingo County rock core (Table 1, \#7) as consisting of granodiorite with minor quartz monzonite and tonalite. The age of this specimen was determined by Potassium - Argon dating at $939 \pm 34$ Ma (Heald, 1981). Generally, the deep wells reveal the basement in this area of West Virginia to consist of as gneiss and intrusive igneous rocks including synite, granite, granodiorite, and tonalite (King et al.1998). The gravity models of Ammerman and Keller (1979) indicate that basalt flows could be present in the Rome trough of eastern Kentucky, however, no evidence exists for the presence of basalt flows in the West Virginia portion of the trough. 


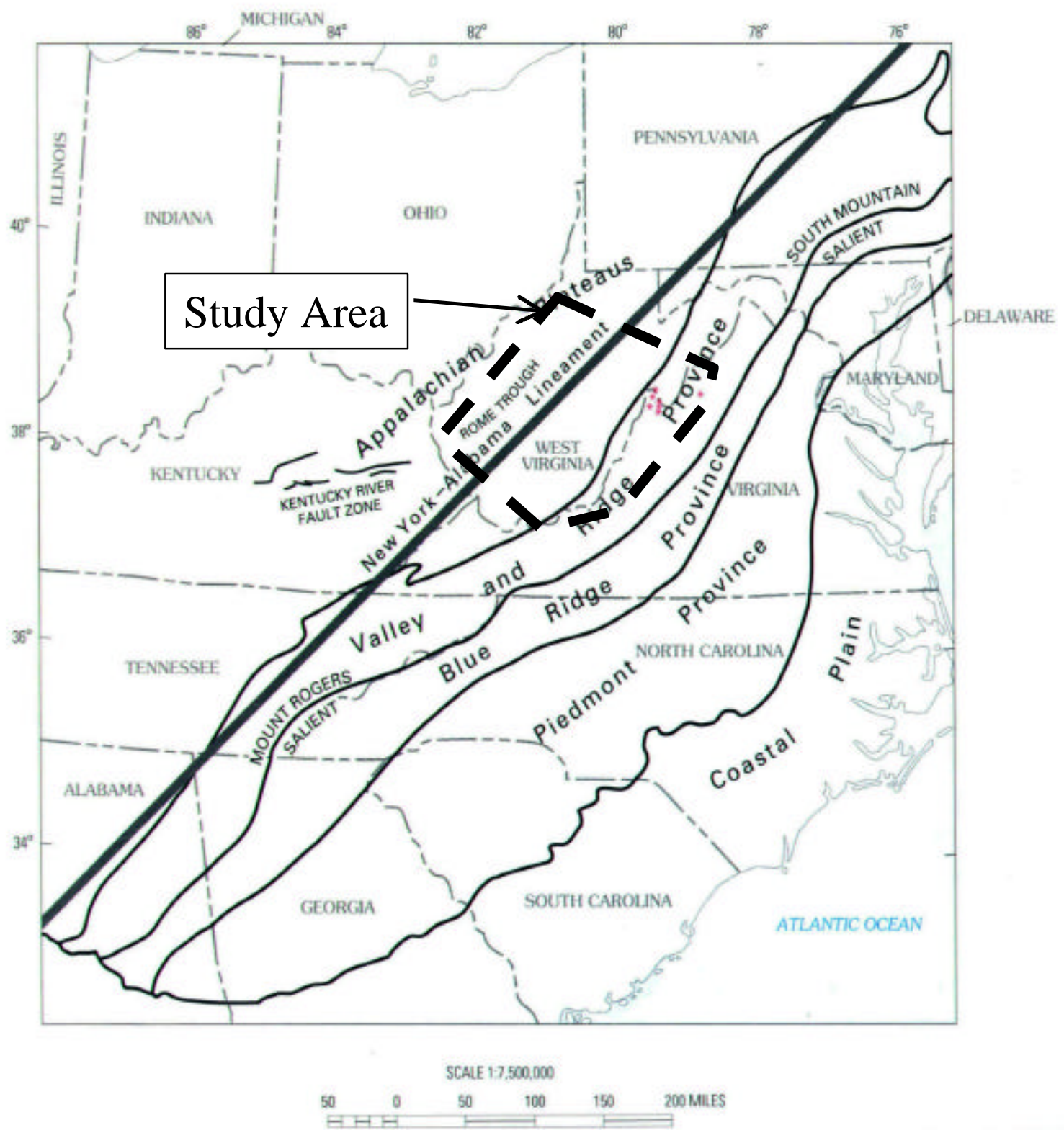

(Taken from King et al., 1998)

Figure 1 : The study area is located in central and southern West Virginia in the Appalachian Plateau physiographic province. 


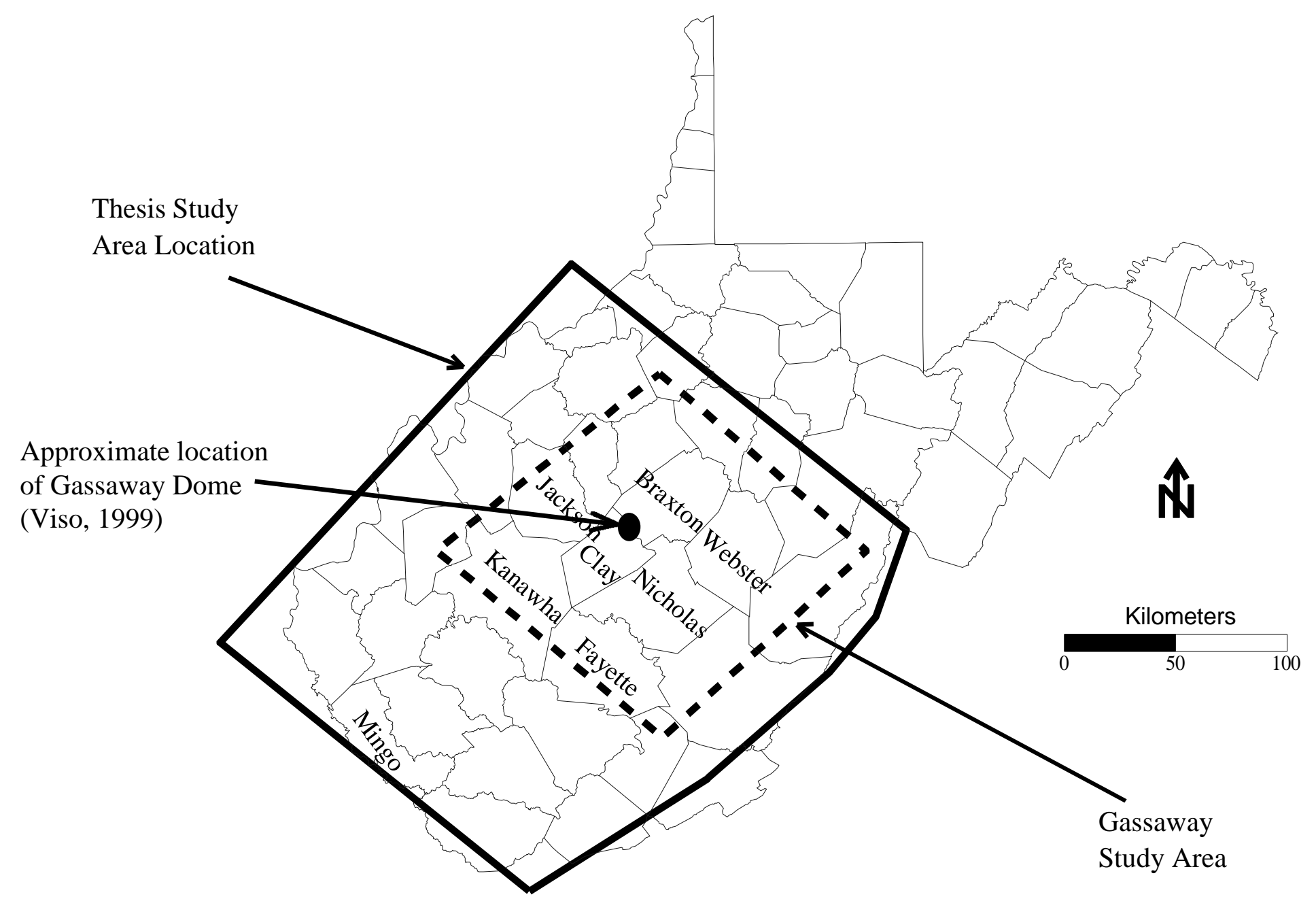

Figure 2: The study area is located in south-central West Virginia. Detailed model studies were conducted in the Gassaway area. 
Data for deep drill holes that penetrate Precambrian basement rocks, West Virginia (taken from King et al, 1998)

\begin{tabular}{|c|c|c|c|c|c|c|c|}
\hline \# on Map & County & Drill Hole Name & $\begin{array}{l}\text { Surface Altitude } \\
\text { (ft) }\end{array}$ & $\begin{array}{c}\text { Depth to } \\
\text { Precambrian Basement } \\
(\mathrm{ft})\end{array}$ & $\begin{array}{l}\text { Total Depth } \\
\quad(\mathrm{ft})\end{array}$ & $\begin{array}{c}\text { Depth into } \\
\text { Precambrian Basement } \\
(\mathrm{ft})\end{array}$ & $\begin{array}{c}\text { Lithology of } \\
\text { Precambrian basement }\end{array}$ \\
\hline 1 & Cabell & $\begin{array}{l}\text { Cyclops Corp. } \\
\# 1 \text { E. Kingery }\end{array}$ & 667 & 8,490 & 8,552 & 62 & $\begin{array}{l}\text { Quartz-feldspar-biotite } \\
\text { (minor hornblende- } \\
\text { magnetite) gneiss }{ }^{1}\end{array}$ \\
\hline 2 & Calhoun & $\begin{array}{l}\text { Exxon Corp. } \\
\# 1 \text { Gainer-Lee }\end{array}$ & 1,230 & 20,051 & 20,222 & 171 & $\begin{array}{l}\text { Quartz-oligoclase-biotite } \\
\text { gneiss containing garnet, } \\
\text { graphite, sillimanite }{ }^{1}\end{array}$ \\
\hline 3 & Jackson & $\begin{array}{l}\text { Exxon Corp. } \\
\# 1 \text { W.J. McCoy }\end{array}$ & 930 & 17,620 & 17,675 & 55 & Gneiss and granite layer ${ }^{1}$ \\
\hline 4 & Lincoln & $\begin{array}{l}\text { Exxon Corp. } \\
\# 1 \text { D.E. McCormick } \\
\end{array}$ & 737 & 18,919 & 19,124 & 205 & $\begin{array}{l}\text { Cuttings: tonalite- } \\
\text { granodiorite }^{2}\end{array}$ \\
\hline 5 & Mason & $\begin{array}{l}\text { United Fuel } \\
\# 1 \text { G. Arrington }\end{array}$ & 609 & 8,588 & 8,635 & 47 & $\begin{array}{l}\text { Hornblende gneiss }{ }^{3} \text { and } \\
\text { syenite }^{4}\end{array}$ \\
\hline 6 & Mason & $\begin{array}{l}\text { Union Drilling, Inc. } \\
\# 1 \text { R.L. Jividen }\end{array}$ & 626 & 10,564 & 10,598 & 34 & No sample \\
\hline 7 & Mingo & $\begin{array}{l}\text { Columbia Gas } \\
\text { Transmission Co. } \\
\# 1 \text { Tract } 10\end{array}$ & 958 & 19,570 & 19,600 & 30 & $\begin{array}{l}\text { Granodiorite and minor } \\
\text { quartz monzonite and } \\
\text { tonalite; shearing; K/Ar } \\
\text { biotite age } 939+/-34 \\
\mathrm{Ma}^{5} \\
\end{array}$ \\
\hline 8 & Wayne & $\begin{array}{l}\text { Exxon Corp. } \\
\# 1 \text { J.P. Smith }\end{array}$ & 594 & 14,590 & 14,625 & 35 & "Precambrian Granite" ${ }^{6}$ \\
\hline 9 & Wood & $\begin{array}{l}\text { Hope Natural Gas Co. } \\
\text { \#1 Power Oil Co. } \\
\text { (Sandhill) }\end{array}$ & 1,050 & 13,272 & 13,331 & 55 & $\begin{array}{l}\text { Banded gneiss of } \\
\text { granodiorite, tonalite, } \\
\text { and amphibolite } ; \\
\mathrm{Rb} / \mathrm{Sr} \text { biotite age } 870 \\
\mathrm{Ma}^{8}\end{array}$ \\
\hline 10 & Wood & $\begin{array}{l}\text { Exxon Corp. } \\
\# 1 \text { H.H. Deem }\end{array}$ & 694 & 13,254 & 13,266 & 12 & Granite Gneiss $^{1}$ \\
\hline $\begin{array}{l}{ }^{1} \text { Lithologic Log } \\
{ }^{2} \text { Petrographic aa } \\
{ }^{3} \text { Summerson (1 } \\
{ }^{4} \text { McGuire and H } \\
{ }^{5} \text { Heald (1981) } \\
{ }^{6} \text { Schweitering at } \\
{ }^{7} \text { Bass (1959) } \\
{ }^{8} \text { Bass (1960) }\end{array}$ & $\begin{array}{l}\text { T. Ryder (U.S. } \\
\text { sis of thin sect } \\
\text { ell (1963) } \\
\text { Roberts (1988) }\end{array}$ & $\begin{array}{l}\text { Geological Survey, unpub. Data) } \\
\text { ion of cuttings by Louis Pavlides }\end{array}$ & ological Survey, oral c & commun., 1992) & & & \\
\hline
\end{tabular}

Table 1: A summary of examined basement core in West Virginia is shown above. 


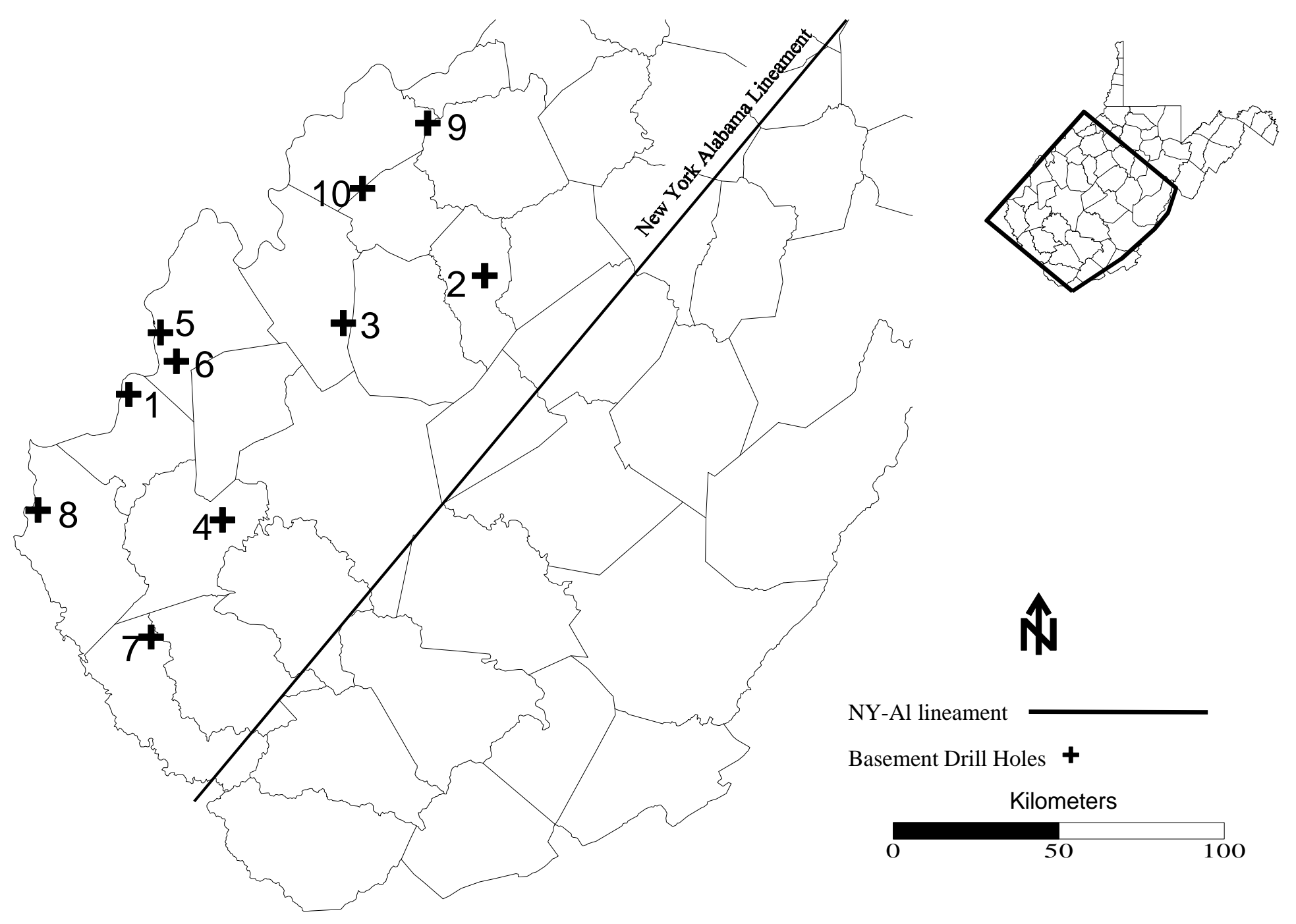

Figure 3: The location of basement drill holes in West Virginia. The drill hole numbers correspond to Table 2 drill hole descriptions. 
Table 2 provides data on the range of measured magnetic susceptibility measured for some common rocks and minerals.

\section{Table 2: Magnetic Susceptibility of Common Rocks and Minerals}

\begin{tabular}{cc}
\hline Material & $\begin{array}{c}\text { Magnetic Susceptibility, cgs units } \\
\left(\mathrm{k} \mathrm{x} \mathrm{10} 0^{6}\right)\end{array}$ \\
\hline Magnetite & $300,000-800,000$ \\
Pyrrhotite & 125,000 \\
Ilmenite & 135,000 \\
Quartz porphyries & 2,500 \\
Rhyolites & 3,000 \\
Granites & 2,700 \\
Pyroxenites & 10,500 \\
Gabbros & 7,200 \\
Leucite Rocks & 9,800 \\
Dacite-quartz-diorites & 10,400 \\
Andesites & 13,500 \\
Diorites & 10,400 \\
Periodotites & 13,800 \\
Basalts & 14,300 \\
Diabases & 13,100 \\
\hline
\end{tabular}

The Baltimore Gneiss of Maryland provides a possible lithological analogue for the basement in West Virginia. Crowley (1976) states the Baltimore Gneiss contains many lithologies including a layered gneiss, an augen gneiss, a streaked-augen gneiss, a hornblende gneiss, and the Slaughterhouse granitic gneiss members. The streaked-augen gneiss member is known to contain localized amounts of magnetite that probably account for an unusually high positive magnetic anomaly centered over the Texas Dome in Maryland (Crowley, 1976). 


\subsubsection{Tectonic History}

The basement rocks beneath the study area have been deformed by several tectonic events. The earliest compressional event known to have influenced the area is the Middle Proterozoic Grenville Orogeny. Beardsley and Cable (1983) maintain that the Grenville orogeny formed low-angle thrust faults and imbricated thrust sheets. That event was followed by an episode of rifting during the Lower and Middle Cambrian, that produced the Rome trough and the Catoctin (meta) basalts further to the east (Badger and Sinha, 1988). The trough underlies much of western West Virginia (Beardsley and Cable, 1983). The failed rift event that formed the Rome trough was thought by Beardsley and Cable (1983) to be associated with sea floor spreading in the Early Cambrian that led to the formation of the Iapetus Ocean.

The event that produced the New York-Alabama lineament (NY-Al) lineament is thought by Gay (1996) to have occurred after the Grenville orogeny (1.0-1.1 Ga), but before the well-recognized Paleozoic orogenies $(0.45-0.25 \mathrm{Ga})$. This hypothetical suture is represented by the NY-Al (The New York - Alabama lineament) observed in Applied Geophysics Incorporated's (AGI) residual magnetic anomaly data and also in the total intensity anomaly data (WVGES, 1978). The strongest evidence for this age relationship comes from the apparent truncation of the Grenville Province by this suture. Gay (1996) also maintains that the linearity of the NY-Al indicates it is a tectonic system similar to the San Andreas strike-slip fault system along which continental blocks are currently being displaced. Gay (1996), however, states that he knows "of no evidence for the existence of this accretionary event other than the aeromagnetic data." 


\subsection{Total-Intensity and Residual Aeromagnetic Data and Maps}

The difference between residual and total-field (total-intensity) anomalies and their resulting magnetic signatures are shown on Figure 4 (taken from Gay, 1996). Residual anomalies reveal the presence of shallower magnetic susceptibility contrasts. The models shown in Figure 4 use three vertical bodies that are 3 miles wide and buried from 1 to 5 miles in depth (Cases I through III). As the bodies are buried more deeply (Case I to II to III) the total intensity curve has diminished individual, and consolidates the magnetic peaks into one broad wavelength magnetic anomaly. The residual anomaly curve, however, reveals separate anomalies over each body, especially for shallow bodies (Case III). Basement depths in the West Virginia region are of the order of 5 miles. Thus, the residual anomaly map helps resolve detailed variations in basement magnetic susceptibility.

\subsubsection{Data from the Aeromagnetic Map of West Virginia (WVGES, 1978)}

The study of the Gassaway area focuses on the analysis of six cross-strike transects (profiles) of the NY-Al and one along-strike magnetic transect digitized from the total intensity Aeromagnetic Map of West Virginia (WVGES, 1978 and King et al. 1998). Figure 5 shows total intensity data (WVGES, 1978) for West Virginia, and the cross-strike and along-strike transect locations from the Gassaway study area. The WVGES (1978) data were acquired along flight lines that were 2 miles apart and 1,000 ft above ground level. In this study, WVGES (1978) basic data were extracted from a 1:250,000 contour map of the data. Hand drawn profiles from the 1:250,000 map were then digitized at a 1,000 meter interval. 


\section{Total Intensity Scale}

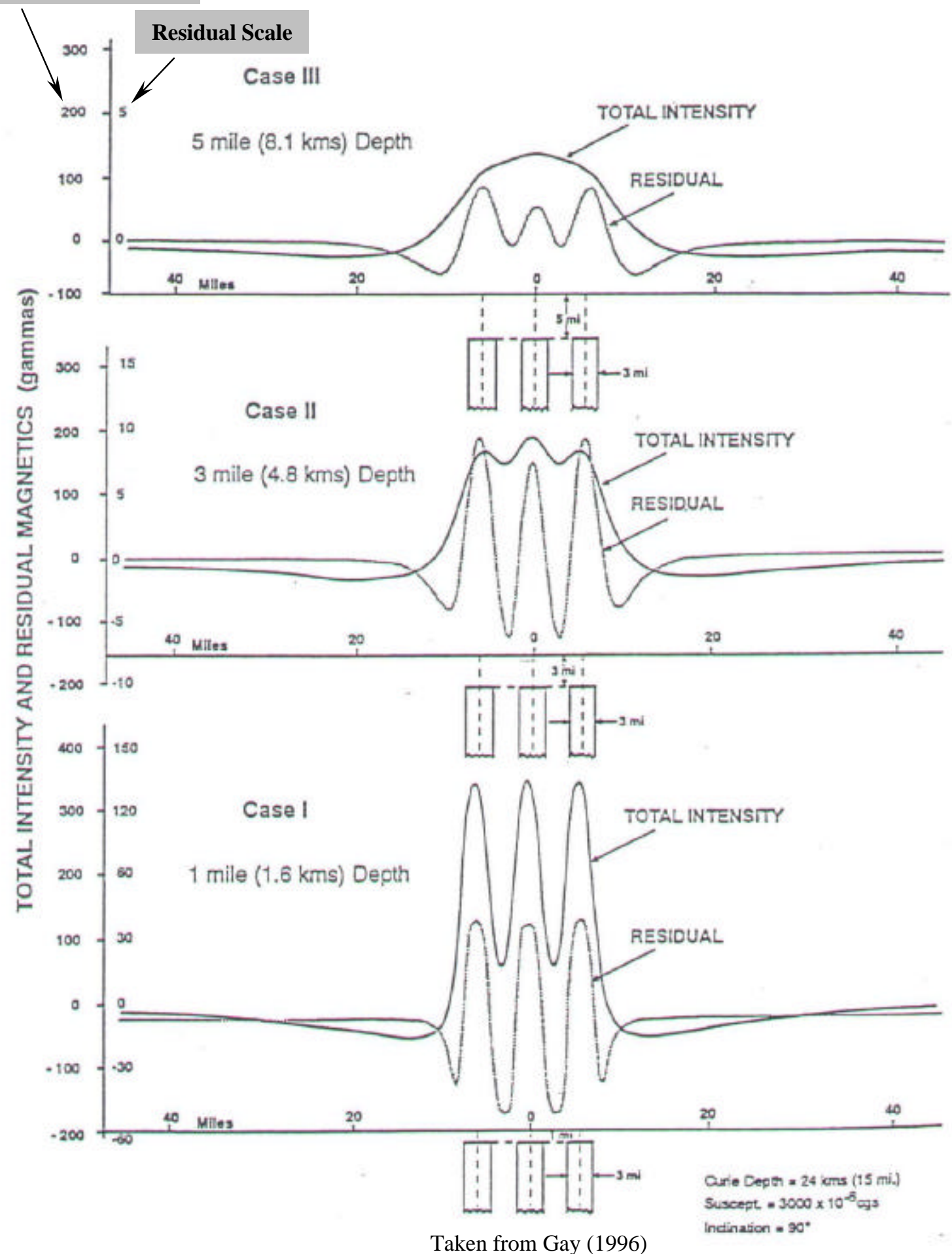

Figure 4: A residual separation procedure of total intensity data will allow the identification of individual objects and eliminate the possibility of erroneously interpreting that the anomaly is due to one large object with increasing depth. 


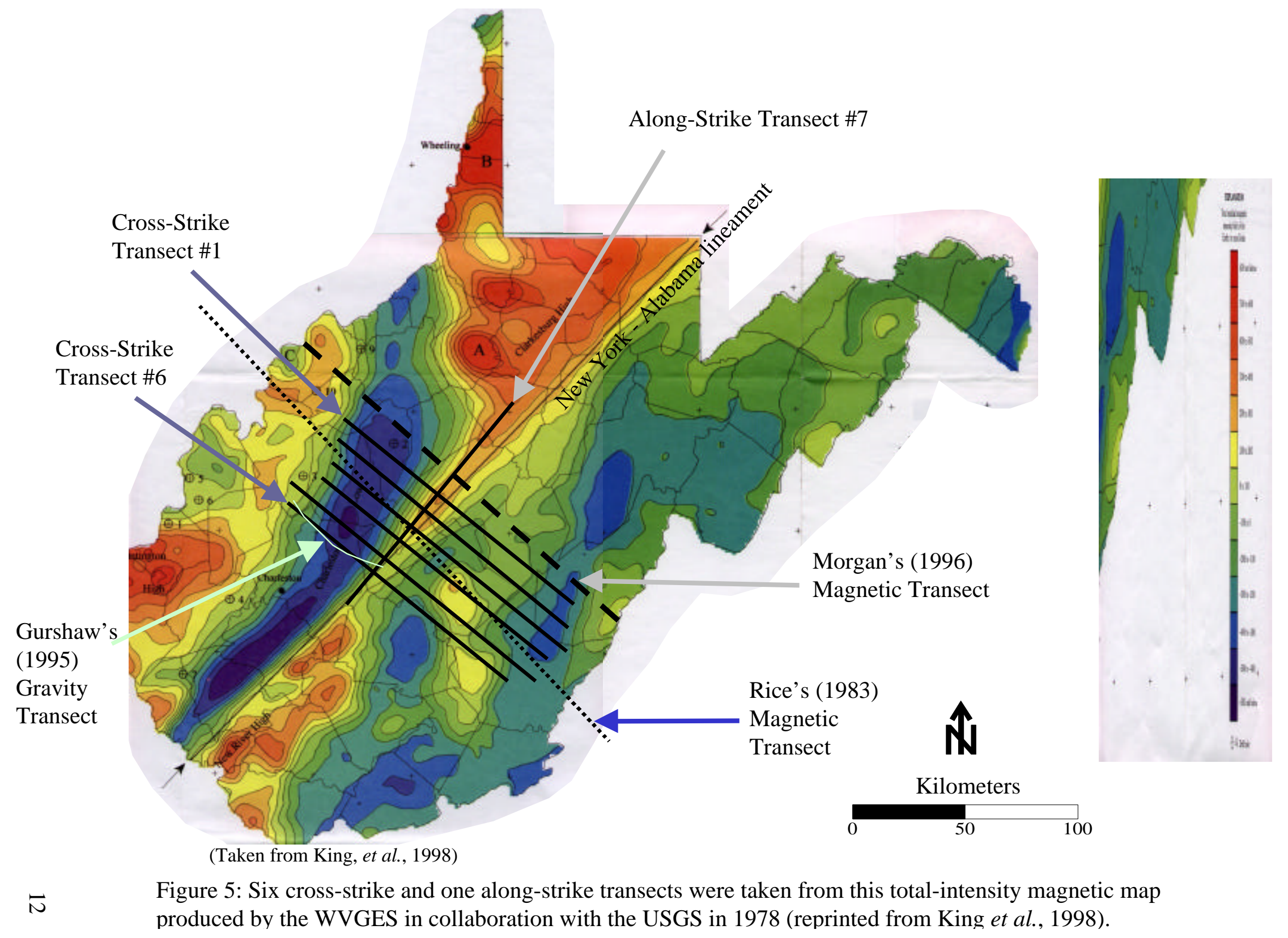




\subsubsection{Data donated from Applied Geophysics Incorporated}

S. Parker Gay of Applied Geophysics Incorporated (AGI) supplied a residual anomaly map (NewMag®) of their entire WV survey area. AGI also provided higher resolution total intensity and residual magnetic data along several selected transects. Figure 6 illustrates the locations of the total-intensity and residual profiles provided for this study by AGI. Figure 7 shows a portion of the NewMag residual magnetic map donated by AGI.

The AGI total field anomalies were taken directly from the flight line measurements. The data point spacing along the flight line is 20 meters, and the flight elevation was approximately 1,000 to 2,000 feet above ground level. Basement depths in the area are generally greater than 5,500 meters. The wavelength of a point source located on the basement surface at a depth of 5,500 meters is approximately 8,500 meters. Anomalies with wavelengths of less than 8,500 meters are not expected to occur, because the blanket of sediments covering the basement is not believed to contain significant quantities of magnetic source rocks. For this reason, the flight line data were resampled from a 20 meter interval to a 1,000 meter interval to reduce computation time in the modeling process.

\subsection{Previous Studies}

Initial model studies undertaken in the Gassaway area used a starting model that was modified from a magnetic model derived by Morgan (1996) along a northwestsoutheast transect that crosses the Gassaway magnetic anomaly in central West Virginia. His study was confined to a single transect that extended across the basin. Morgan's 


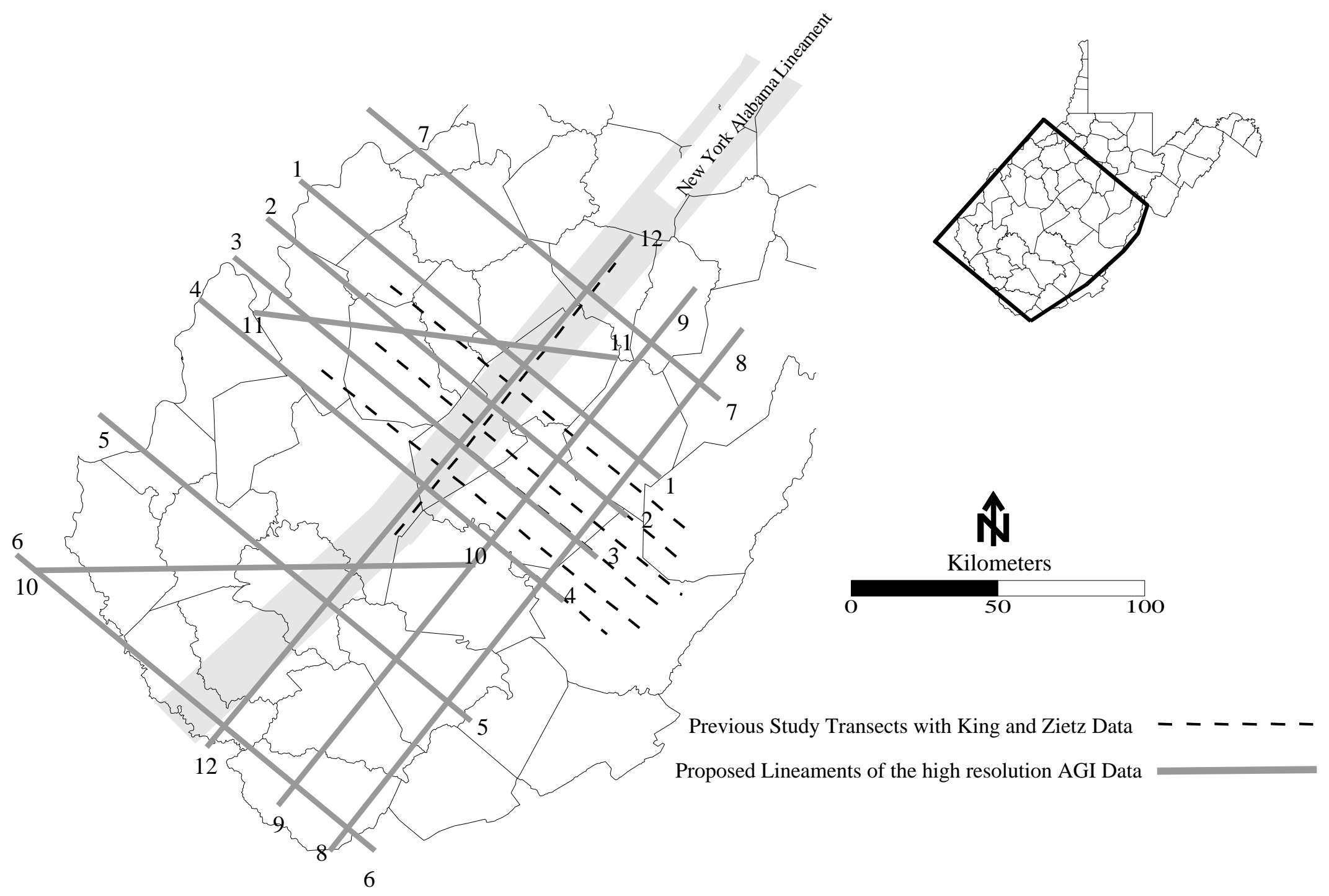

Figure 6: The location of transects provided by AGI are shown in solid thick lines. Transects modeled using the WVGES (1978) data are represented with black dotted lines. 


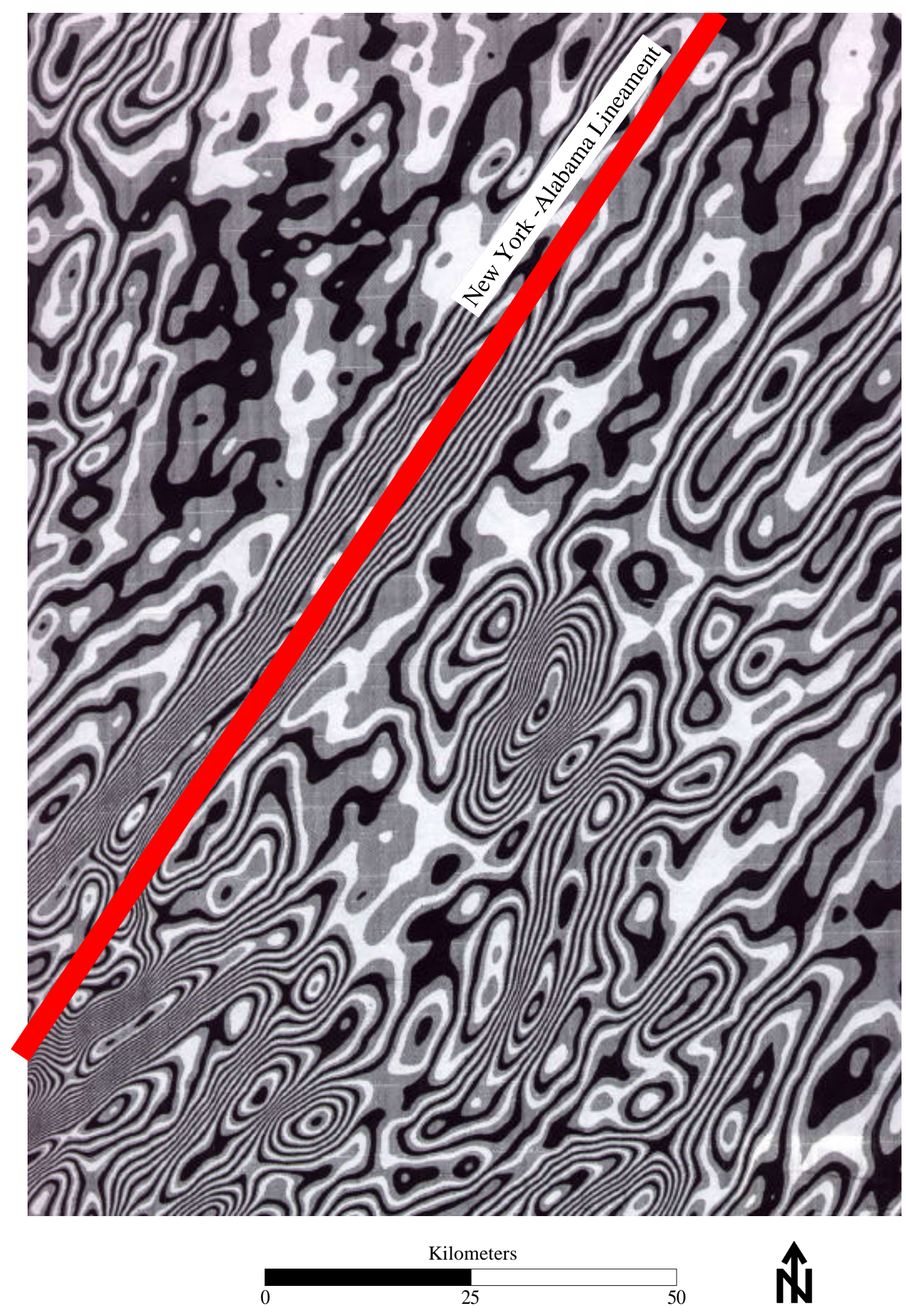

Figure 7: The Applied Geophysics Inc. (AGI) NewMag® residual map forms the basis for interpretation of possible basement patterns or structures on either side of the NY-Al. 
(1996) model revealed the presence of several potentially large magnetic source objects. Morgan (1996) stated that, "isolated magnetic bodies of variable strike length and susceptibility incorporated at mid- to lower crustal levels could explain the magnetic anomalies observed along the profile." Gurshaw (1995) modeled gravity anomalies constrained by seismic data along a transect extending from northwest to southeast through Jackson and Kanawha counties in West Virginia. Gurshaw concluded that the short-wavelength positive gravity features along the gravity profile are associated with high-density areas within the upper crust. He suggested that the high-density regions could be a pre-Grenvillian plutons, but did not model the magnetic field variations present along his profile.

German (1985) argues that the strong magnetic signature of the NY-Al arises from a mafic source within the upper crust. He hypothesizes that the lineament may represent a suture with some superimposed failed rift intrusives and extrusives, along the western margin of Appalachian tectonism. King and Zietz (1978) comment that the great length, linearity, and profound horizontal displacement of the NY-Al denotes a strike-slip fault.

King et al. (1998) examined the total field magnetics of West Virginia and inferred that the regional magnetic anomalies are not from dense gabbroic or ultra mafic rocks, but instead are from of intermediate composition and average density for metamorphic and plutonic rocks. The magnetic variations in the aeromagnetic map of West Virginia (Figure 4) are typical, according to King et al. (1998), of "a heterogeneous complex of crystalline basement rocks. " The NY-Al is more sharply defined and 
continuous through West Virginia than anywhere else along its length, possibly due to contrasts of basement lithology on either side of the lineament, which could arise along a large-scale transcurrent fault (King et al., 1998).

Ammerman and Keller (1979) modeled the simple Bouguer gravity variations in eastern Kentucky to delineate the Rome trough. Their study indicates the possibility that the Rome trough may contain basalt flows in eastern Kentucky. Their observation also suggests that mafic rocks that rose through the crust might be responsible for some magnetic features observed in the West Virginia region.

It is also important to consider the extensive seismic data analysis and interpretation of south central West Virginia basement structure. Shumaker has produced a depth to basement map based on the compilation of seismic and deep well data across West Virginia (Figure 8).

\subsection{Magnetic Modeling Methods}

Interpex Ltd.'s MAGIXXL program was used to perform the magnetic modeling procedures in this study. MAGIXXL allows the user to vary the magnetic susceptibility, strike length, cross sectional configurations, and the corner coordinates ( $\mathrm{X}$ and $\mathrm{Y}$ coordinates) of each body associated with individual anomalies observed along the profiles (transects). Fine-tuning of the model is accomplished by using an automated inverse modeling option, which iteratively adjusts the configuration of the magnetic object (or objects) to minimize error between the calculated and observed magnetic intensities.

Figures 9 (A) and (B) illustrate modeling results obtained for profile (transect) lines 1 (A) and 6 (B) over the Gassaway area. Note that Body $\mathrm{C}^{\prime}$ is largely responsible for 


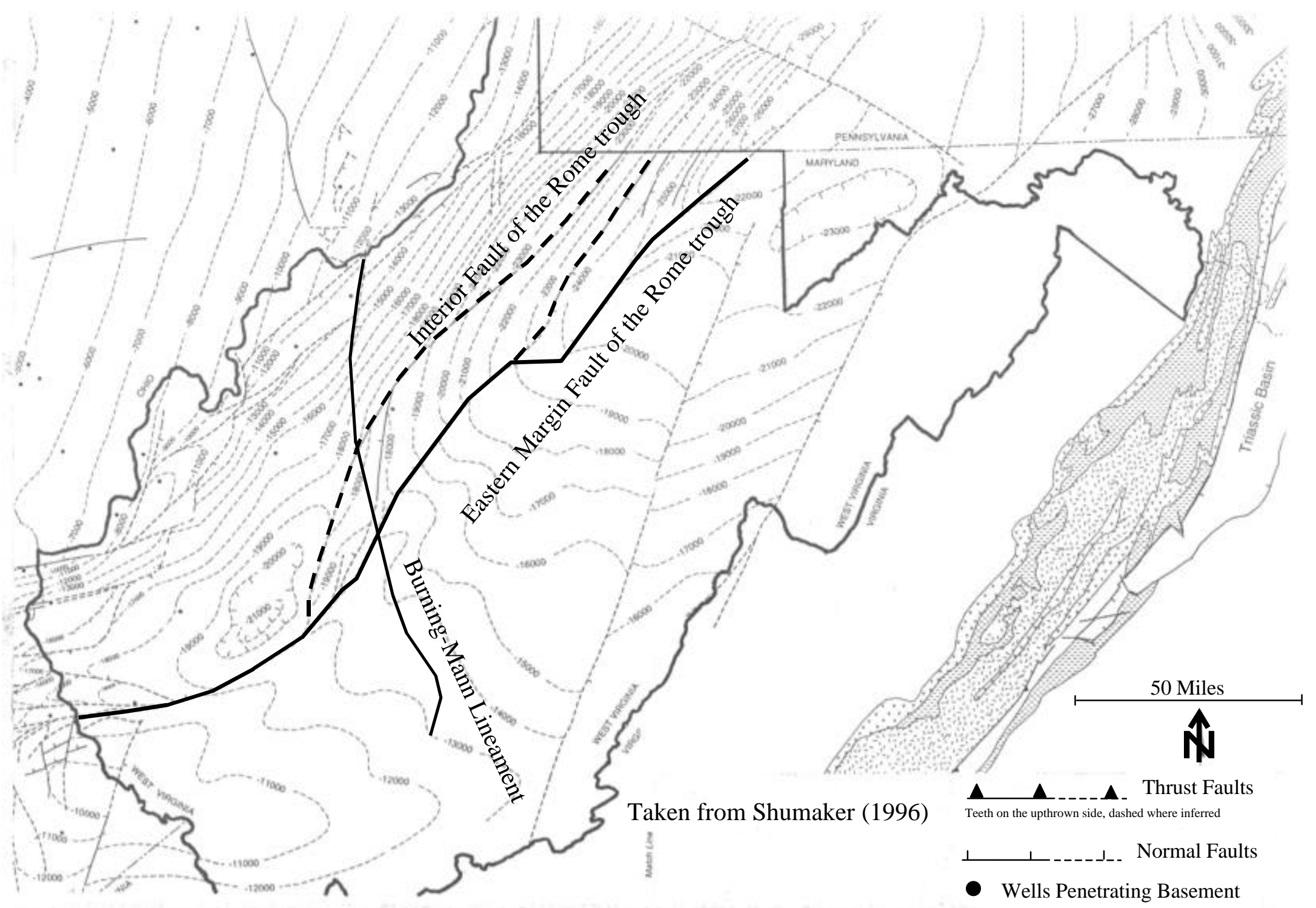

Figure 8: A basement topographic map where normal faults have been documented and inferred. 


\section{A. Profile Line 1}

New York - Alabama Lineament

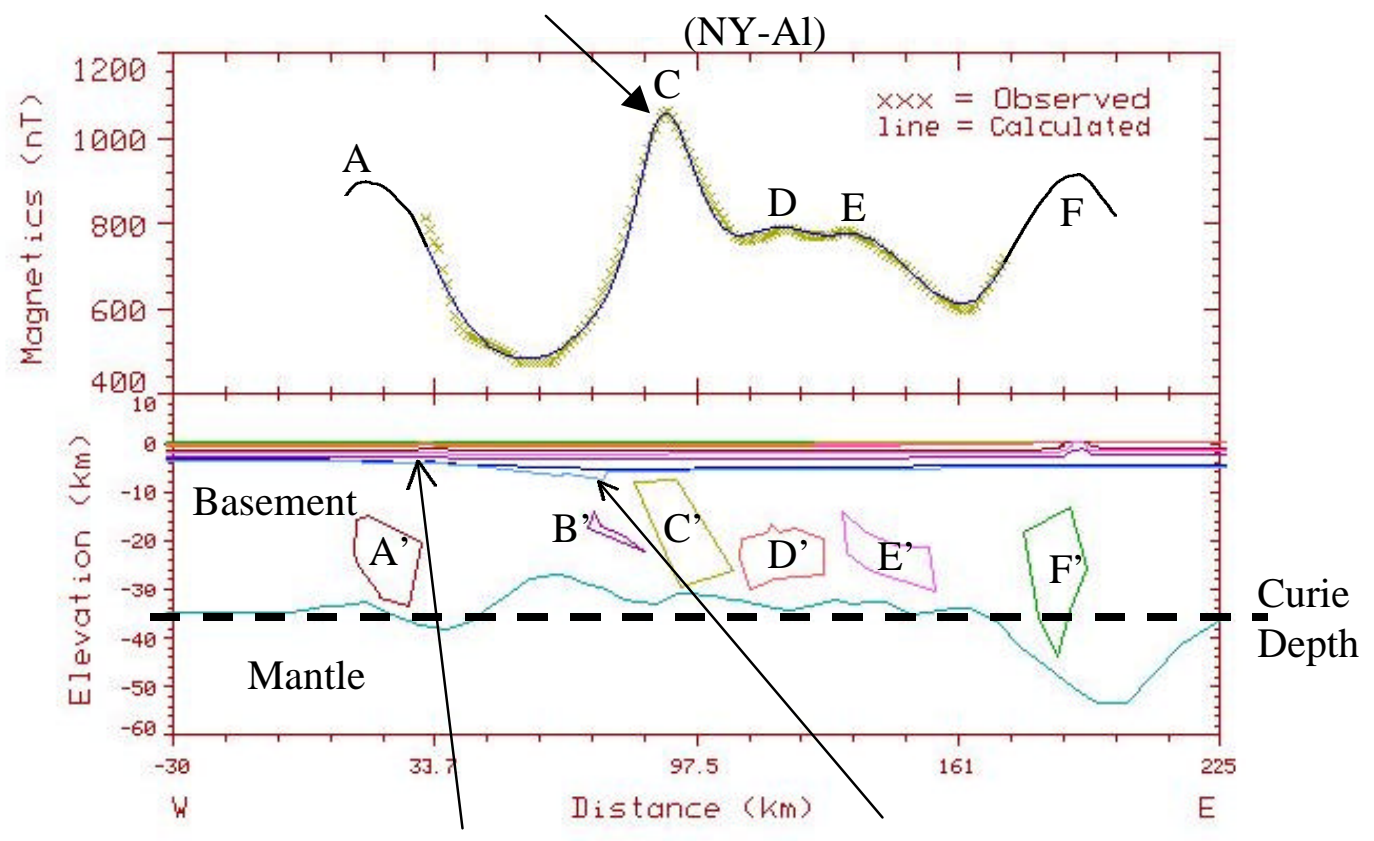

West Margin of the Rome Trough

East Margin of the Rome Trough

\section{B. Profile Line 6}

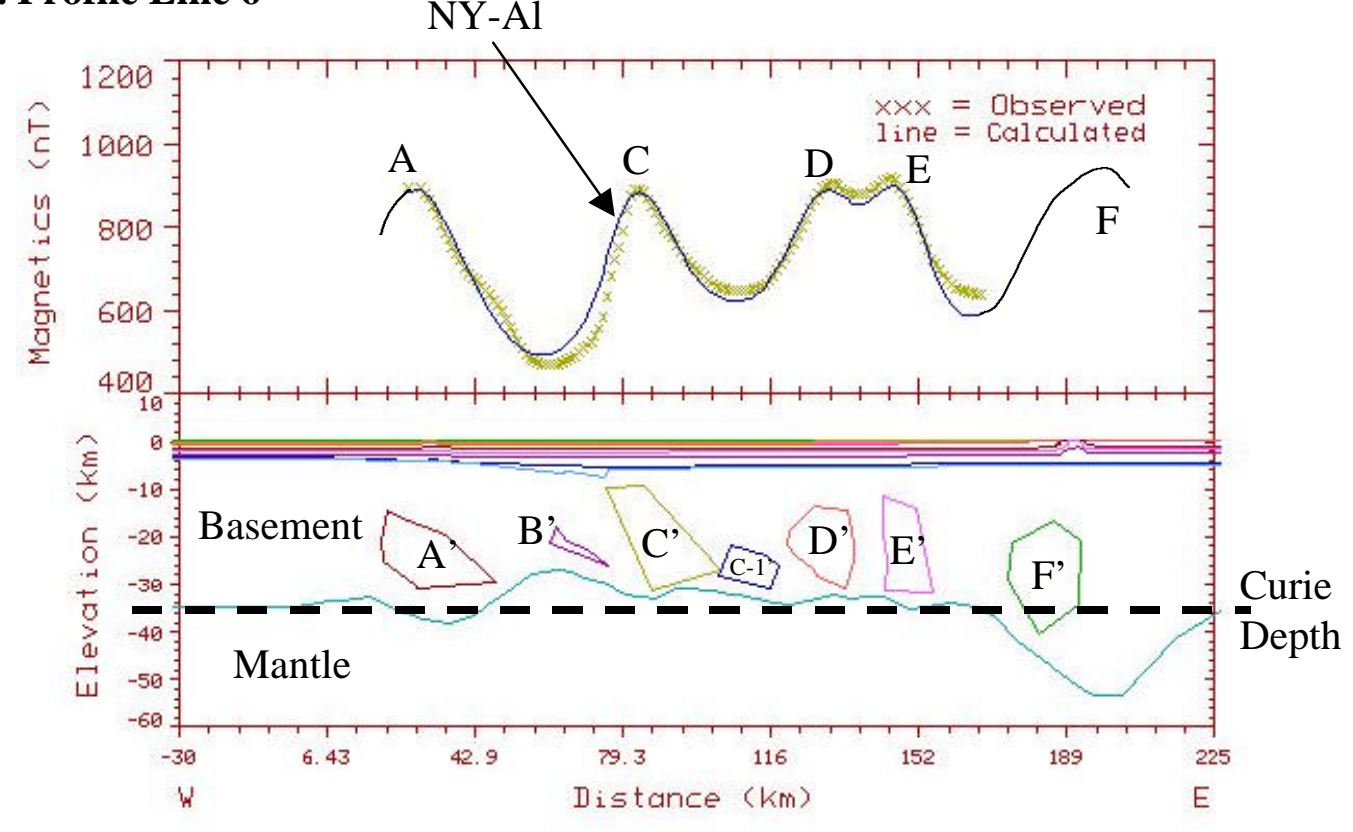

Figure 9: Calculated (solid line) and observed (marked with X's) magnetic field data are shown in the upper portion of the MAGIXXL modeling program window. 
Anomaly C. The other bodies such as A', D', E' and F' are associated with anomaly peaks $\mathrm{A}, \mathrm{D}, \mathrm{E}$, and F, respectively. As the separation between anomalies $\mathrm{A}$ and $\mathrm{C}$ becomes smaller from line 1 to line 6 , the separation between the sources (bodies $\mathrm{A}^{\prime}$ and $\mathrm{C}^{\prime}$ ) must also be decreased. Note that the distance of these two magnetic anomalies from the NY$\mathrm{Al}$ also increases from line 1 to line 6. The increased magnitude of anomalies $\mathrm{D}$ and $\mathrm{E}$ requires that bodies $\mathrm{D}^{\prime}$ and E' be increased in size and moved closer to the surface. No change in susceptibility or strike length of the magnetic bodies was introduced into the model shown in Figure 9. The modeling procedure is the same for total intensity versus residual magnetic models. The fitting error for all models in this study is less then 25 RMS.

\subsection{Importance of Study}

Observations from this study, in combination with the recent structural analysis of the Gassaway Dome (Viso, 1999), may provide insights into possible relationships between the origins of sedimentary and basement structures observed in the region.

Studies of geophysical data have long been recognized as a source of information about deep basement structures and their potential influence on younger sedimentary structures and formation of hydrocarbon traps (Dobrin and Savit, 1988; Gay, 1999). Continued evaluation of magnetic anomalies at a more regional scale will provide a better understanding of the nature of basement heterogeneities responsible for basementcontrolled sedimentary structures in the Appalachian foreland of central West Virginia. These include the Burning-Mann lineament, and an unnamed lineament along which the Gassaway dome is located, and lineaments to the southwest across the NY-Al are 
possibly associated with the Warfield anticline. The implication and location of these Appalachian structures to various magnetic anomalies will be discussed later in the study. 


\section{Chapter Two: Model Studies of the Gassaway Area using WVGES (1978) and AGI Aeromagnetic Data}

\subsection{Magnetic Modeling of Gassaway Area with WVGES (1978) data}

The models presented in this chapter are used to evaluate the characteristics of the magnetic source object producing the NY-Al magnetic anomaly in the vicinity of Gassaway, WV. Features of the source body evaluated in the study include susceptibility, depth, geometrical form and dip. The bodies represented by the models of this chapter are those of a hypothetical suture zone (tabular bodies with shallow dips), or a transform fault zone (tabular bodies with vertical dip).

Before discussing the models developed in this study, background information concerning the model developed by Morgan (1996) is revisited.

\subsubsection{Morgan's (1996) magnetic models}

Morgan modeled total intensity data taken from the aeromagnetic map of West Virginia along a single transect from the WVGES (1978) data. His transect extended entirely across West Virginia from Wood County in the west to Pocahontas County in the east (for location of Morgan's study refer back to Figure 5). The background magnetic susceptibility of the basement in Figure 10 is assumed to be zero. The magnetic anomalies were assumed to be produced by susceptibility contrasts between a relatively low susceptibility granitic basement and higher susceptibility intrusions. Morgan modeled the simple tubular-like bodies within the basement as areas of high susceptibility 


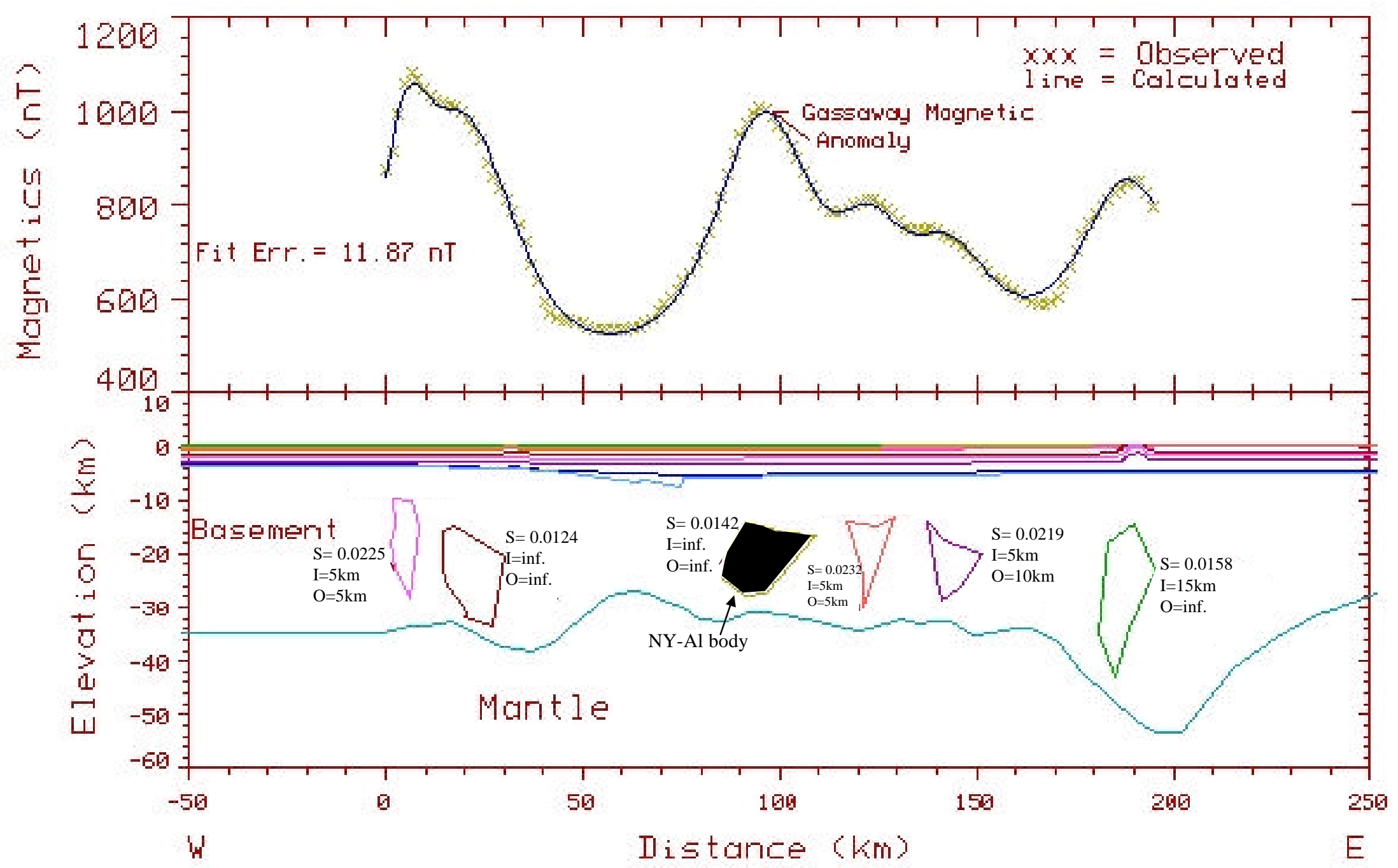

Figure 10: The magnetic model above was created by Morgan (1996) from Wood County to Pocahontas County West Virginia. The basement magnetic susceptibility is set at zero, and the bodies within the basement were interpreted by Morgan as mafic igneous intrusions within the lower crust. 
magnetic materials. Morgan (1996) interpreted these high susceptibility areas as mafic igneous intrusions. The strike lengths represent the distance these bodies extend in and out of the cross section (as shown on Figure 10). Bodies caused by local features have a small strike-length. Extensive regional trends are indicated by bodies with larger strikelength.

\subsubsection{Incorporation of Morgan's (1996) models to the Gassaway Anomaly study}

Morgan's model was modified for this study. Figure 11 illustrates some of the modifications made to Morgan's model. The key difference is that this study uses a geometrical configuration of source bodies defined to suggest various geological or tectonic relationships. Many authors have suggested (King and Zietz (1978), King et al., (1998), Gay (1996), and German (1985)) that the origin of the NY-Al lineament likely to be either a transform fault or sutures zone. This study has utilized source body shapes that suggest a suture zone or transform fault origin. Transform faults and suture zones are assumed to penetrate the entire thickness of the crust and thus extend as magnetic objects through that portion of the crust above the curie depth.

Morgan modeled gravity anomalies along his profile to estimate crustal thickness variations and depth to mantle. In this study our interest is only in the magnetic modeling and so, with the exception of Morgan's profile, the base of the magnetic crust is represented by a flat horizon at 35 kilometers beneath the surface. This depth is considered to be the Curie depth (Dobrin and Savit, 1988). At depths greater than the Curie depth the temperature is too high for magnetic domains to form.

In the process of modeling the NY-Al (New York - Alabama lineament) it was 

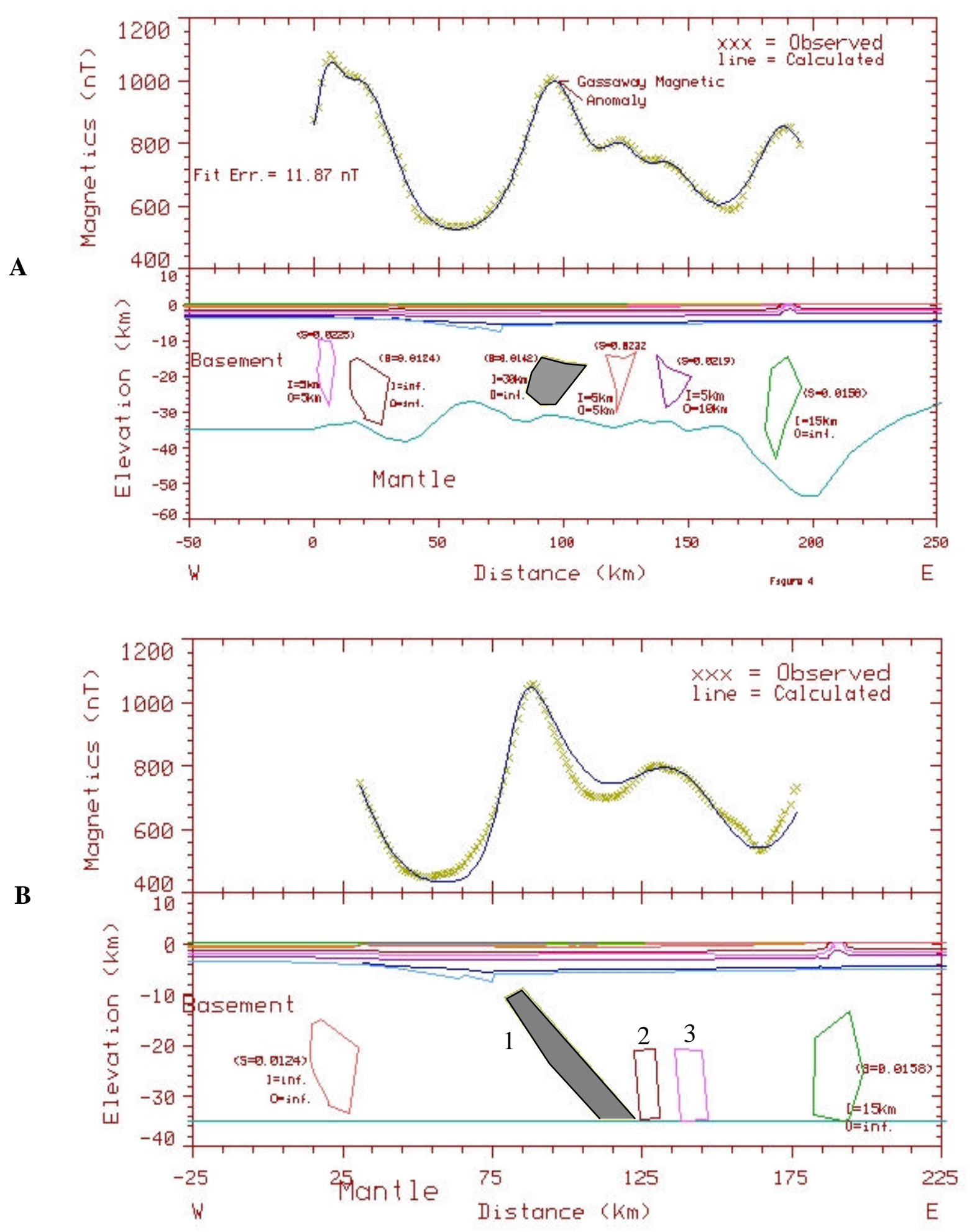

Figure 11: Model A is the magnetic model from Mogan (1996), model B is a typical model from this study. The mantle topography has been flattened at 35 kilometers, and bodies which did not correspond to a magnetic peak were deleted in order to make the models as simple as possible. Also, the main bodies of interest: 1 (black, the NYAl) body, 2 and 3 shown in model B extend though to the base of the basement. 
recognized that the bodies on either side of the NY-Al source object did have a subtle influence on the shape of the NY-Al anomaly. These bodies were also modeled as simple crust-penetrating tabular bodies. The bodies outside of the NY-Al body, and beyond the area of immediate interest (well to the east and west of NY-Al), have been only slightly modified from those presented by Morgan so that an adequate fit could be obtained between the calculated and observed data.

\subsubsection{Models Cross Strike to the NY-Al with WVGES (1978) Data}

Several basement structural configurations with variable magnetic susceptibility contrasts were tested as possible sources of the Gassaway magnetic anomaly. The purpose of modeling cross strike lines 2, 3 and 4 (Figure 6) was to investigate the dip, depth to the mid-point, and the magnetic susceptibility of the hypothetical source body responsible for the Gassaway anomaly (a magnetic high which lies along the NY-Al).

The geological origins of the NY-Al portrayed in the magnetic models must be consistent with what is known about the basement and crust of central West Virginia. The basement map shown in Figure 8 (Shumaker, 1996) reveals that the basement surface through central West Virginia is relatively undeformed east of the Rome trough. Large scale faulting with offsets of a kilometer or more are confined to the Rome trough. The large vertical displacements modeled by Rice (1983) (Figure 12) are not consistent with known structure in the area (Figure 8).

\subsubsection{Susceptibility trends of the Gassaway Magnetic Body}

Figure 13 shows two models of an east dipping body shown to rise from the base 


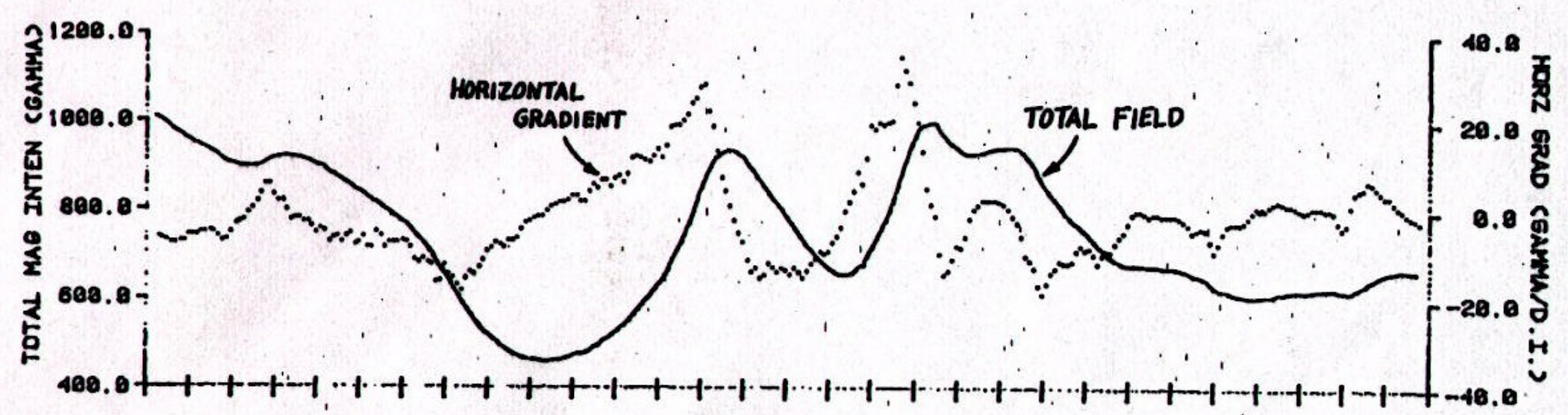

INCREMENT SPACTING = 18 D.I. (6.4 KM)

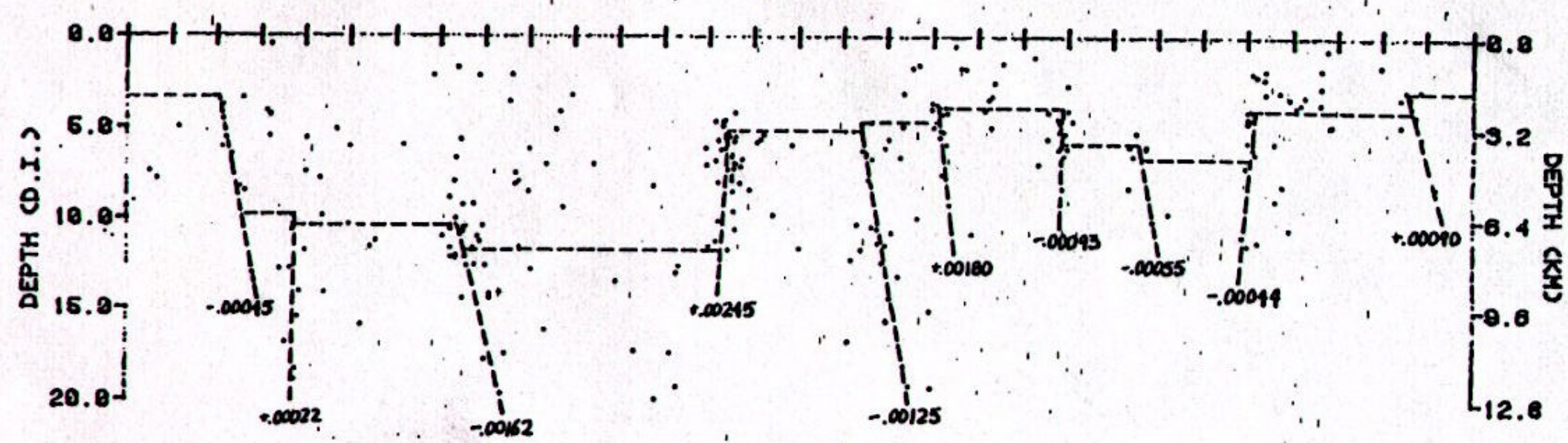

Figure 12: The magnetic model above was created by Rice (1983). Profile of the total field magnetic anomaly and associated basement configuration interpreted from profile D-D' in Figure 6. Dots represent derived solutions, and dashed lines show basement interface and faults. 

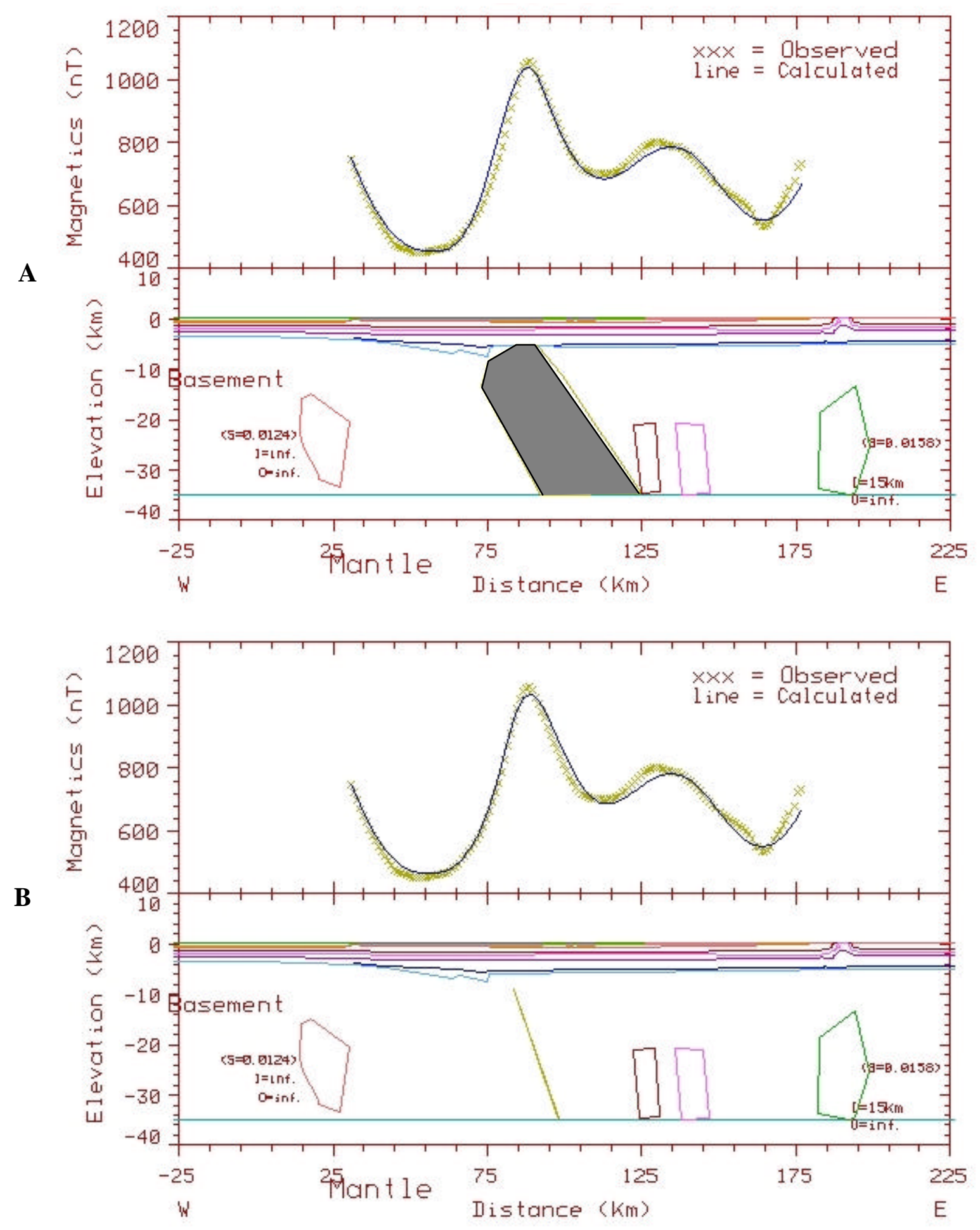

Figure 13: The range in magnetic susceptibility contrast for geologically plausible bodies is shown by two models. A) The NY-Al source body is east dipping with a magnetic susceptibility of 0.0039 and is 40 kilometers wide and extends through the entire crust. B) The NY-Al body is 0.01 kilometers wide and extends from the bottom of the basement to within 8 kilometers of the top of the basement and has a magnetic susceptibility of $100 \mathrm{cgs}$ units. 
of the crust. The purpose of showing the models on Figure 13 are document the extreme magnetic susceptibilities possible for the NY-Al source body. The bodies in Figure 13 are given a very high magnetic susceptibility of 199.9 cgs units (Figure 13B) and an extremely low magnetic susceptibility (Figure 13A) of $0.0039 \mathrm{cgs}$ units. This was done in order to investigate the range of possible magnetic susceptibilities while maintaining a specific geological interpretation of a transform system. The low-susceptibility case, Figure 13A, represents one end-member that extends the entire thickness of the crust and has an infinite strike length. The source body derived in this model has a magnetic susceptibility of $0.0039 \mathrm{cgs}$ units. Figure 13B portrays a slender sheet-like body that measures $0.01 \mathrm{~km}$ horizontally and extends from the basement bottom to within 8 kilometers of the basement surface. This sheet-like source body has magnetic susceptibility contrast of 199 cgs units. Both models fit the observed data with less then a 20 nT RMS fitting error.

The range in magnetic susceptibility contrast for these bodies $(0.0035$ to $100 \mathrm{cgs}$ units) indicates that the Gassaway magnetic anomaly upon the NY-Al could be fit by just about fit any known lithology (see Table 1).

\subsubsection{Depth to the Mid-Point of the Gassaway Magnetic Anomaly}

The maximum depth to the mid-point of a body producing the NY-Al anomaly using the simple transform fault interpretation is represented by a vertically dipping body in Figure 14. While attempting to investigate the range of magnetic susceptibilities the NY-Al source body could accommodate, the depth to the mid-point of a body (regardless

of its magnetic susceptibility) in the Gassaway area was found to be approximately $20 \mathrm{~km}$ below current sea level. For example, the bodies shown in Figure 14 illustrate this 

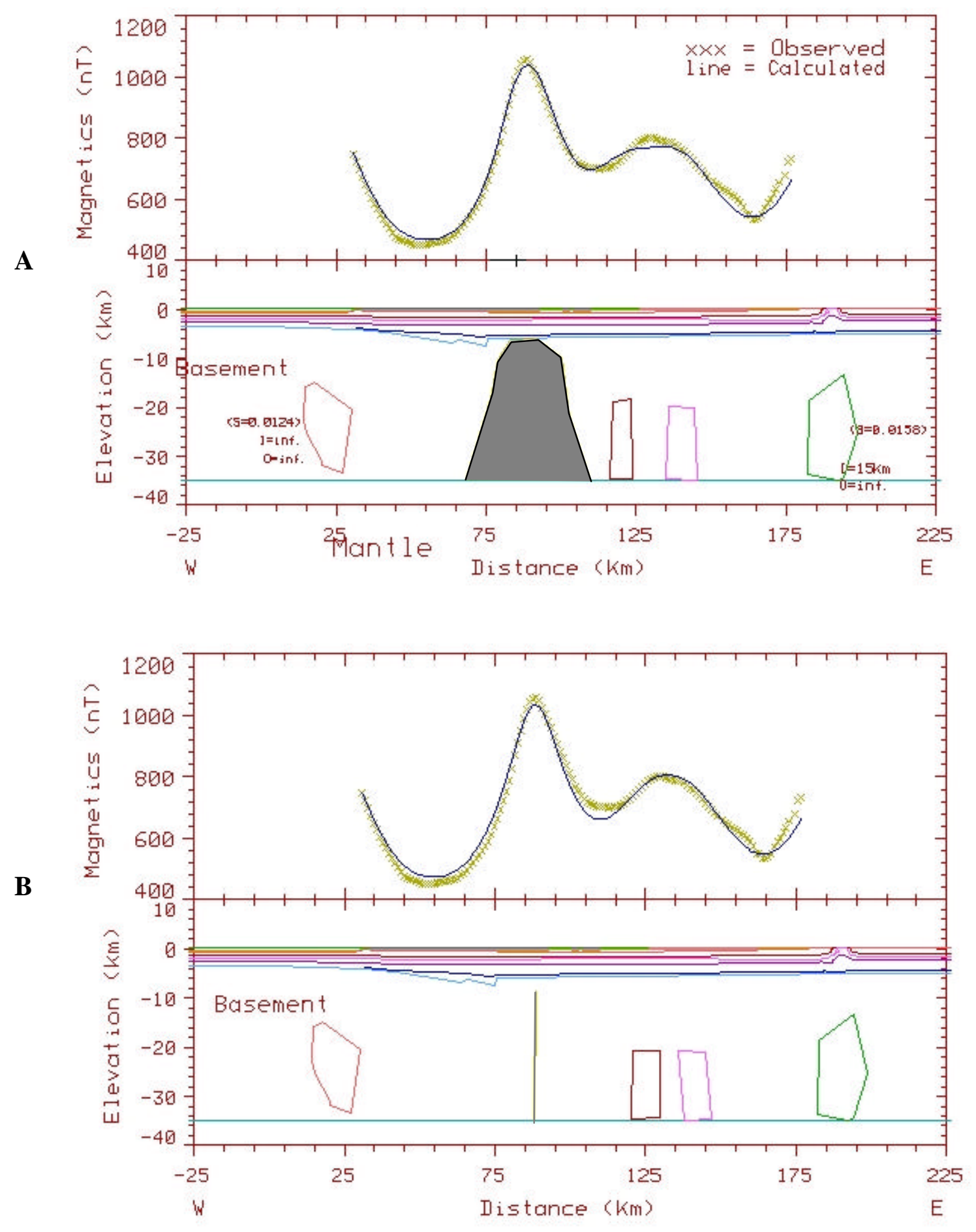

Figure 14: A) shows a large body with a magnetic susceptibility of 0.0039 cgs units. B) shows a very narrow vertical body with a large magnetic susceptibility contrast of $199.0 \mathrm{cgs}$ units. These models show that regardless of magnetic susceptibility or body dimension, the mid-point of the body responsible for the NY-Al must be located at 18 to 20 kilometers below current sea level. 
finding along profile 2 . This $20 \mathrm{~km}$ depth represents a maximum depth and does not preclude the possibility that the anomaly could be produced by magnetic materials distributed more diffusely at shallower depths. This maximum depth does preclude the possibility that magnetic source could be produced by objects centered at greater depths.

The magnetic body associated with the NY-Al anomaly in Figure 14A (transect line 2) extends through the entire thickness of the basement and measures approximately $35 \mathrm{~km}$ vertically by $25 \mathrm{~km}$ horizontally in cross-section. It has an infinite strike length, and has a magnetic susceptibility of $0.0039 \mathrm{cgs}$ units. The RMS fitting error for the object in Figure 14A is less then $15 \mathrm{nT}$.

The model in Figure 14B, however, shows that a much thinner and shorter body can reproduce the NY-Al along profile 2 . The body measures $27 \mathrm{~km}$ vertically with a 0.1 $\mathrm{km}$ width, extends to infinity in both directions along-strike, and has a magnetic susceptibility of $199.8 \mathrm{cgs}$ units. The calculated magnetic field intensities over this model fit the observed data also with less than 15 nT RMS error.

Both of the bodies in Figure 14 are centered at approximately 18 to 20 kilometers. Other models, such as those shown in Figures 15 through 17, which will be discussed later, have depths to mid-point less than $20 \mathrm{~km}$. Also, as the wavelength of the NY-Al anomaly is consistent from profile 2 to profile 4 (figures 15 through 17), the estimate of

maximum 18 to 20 kilometer depth to mid-point does not vary throughout the Gassaway area.

\subsubsection{Dipping Suture Zone Model for the Gassaway Anomaly}

Figures 15, 16 and 17 show models of profiles 2, 3 and 4 respectively (refer to 

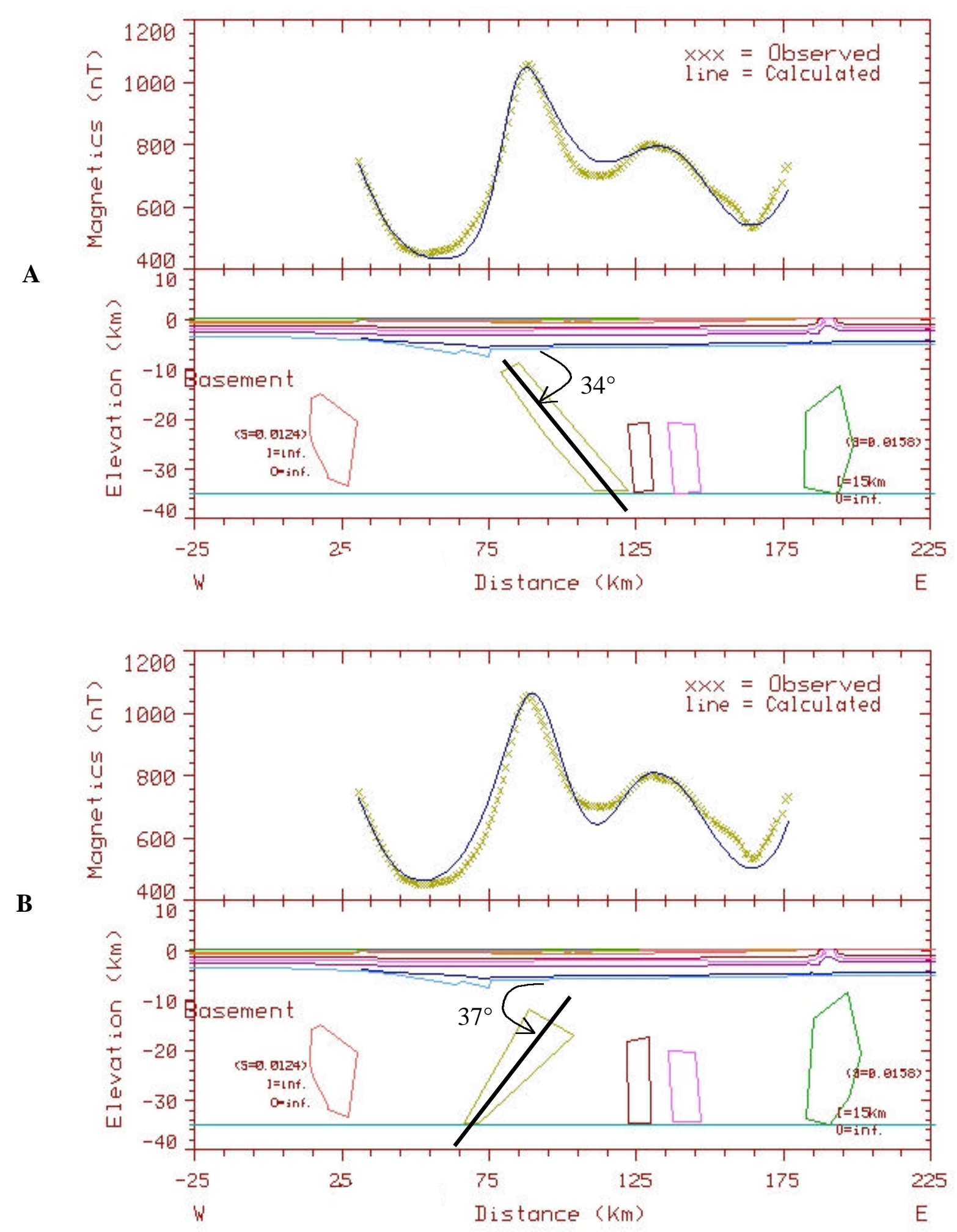

Figure 15: Models derived for the minimum east dip (A) and west dip (B) for NY-Al source body with a susceptibility of 0.0143 cgs units (similar to a basalt) along profile 2 . Both models are displayed with a vertical exaggeration of $1.7 \mathrm{x}$. 


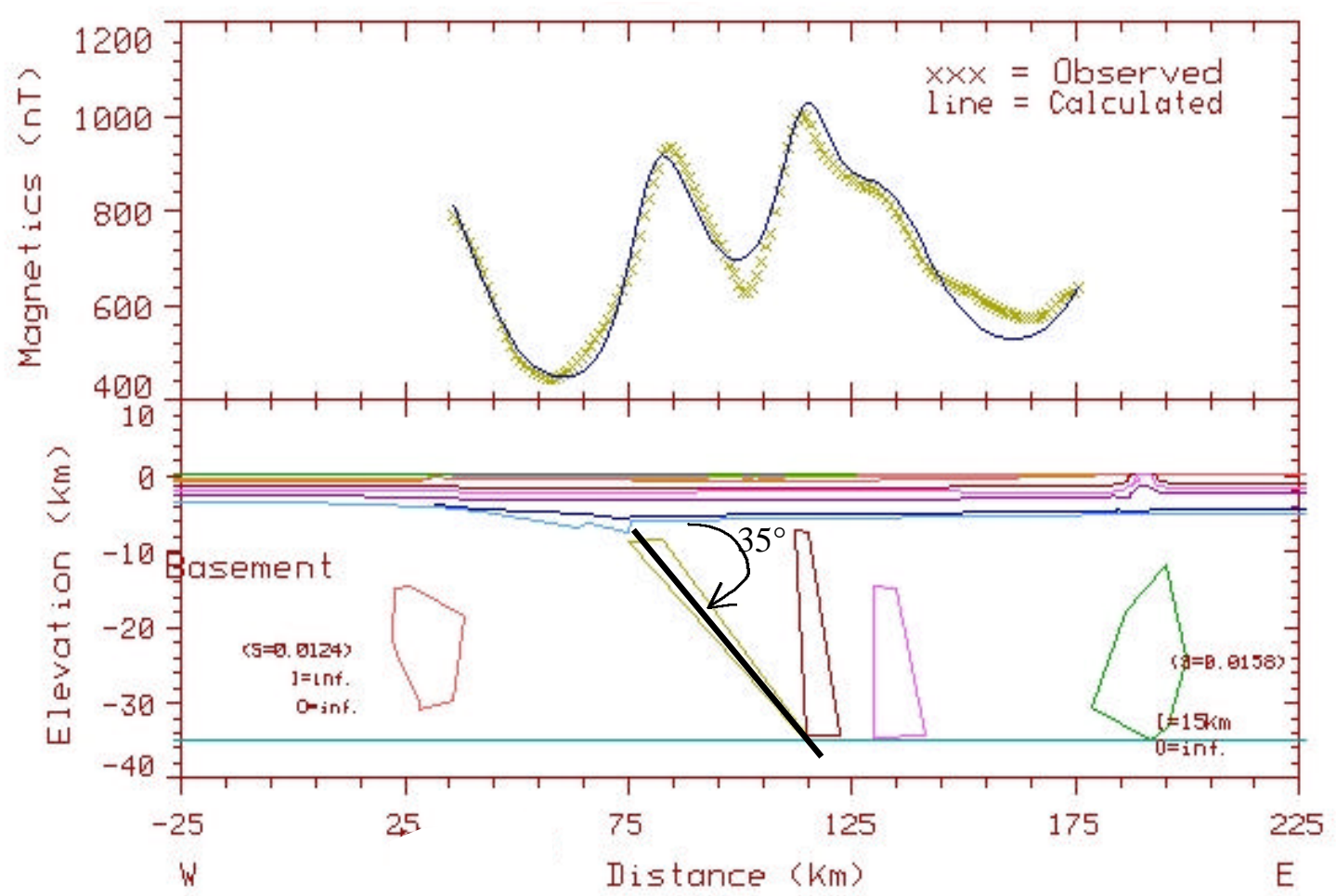

B

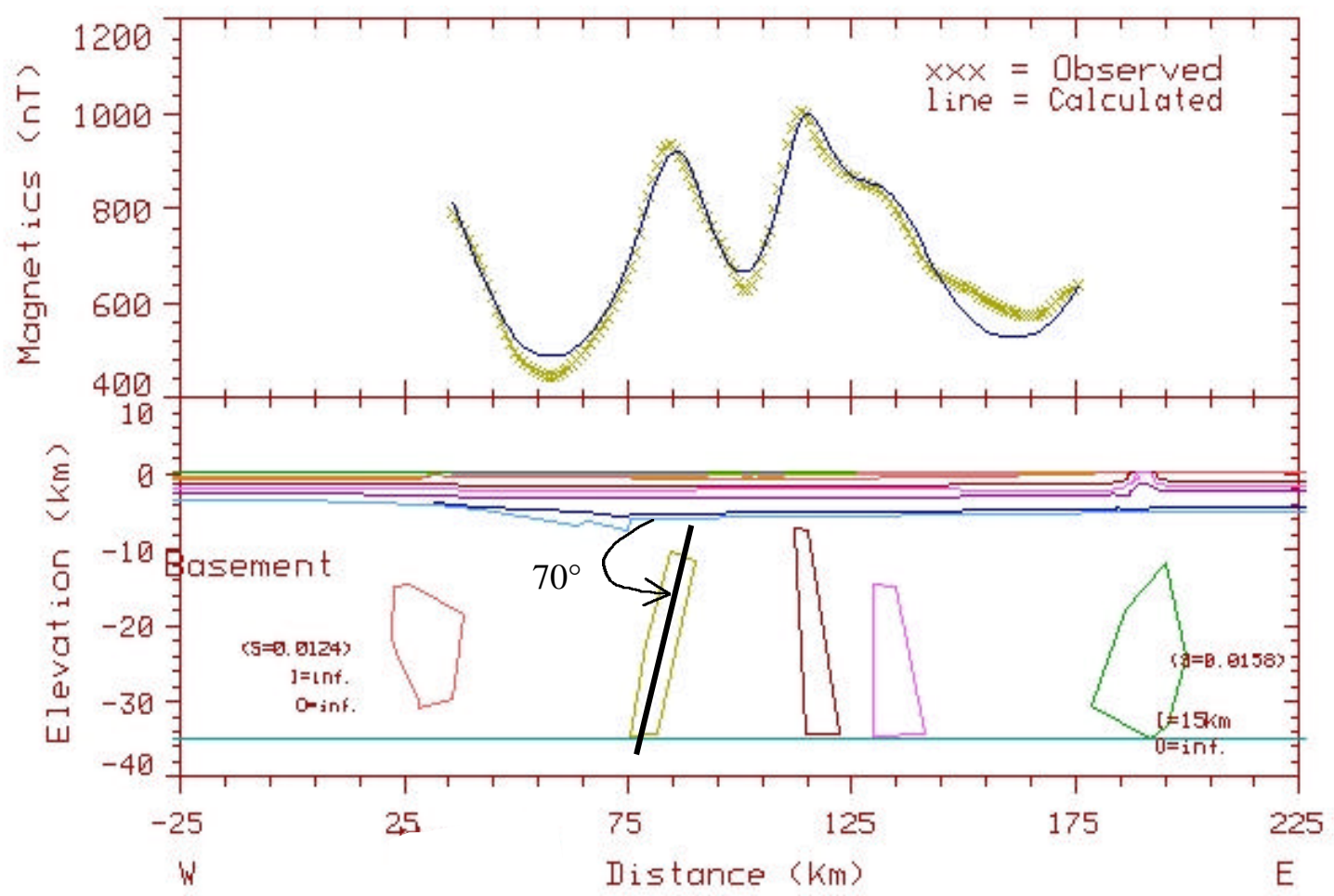

Figure 16: The NY-Al source body minimum dips along profile 3 is shown in figure 16A and B. The magnetic susceptibility of this NY-Al body is $0.0143 \mathrm{cgs}$ units. The models shown here are exaggerated $1.7 x$ vertically. 

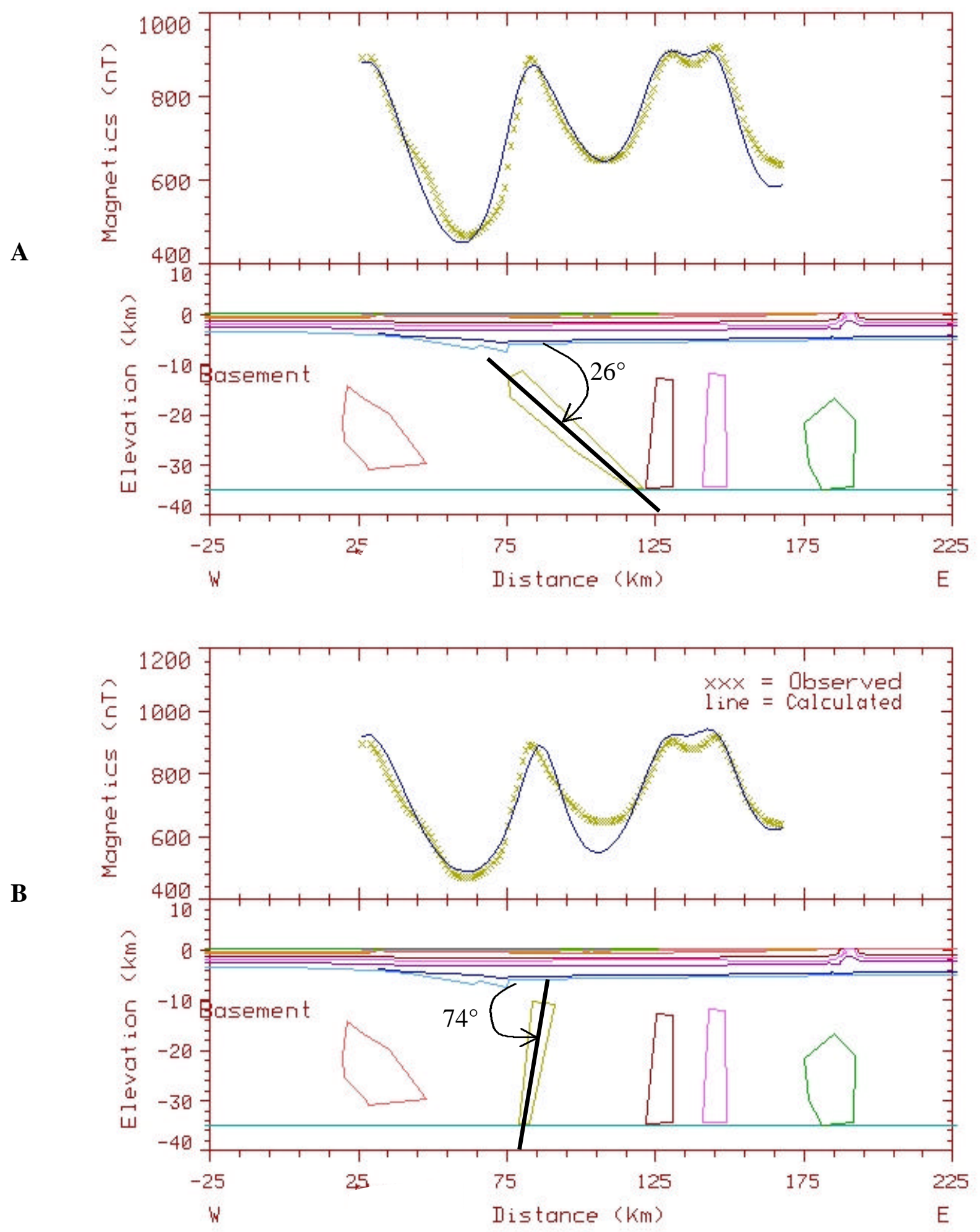

Figure 17: The minimum NY-Al source body (susceptibility of 0.0143 cgs units) dip along profile 4 is shown in (A) and (B). The models above are exaggerated $1.7 \mathrm{x}$ vertically. 
Figure 6 for profile locations), where both an east dipping and west dipping source body have been modeled. These models (figures 15, 16, and 17) establish the minimum dip angles that can be associated with tabular crust penetrating source used to explain the local Gassaway anomaly. The values of dip were measured from true scale representations of the models.

The results of modeling profile 2 (Figure 15) reveal minimum dip angles for the $\mathrm{NY}-\mathrm{Al}$ body of $34^{\circ}$ to the east, and a minimum dip of $37^{\circ}$ to the west. Results obtained along profile 3 (Figure 16) yield minimum dip angles of $35^{\circ}$ and $70^{\circ}$ to the east and west, respectively. Along profile line 4 minimum dips of $26^{\circ}$ east and $74^{\circ}$ west were obtained (Figure 17). The magnetic susceptibility of this object is held at a constant $0.0143 \mathrm{cgs}$ units (the value for basalt, Table 2) though all models on figures 15 through 17.

\subsubsection{Models Along-Strike to the NY-Al with WVGES (1978) Data}

Several geologically plausible models have been evaluated along the length of the NY-Al (taken from near profile 12 on Figure 6). Figure 18A shows a simple vertical body, which extends to the bottom of the basement and strikes infinitely from the southwest to the northeast. The relief across the top of this vertical body has been modeled to simulate the variations in the total field anomaly of the NY-Al in the vicinity

of Gassaway, West Virginia. The magnetic body shown in Figure 18B employs the same body surface relief, but has been modeled to have an eastward dip. Three dimensional diagrams of the NY-Al body are shown to the right of each model. The Gassaway magnetic high shown in these models is associated with a high relief feature across the top of the source body. 


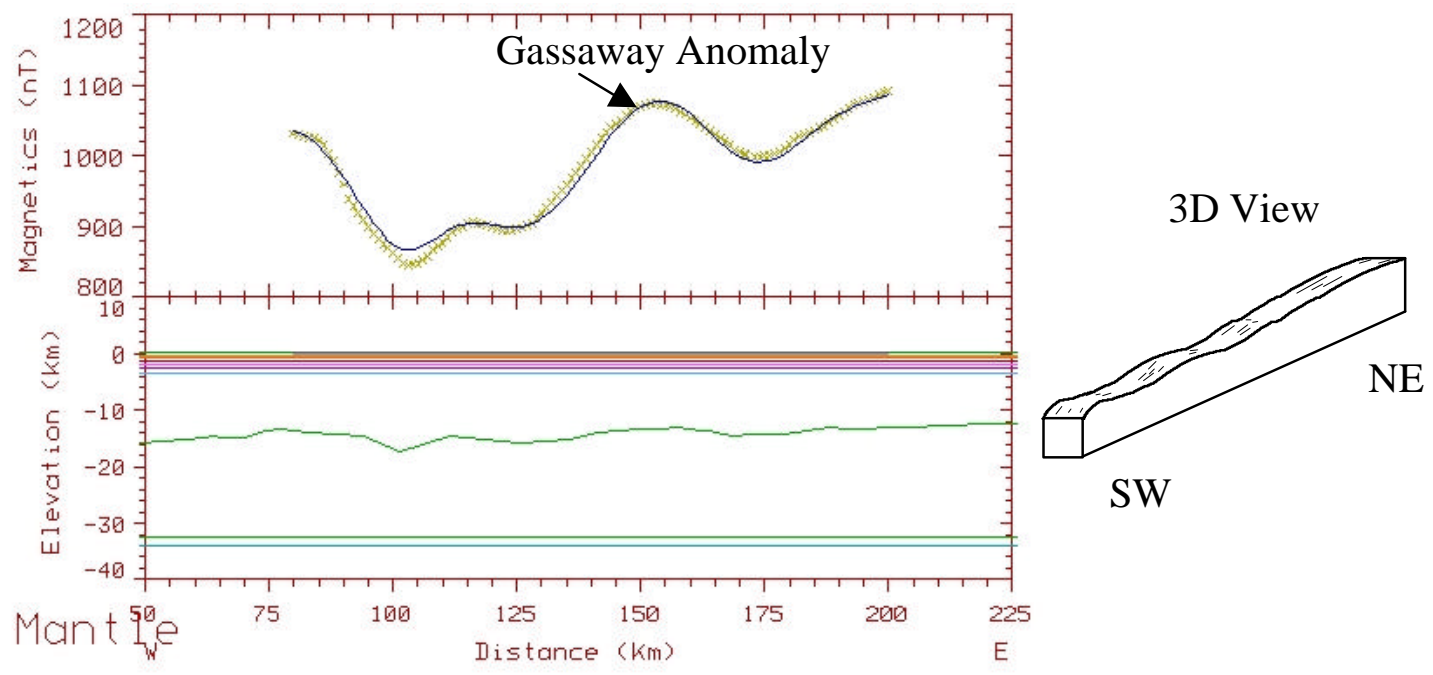

SW

$\mathrm{NE}$

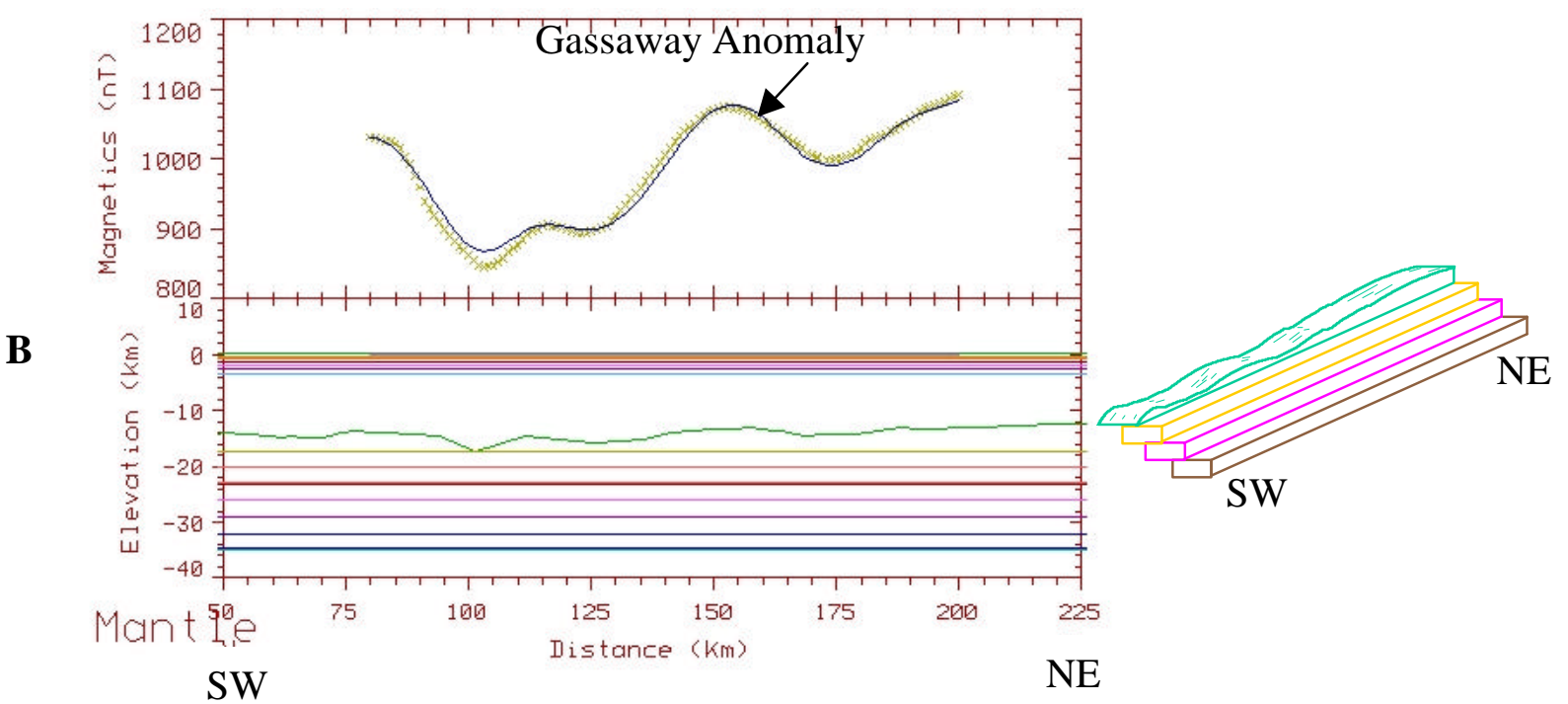

Figure 18: The along strike models (taken from near profile 12 on Figure 6) in A and B utilize the same magnetic susceptibility contrast of $0.0142 \mathrm{cgs}$ units and the same topographical changes on top of the NY-Al body to model the Gassaway magnetic anomaly. A) The body strikes infinitely from the SW toward the NE, and is oriented vertically in cross-section. B) The body strikes infinitely, but is dipping toward the east with magnetic blocks "stepping out" at a 5 kilometer interval. Both of these bodies extend to the bottom of the basement. 
Two additional models are shown in Figure 19. Figure 19A simulates the Gassaway magnetic high using faulted offsets along the top of the NY-Al body while maintaining a constant magnetic susceptibility of 0.0142 cgs units. The model shown in Figure 19B produces the magnetic field variations using a series of bodies with differing susceptibilities and very little variation in relief.

\subsection{Data and Model Comparison of WVGES (1978) data to the AGI Data}

Comparisons of the AGI total intensity data to the WVGES (1978) data reveals that they are very similar. Selected comparisons are illustrated in figure 20 and 21.

\subsubsection{Cross Strike Data Set Comparison}

Plots 20A and 20B along with 21A represent cross strike profiles of WVGES and AGI total magnetic intensity along profiles 2,3 , and 4 respectively. Notice the similarity NY-Al anomaly wavelengths in figures $20 \mathrm{~A}, \mathrm{~B}$, and 21A. Similarities also exist, in the data on either side of the NY-Al within figures 20 and 21. Differences are observed in the anomaly wavelength to the west of the NY-Al on Figure $20 \mathrm{~A}$ and anomaly amplitude of the magnetic high to the east of the NY-Al on Figure 20A). A significant difference between the AGI and WVGES data (1978) can be seen on Figure 20B where an additional small peak appears in the AGI data on a magnetic high east of the NY-Al.

\subsubsection{Along-Strike Data Set Comparison}

The along-strike profile 12 supplied by AGI cannot be compared directly to the 

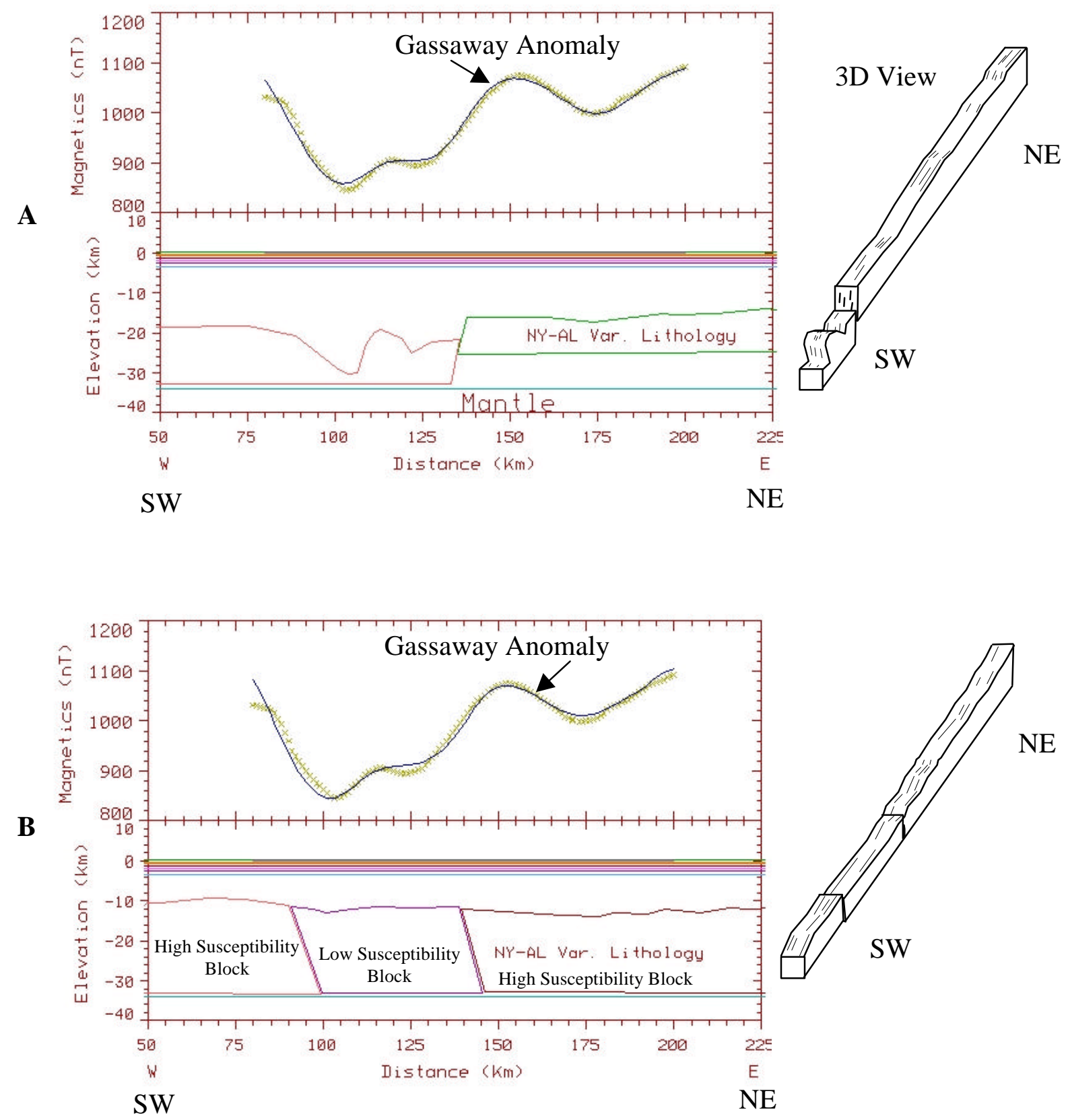

Figure 19: The Gassaway anomaly along the New York - Alabama lineament is modeled as a faulted body (A) taken from near profile 12 on Figure 6. The Gassaway anomaly could be simulated with a variable lithology along the NY-Al body (B). 

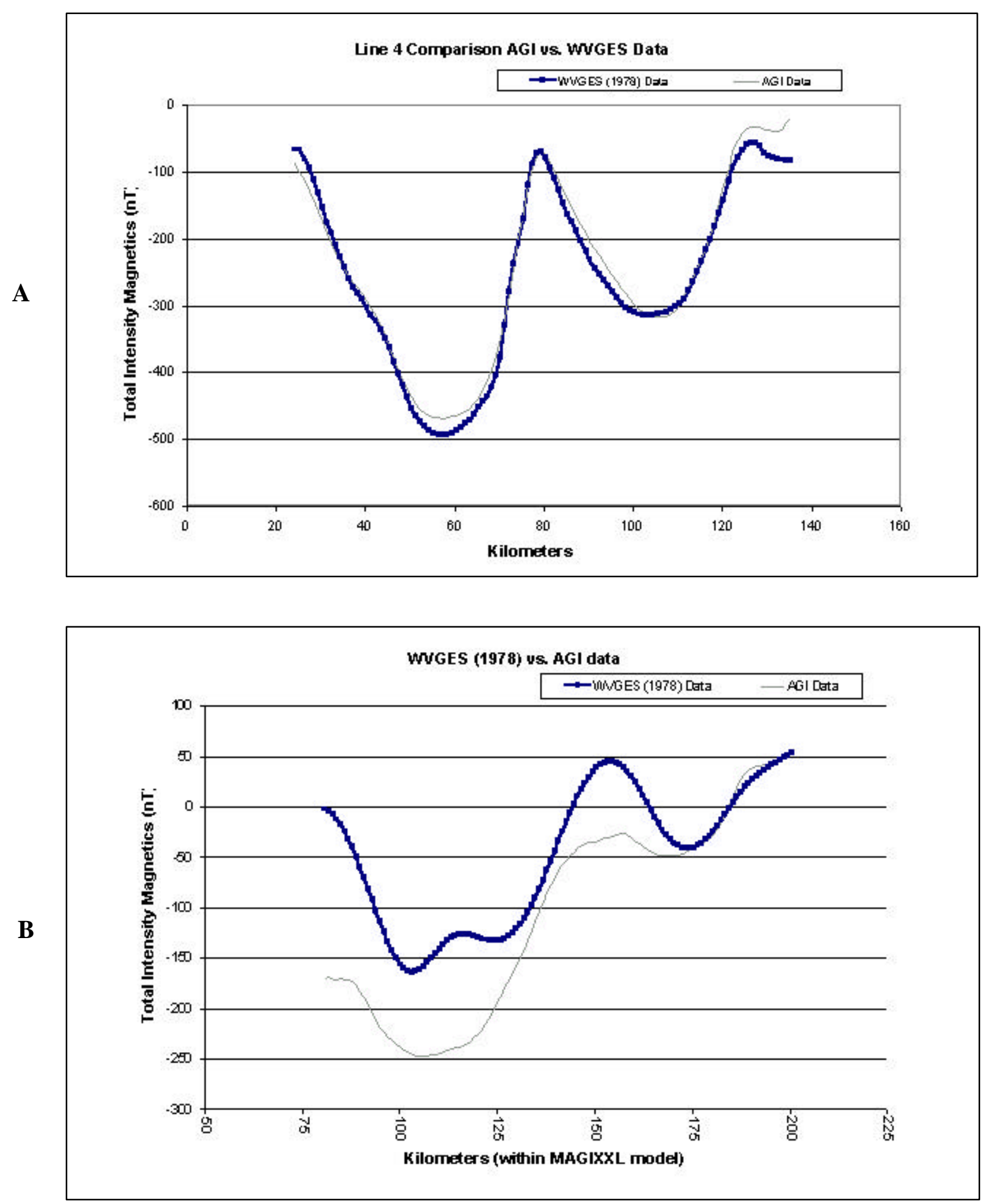

Figure 21: The comparison in (A) shows very little difference between the AGI and WVGES data along profile 4. The comparison in (B) along profile 12 show significant differences in relative amplitude for the data along profile line 12.

This discrepancy, though, is due to different profile locations along transect 12 (refer to Figure 6). 

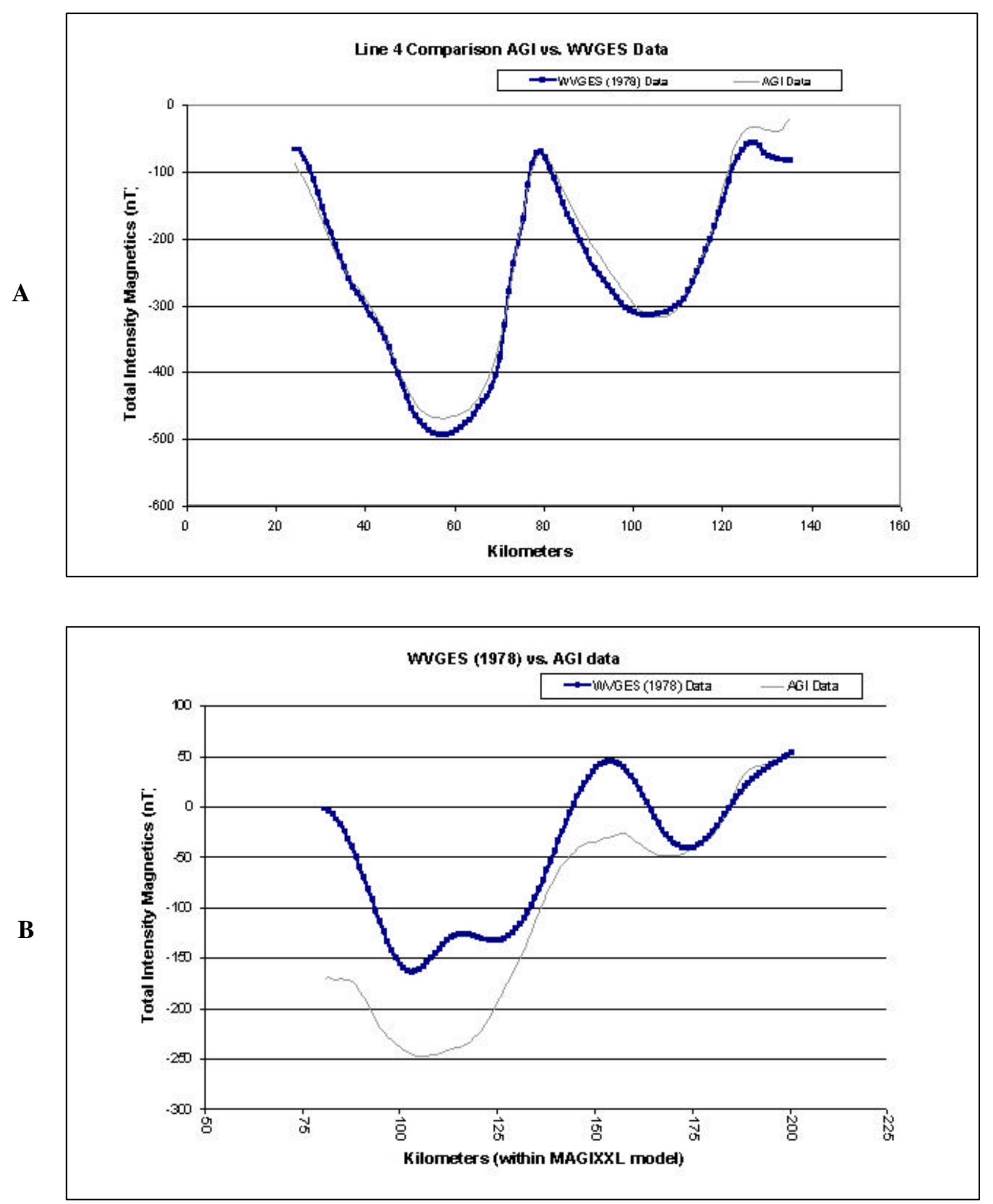

Figure 21: The comparison in (A) shows very little difference between the AGI and WVGES data along profile 4. The comparison in (B) along profile 12 show significant differences in relative amplitude for the data along profile line 12.

This discrepancy, though, is due to different profile locations along transect 12 (refer to Figure 6). 
WVGES profile. The location of the AGI along-strike profile line is slightly offset from the WVGES (1978) profile. Figure 6 shows the location of the WVGES line 12 in comparison to the AGI line 12. The differences in magnetic field observed along these profiles are largely due to the differences in their location. In fact, many of the differences observed in these comparisons can be attributed to the slight differences in the location of the hand digitized WVGES lines and the AGI lines. Visual compariosn of the AGI data to the WVGES data along profile 12 reveals considerably greater similarity.

\subsubsection{Data Set Comparison Summary}

One of the main objectives of this study is to compare AGI and the WVGES (1978) total intensity data sets for the area in the vicinity of Gassaway West Virginia. A comparison of the two data sets reveals an overall similarity. In general, total intensity data from the WVGES aeromagnetic map and the AGI data are quite similar. Based on these comparisons, the magnetic anomaly discrepancies would lead only to minor differences in the resultant models. 


\section{Chapter Three: Magnetic Model Studies Along the New York -Alabama Lineament}

In this chapter additional models are developed outside the Gassaway area along the length of the (New York - Alabama lineament) NY-Al through West Virginia. The models in this chapter are presented to further detail possible characteristics, such as dip, depth to mid-point and magnetic susceptibility contrasts of the NY-Al source object along its length through West Virginia. These models may provide insight into systematic changes in the nature of the NY-Al source body including possible variations in susceptibility and dip along its length. As in Chapter 2, the NY-Al source body will again be modeled to test the possibility that certain tectonic scenarios, such as a suture zone (gently dipping tabular body) or a transform fault (steeply dipping sheet-like body) can explain its origins.

\subsection{Magnetic data and model profile location}

The total intensity magnetic data used in this chapter were supplied by AGI. The data are located along four profiles across the NY-Al. Northwest to southeast trending profiles 7, 1, 5, and 6 (Figure 6) are modeled and presented in this chapter.

Total field intensity magnetics northwest and southeast of the NY-Al source body was modeled using simple objects rooted at the base of the crust. Individual long wavelength anomalies were modeled using a single source body.

\subsection{Susceptibility trends for the NY-Al through Central West Virginia}

Magnetic susceptibility contrasts were modeled along profiles 7, 1, 5, and 6 (northernmost to southernmost transects). Line 6 (Figure 22) is an example of the 
A

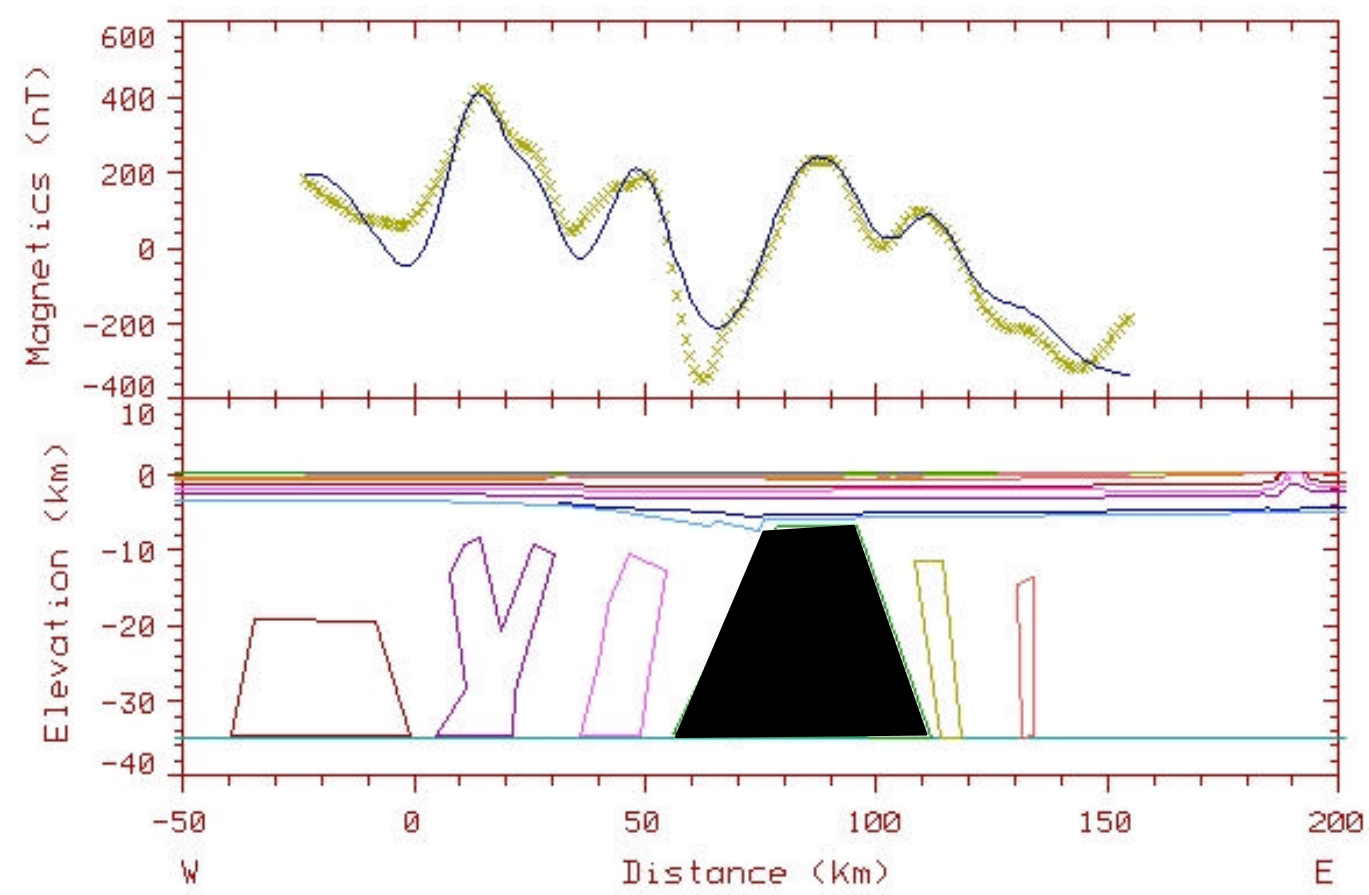

B

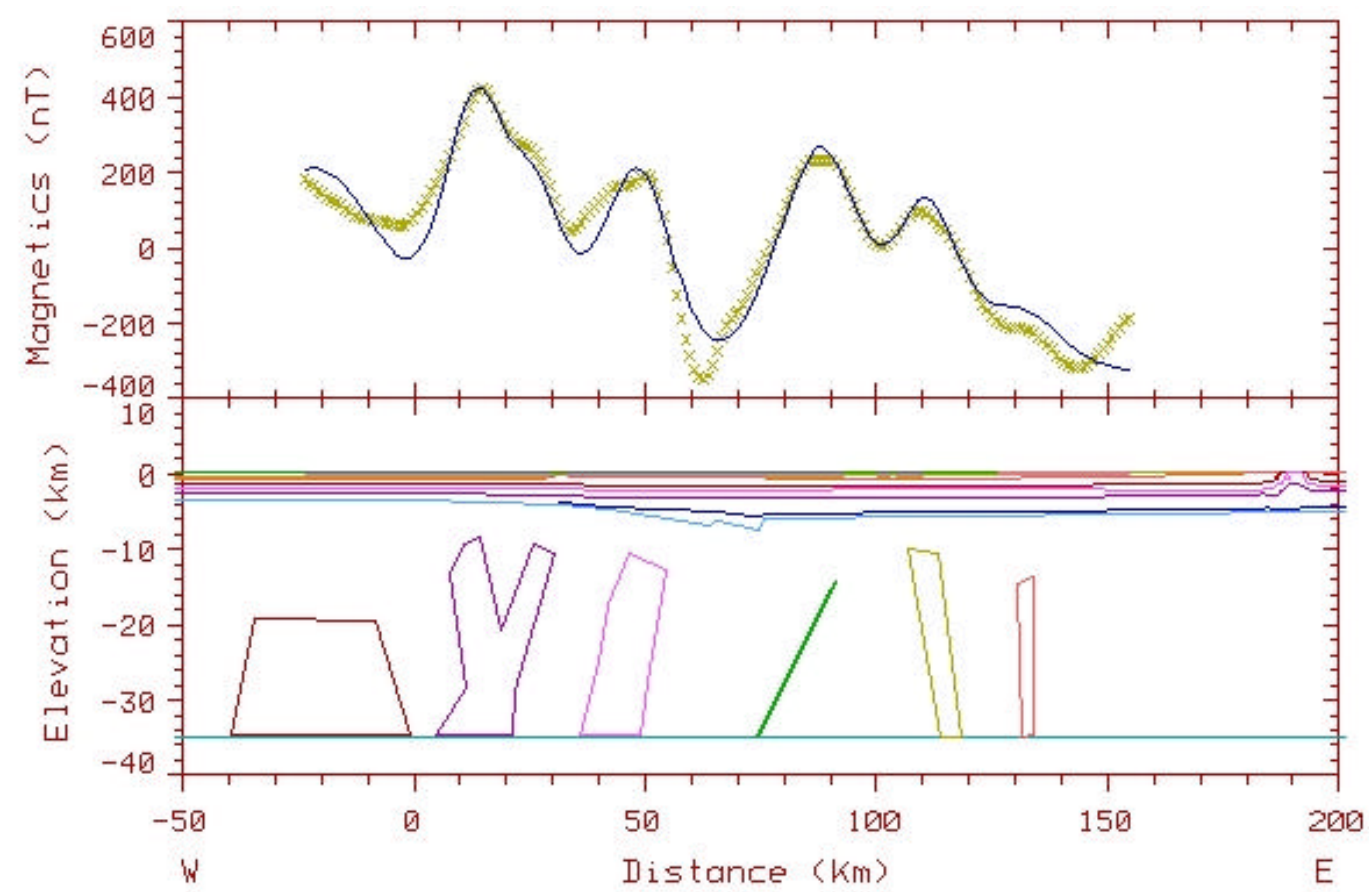

Figure 22: Models of the NY-Al and surrounding anomalies along profile $6 \mathrm{~A}$ ) The NY-Al source body (filled in black) is a large prism -like object with a 0.0045 cgs units. B) The NY-Al source body has been modeled here as a thin sheet-like anomaly with a magnetic susceptibility contrast of $0.9 \mathrm{cgs}$ units. 
differences in model geometry that are obtained when large differences in susceptibility contrast are incorporated in the NY-Al source object. Figure 22 illustrates that the geometrical shapes of the bodies portrayed in the model vary from vertical bodies with rectangular (prismatic) cross section (transform boundary) to dipping sheet-like bodies (suture zone). All source bodies used to represent the NY-Al source had infinite strike length. Table 3 shows a summary of the results obtained from the MAGIXXL modeling procedures to establish a range of magnetic susceptibility contrast modeled along profiles $7,1,5$, and 6.

\section{Table 3: Summary of Magnetic Susceptibility and Depth to Mid-Point for Profiles cross-strike to the NY-Al}

\begin{tabular}{cccc}
\hline Profile & Body Configuration & $\begin{array}{c}\text { Magnetic } \\
\text { Susceptibility } \\
\text { (cgs units) }\end{array}$ & $\begin{array}{c}\text { Depth to } \\
\text { Mid-Point } \\
\text { (below Sea level) }\end{array}$ \\
\hline 7 & Large Prism-like & 0.0025 & $20 \mathrm{~km}$ \\
7 & Small Sheet-like & 0.9 & $22 \mathrm{~km}$ \\
& Large Prism-like & 0.0028 & $20 \mathrm{~km}$ \\
1 & Small Sheet-like & 0.9 & $21 \mathrm{Km}$ \\
5 & Large Prism-like & 0.0055 & $20 \mathrm{~km}$ \\
5 & Small Sheet-like & 0.7 & $21 \mathrm{~km}$ \\
& & & $20 \mathrm{~km}$ \\
6 & Large Prism-like & 0.0045 & $21 \mathrm{~km}$ \\
\hline
\end{tabular}

The range of magnetic susceptibility contrast could be associated with any known felsic or mafic lithologies (Table 1). Bodies, which may contain very high amounts of magnetite, pyrrhotite, and ilmentite, are the only possible lithology constituents for the high magnetic susceptibility contrast models. Bodies having lower magnetic susceptibility contrast could be interpreted as any known lithology with low amounts magnetic material (magnetite, illmentite, and etc). The range of possible susceptibilities allows one to model these anomalies using nearly any lithology, however, for the 
remainder of the model studies, the susceptibility contrast is set relatively constant. The NY-Al source body will have a $0.00143 \mathrm{cgs}$ unit magnetic susceptibility. This susceptibility is consistent with materials carried up from the mantle along a suture, transform or extensional fault system, such as a gabbro or possibly basalt (Dobrin and Savit, 1988 and Telford et al., 1976).

\subsection{Depth to the Mid-Point of the NY-Al through Central West Virginia}

Table 3 shows the depth to the mid-point of NY-Al source bodies at approximately $20 \mathrm{~km}$ below sea level regardless of body size or magnetic susceptibility contrast.

It must be noted, however, that subtle differences do exist in the derived depth to mid-point of the NY-Al source depending on whether it is modeled to have an extremely high magnetic susceptibility or a very low magnetic susceptibility. Generally, the depth to the mid-point of a body with high magnetic susceptibility is slightly deeper (1 - 2 kilometers) than depths derived for low susceptibility bodies (Table 3). Examination of the two bodies used to simulate the NY-Al in Figure 22 reveals these differences in average depth. The results obtained along this profile are representative of results obtained on profiles $7,1,5$ and 6 .

\subsection{Minimum Dip of the NY-Al through Central West Virginia}

Figures 23, 24, 25, and 26 show the southeast and northwestern minimum dips possible for the NY-Al source body along profiles 7, 1, 5, and 6 respectively. These dip estimates were taken from models (figures $23,24,25,26$ ) where the NY-Al source body was modeled in the shallowest dip orientation so that a range of dip estimates could be 
A

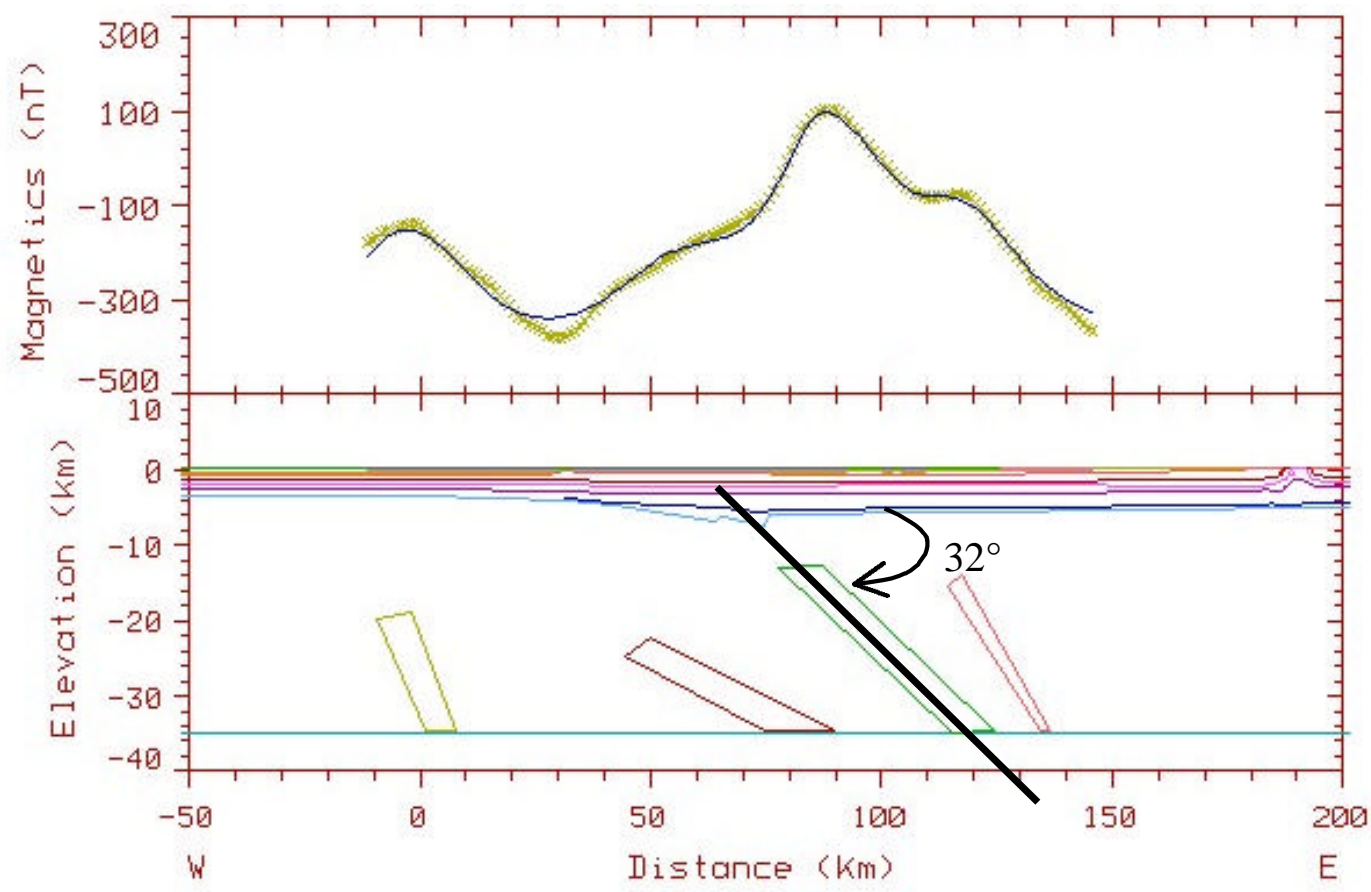

B

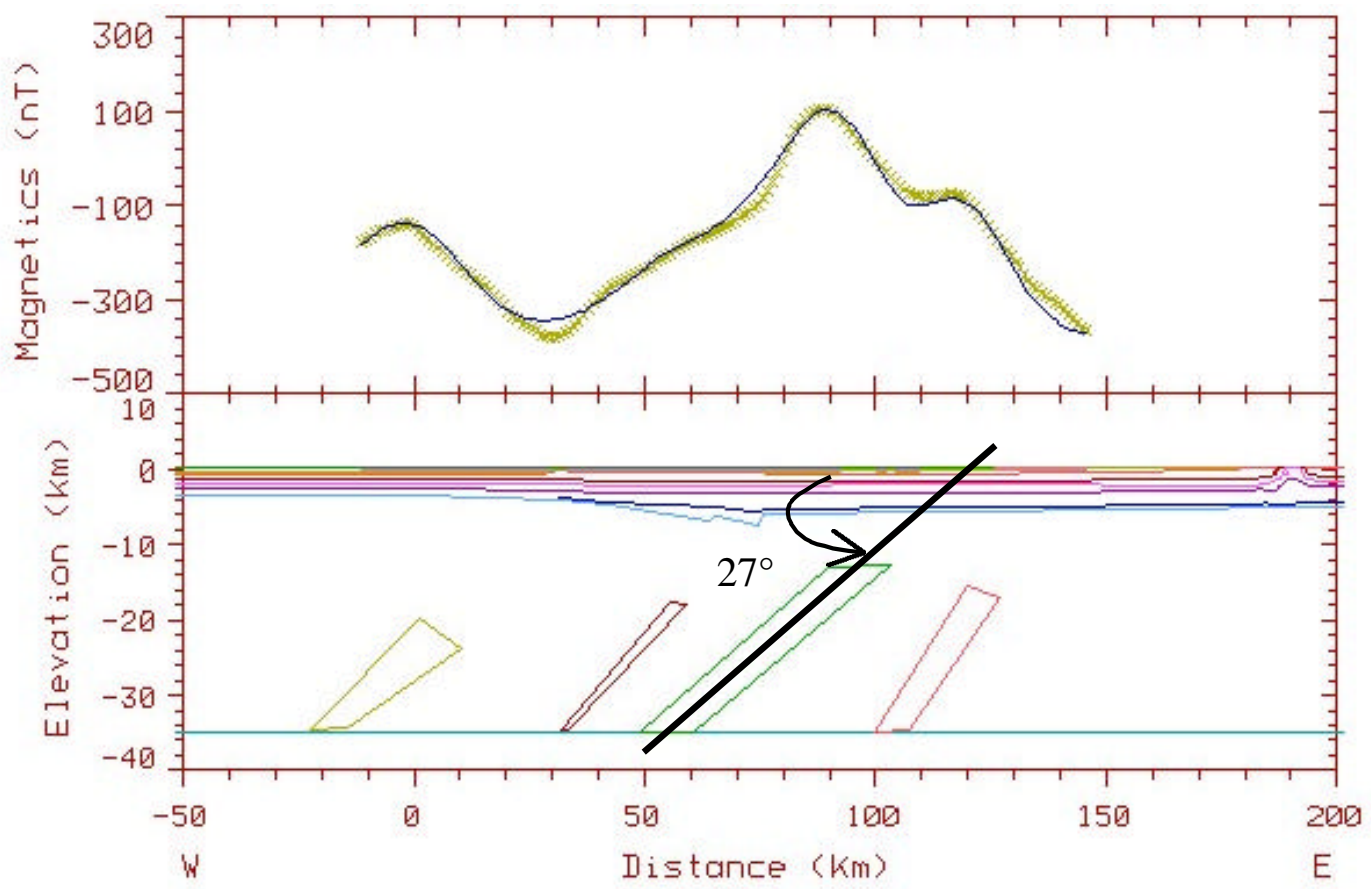

Figure 23: A) A minimum southeastern dip of $32^{\circ}$ was obtained along profile 7 (northernmost requested transect from AGI). B) The northwestern minimum dip along profile 7 was $27^{\circ}$. These models are exaggerated $1.7 x$ vertically. 

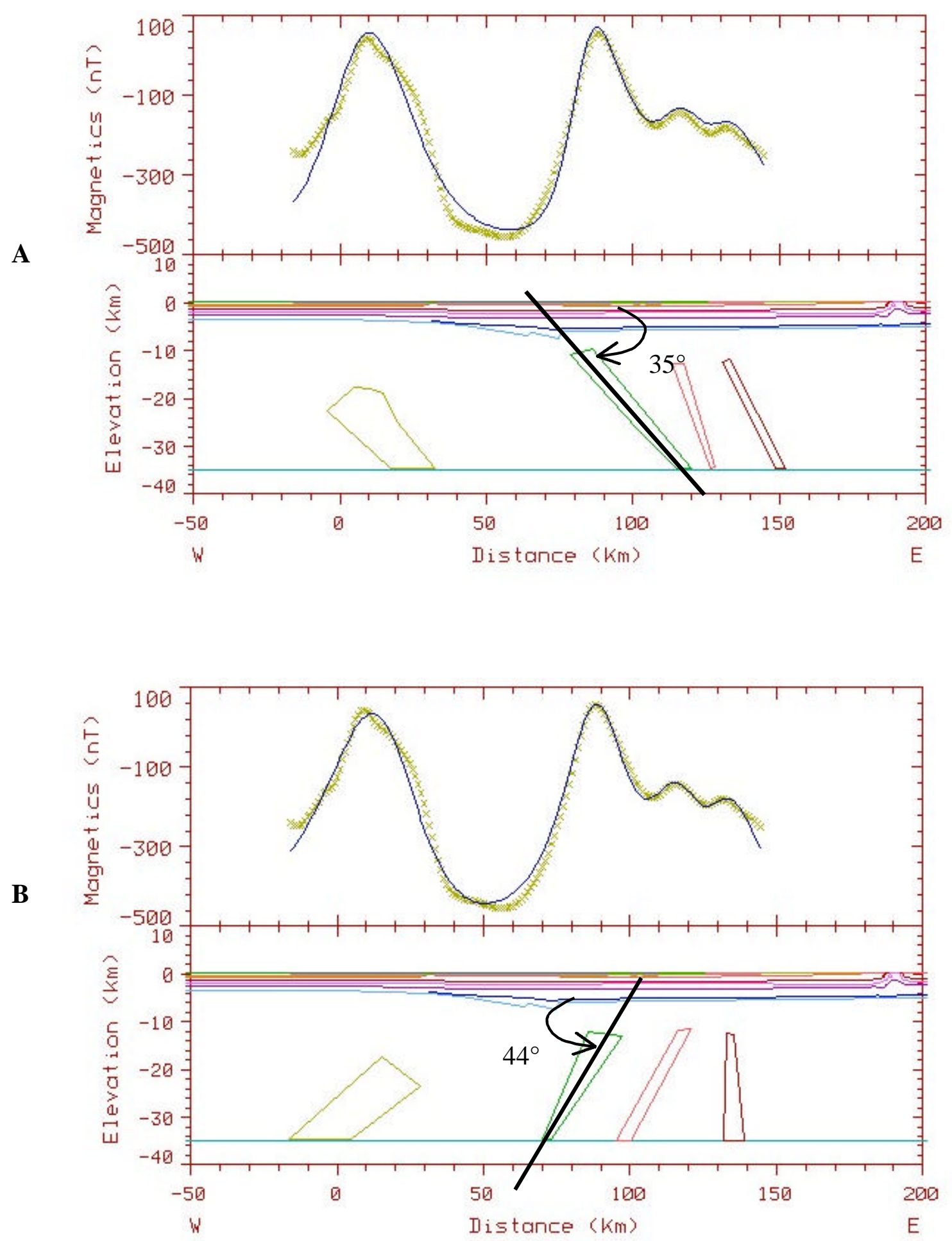

Figure 24: A) A minimum southeastern dip of $35^{\circ}$ was reached along profile 1 . B) The northwestern minimum dip along profile 1 was $44^{\circ}$. These models are exaggerated $1.7 \mathrm{x}$ vertically. 

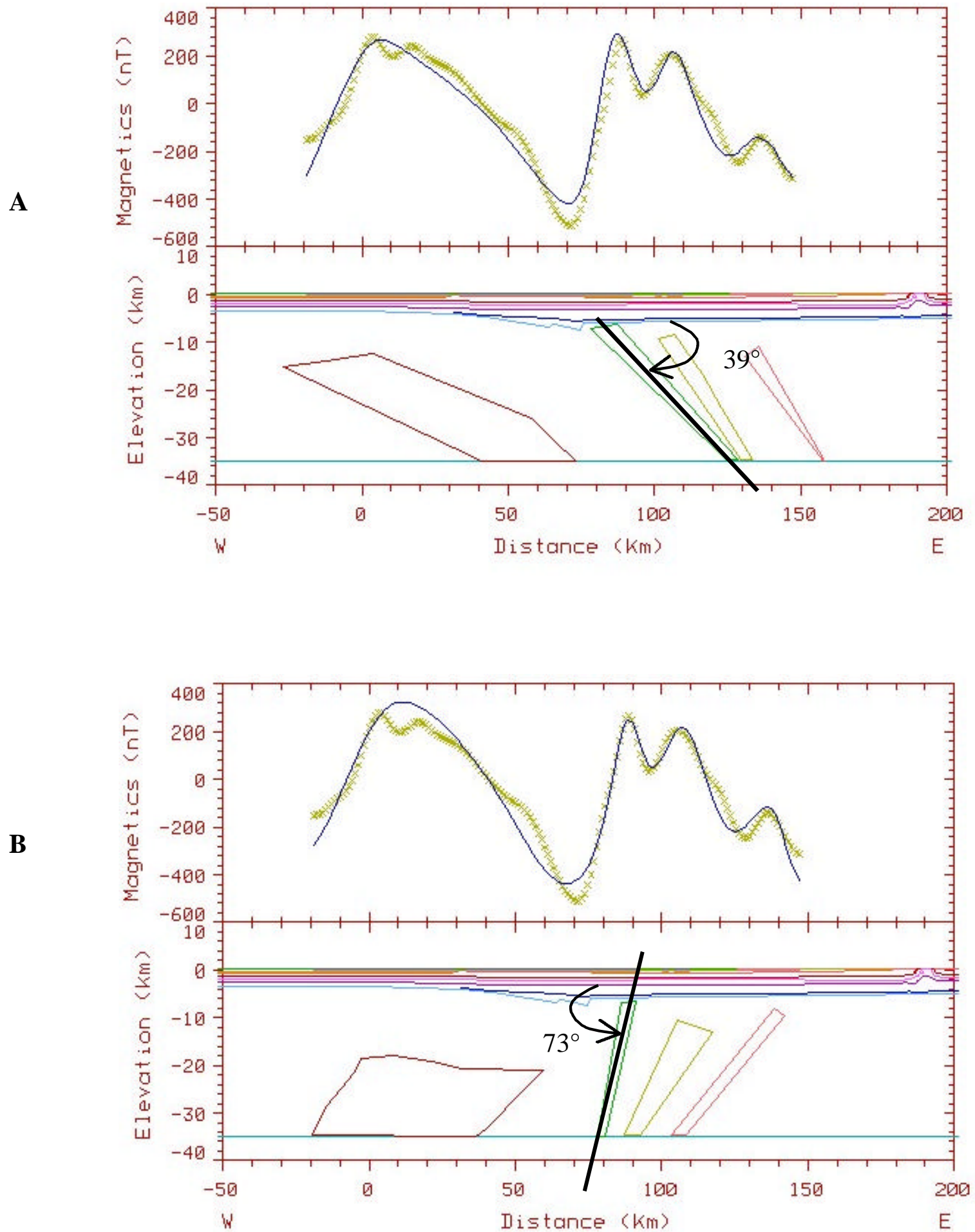

Figure 25: A) A minimum southeastern dip of $39^{\circ}$ was reached along profile 5. B) The northwestern minimum dip along profile 5 was $73^{\circ}$. These models are exaggerated $1.7 x$ vertically. 
$\mathbf{A}$

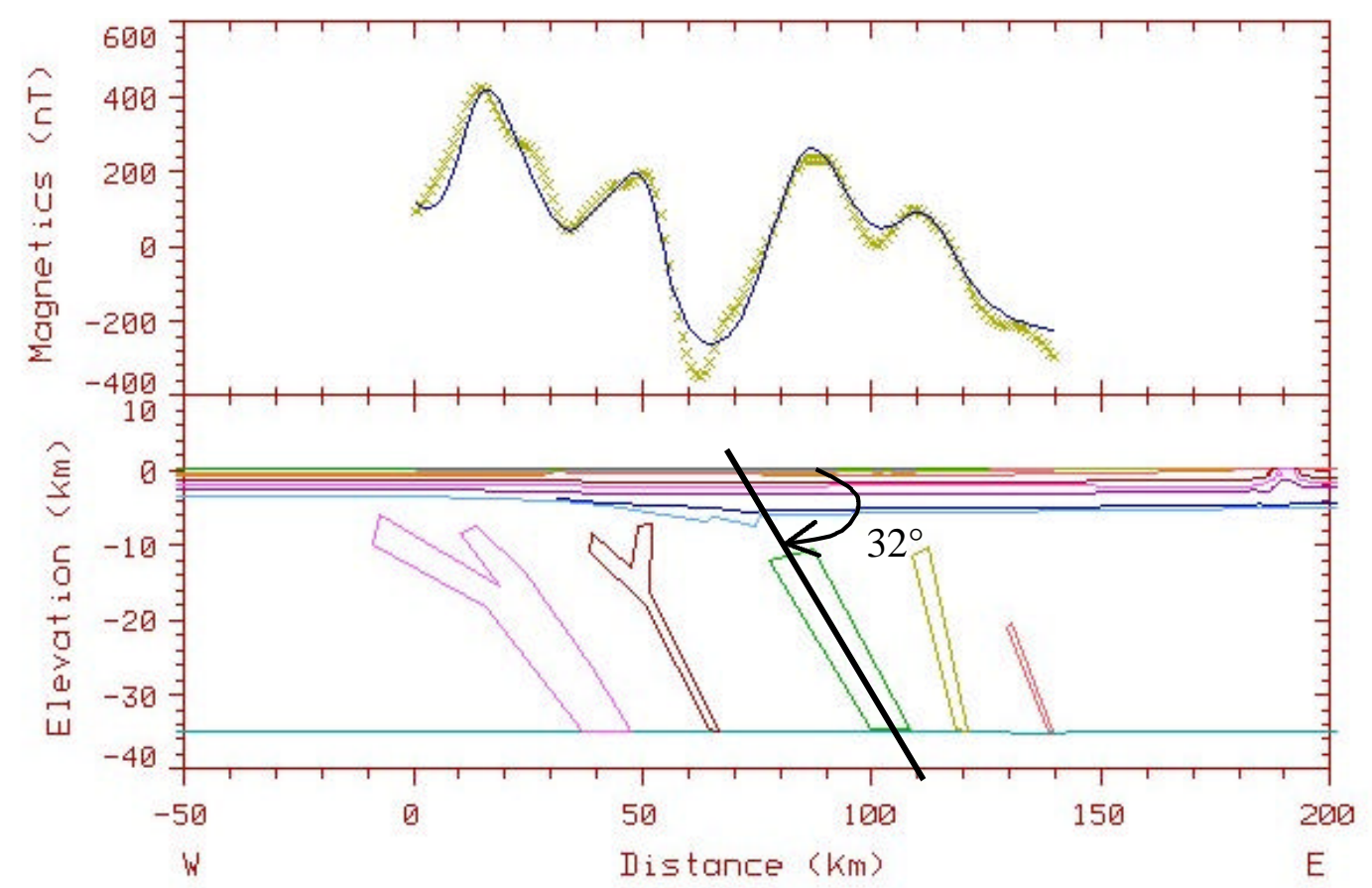

B

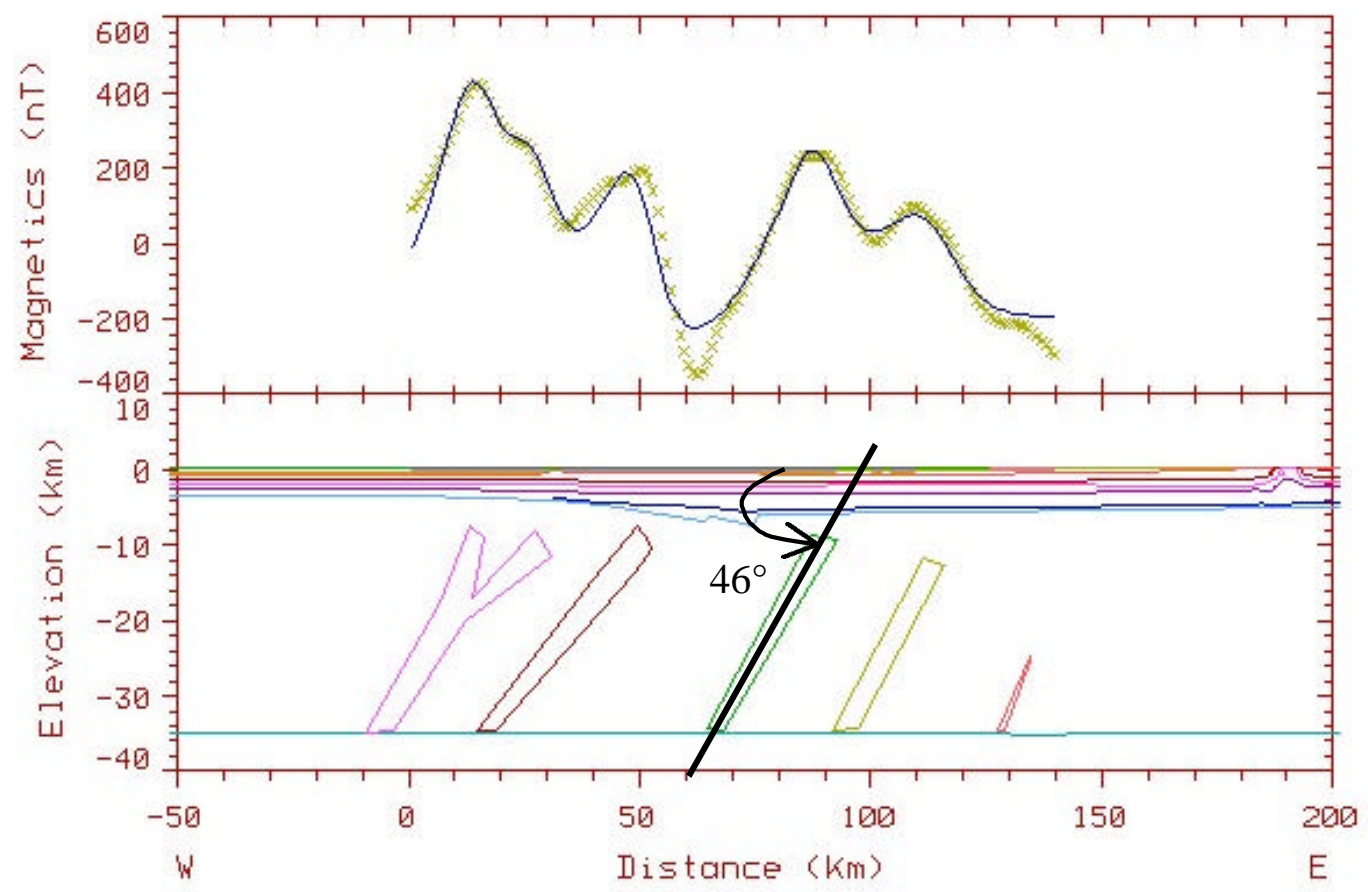

Figure 26: A) A minimum southeastern dip of $32^{\circ}$ was reached along profile 6 (southernmost requested transect from AGI). B) The northwestern minimum dip along profile 6 was $46^{\circ}$. These models are exaggerated $1.7 x$ vertically. 
established. Table 4 summarizes the minimum dips obtained through the magnetic modeling process.

Table 4: Minimum Dip Estimates for the NY-Al Source Body

\begin{tabular}{ccc}
\hline Profile & $\begin{array}{c}\text { Southeastern } \\
\text { Dip Minimum }\end{array}$ & $\begin{array}{c}\text { Northwestern } \\
\text { Dip Minimum }\end{array}$ \\
\hline 7 & $32^{\circ}$ & $27^{\circ}$ \\
1 & $35^{\circ}$ & $44^{\circ}$ \\
5 & $39^{\circ}$ & $73^{\circ}$ \\
6 & $32^{\circ}$ & $46^{\circ}$ \\
\hline
\end{tabular}

\subsection{Observations during the NY-Al modeling process}

While modeling the New York - Alabama lineament, steep to vertical dipping bodies (either to the SE or NW) appeared to fit the NY-Al anomaly along its entire length better than more gently dipping bodies. Overall, fitting shallow NW or SE dipping NYAl source body was quite difficult due to its close proximity to other source bodies. The NY-Al magnetic anomaly could in general be modeled with smaller error when vertical source bodies were used. Note, that as in the preceding chapter, all of the models presented in this chapter are vertically exaggerated $1.7 x$. 


\section{Chapter Four: Residual Aeromagnetic Anomalies and Characteristics of West Virginia}

The purpose of this chapter is to introduce the residual aeromagnetic data donated by Applied Geophysics Incorporated (AGI), and to document trends within the data. Possible geological origins of these residual anomalies will also be noted. The characteristics of the residual anomaly data are summarized in terms of Alignments of Residual Magnetic Anomaly Terminations (ARMATs) and Alignments of Residual Magnetic Anomaly Highs and Lows (ARMAHLs). The coincidence of ARMATs and ARMAHLs with various near surface structures in West Virginia is also evaluated.

\subsection{Description and criteria for finding ARMATs and ARMAHLs in the residual magnetic data}

The ARMATs and ARMAHLs within this thesis were chosen according to specific criteria (described below), such as overall length, and directional trend, etc. An example of interpreted ARMATs and ARMAHLs is shown on AGI's residual aeromagnetic map (Figure 27). Figures 28 and 29 show all of the ARMAHLs and ARMATs interpreted within the AGI data set.

\subsubsection{ARMAT Criteria}

- An Alignment of Residual Magnetic Terminations (ARMATs) has to occur over a minimum straight line distance of 20-kilometers.

- An ARMAT must terminate at least 2 magnetic anomalies.

- As a rule, ARMATs do not cross ARMAHLs. 


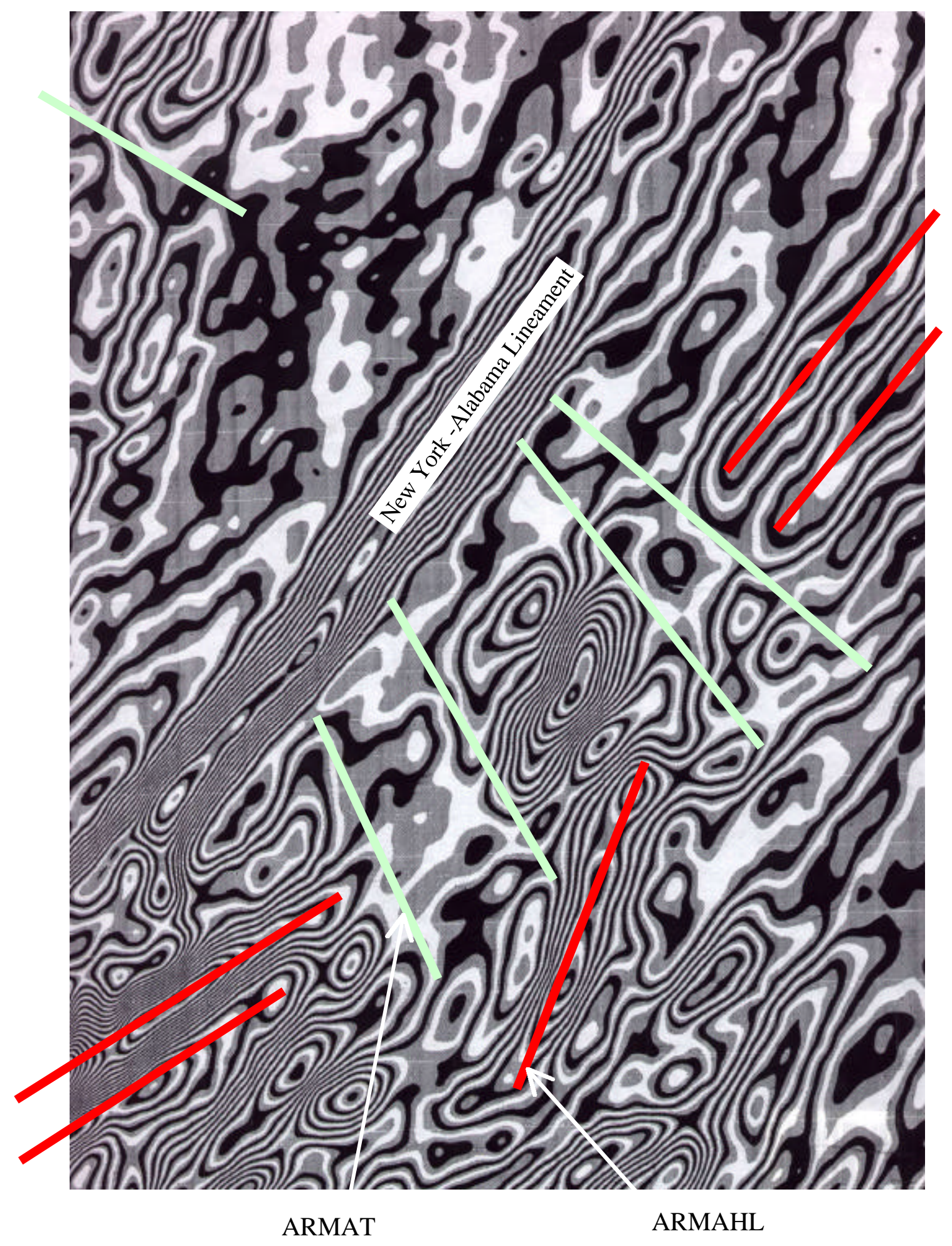

Figure 27: Applied Geophysics Inc. (AGI) NewMag® residual map (part of which is shown here) forms the basis for interpretation of possible basement patterns or structures on either side of the NY-Al. The light colored lines (green) mark magnetic anomaly truncations (ARMATs). The darker lines (red) represent anomaly highs and lows (ARMAHLs). 


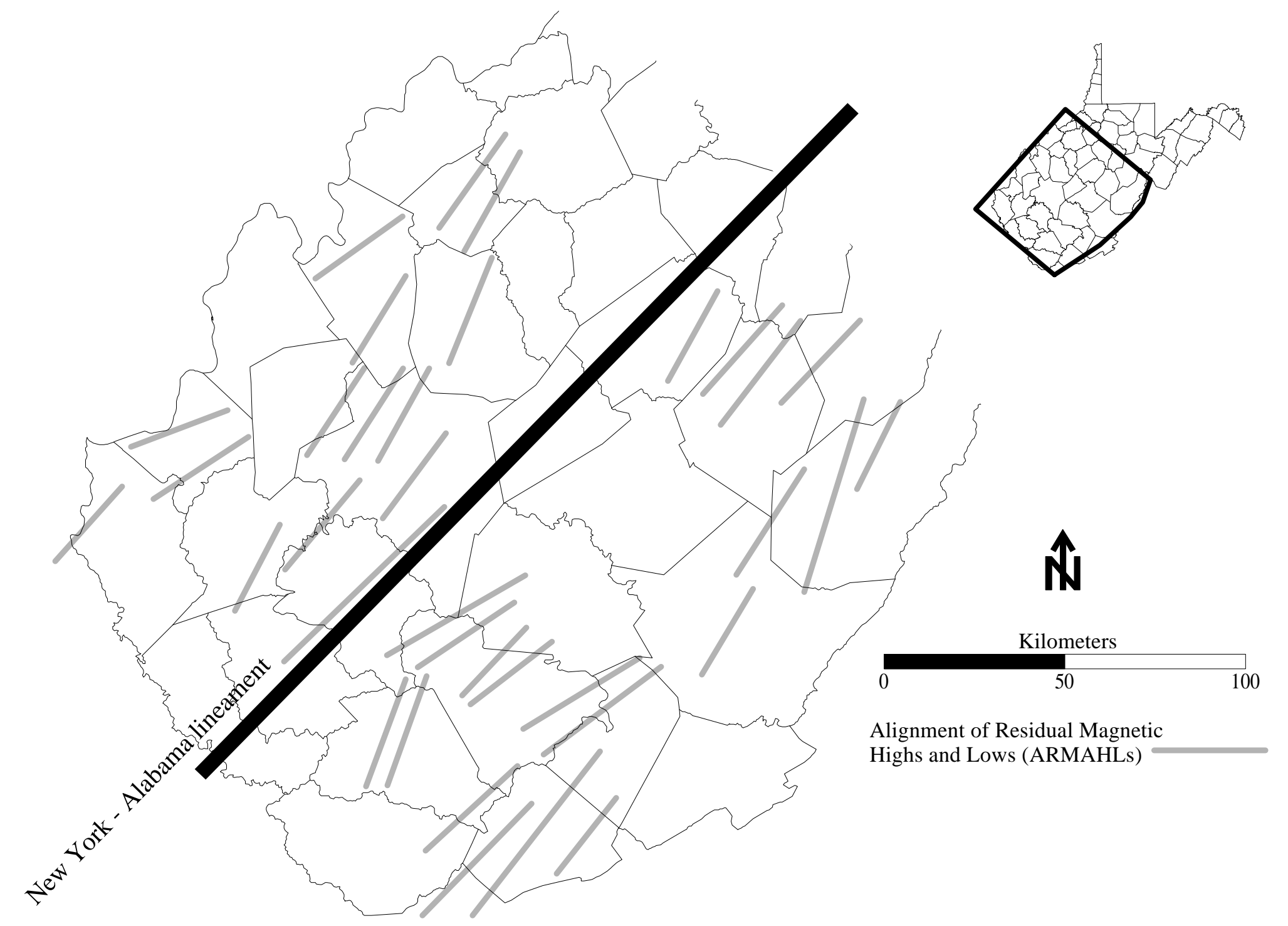

Figure 28: The distribution of ARMAHLs using the AGI data set, is shown within the study area. 


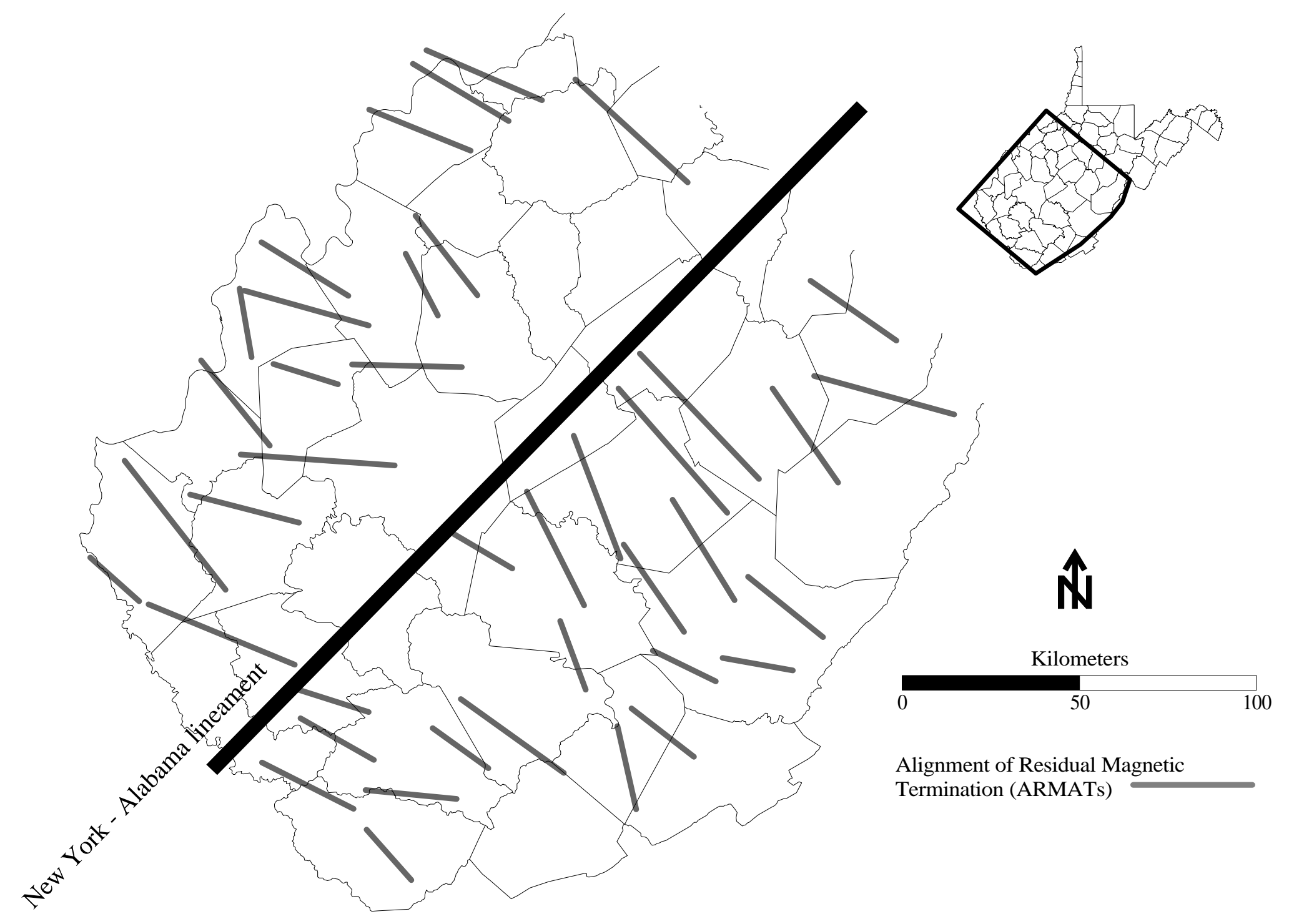

Figure 29: Location map of ARMATs using the AGI data set, found in the AGI residual aeromagnetic map of the study area. 


\subsubsection{ARMAHL Criteria}

- ARMAHLs were required to be at least 30-kilometer in straight line distance.

- An ARMAHL cannot cross an ARMAT.

- If there is a significant bend in the alignments forming an ARMAHL, it is divided into two separate ARMAHLs. These bends commonly occurred at "saddles" along magnetic highs or "ridges" between lows

\subsection{The trends in the residual magnetic within southern West Virginia}

The residual magnetic features of West Virginia are divided into five geographic regions based on the tendency to form clusters (Figure 30). Differences in residual magnetic anomaly length and trend are shown by region, but have been not statistically evaluated. A statistical assessment of the data goes beyond the scope of the proposed project.

The New York - Alabama lineament is such a pronounced feature in the residual anomaly map that it is defined as a separate region (Region I). It is characterized by a singular, long trending residual magnetic high through central West Virginia. Region II included most of West Virginia northwest of the NY-Al (Figure 30). Region III was separated from Region II because it stands out as a zone of low intensity anomalies in which cannot be differentiated into ARMATs or ARMAHLs. Region IV and Region V lie in the southern portion and eastern portions of West Virginia, respectively (and both are SE of the NY-Al). 


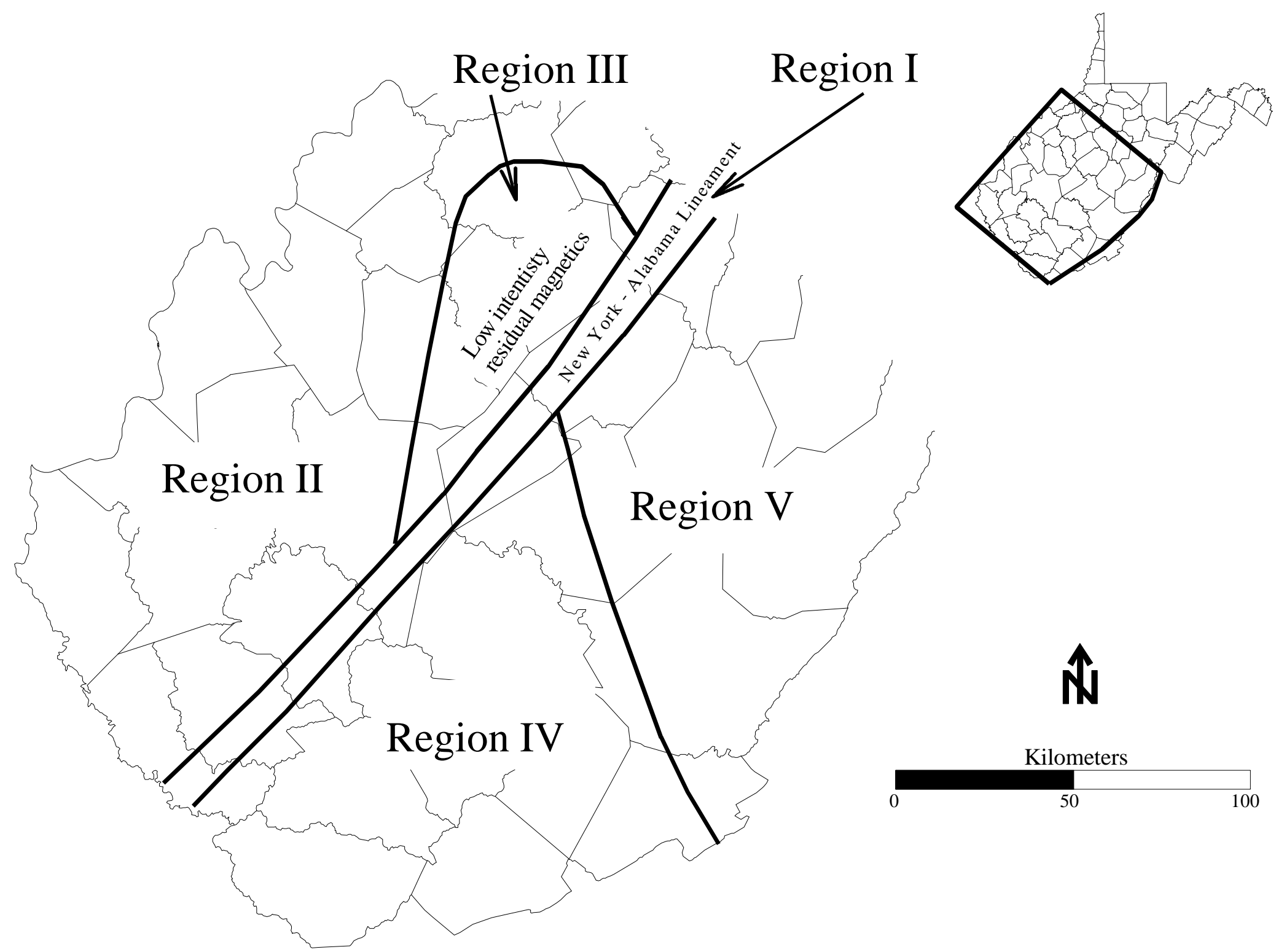

Figure 30: Magnetic regions I through V are the geographic locations where the ARMATs and ARMAHLs are examined for direction trends 


\subsubsection{ARMAHL directional trends in residual aeromagnetic data in West Virginia}

The trends of ARMATs and ARMAHLs in residual magnetic data were sumarized according to for each region in rose diagram form. Rose diagrams of the ARMAHLs (Figure 31) reveal predominately northeast trends ranging from $020^{\circ}$ to $056^{\circ}$.

The trend of ARMAHLs in Region II are slightly different from those across the NY-Al to the southeast (regions IV and V). The ARMAHL trends from Regions IV and $\mathrm{V}$ are combined into the larger rose diagram (Figure 31). The dominant trend in the combined Region IV and V plot is $045^{\circ}$. Secondary trends of $021^{\circ}, 035^{\circ}, 057^{\circ}$ are also present. In general, the differences in ARMAHL trends between regions appear to be insignificant. No statistical comparisons were made.

\subsubsection{ARMAT directional trends in residual aeromagnetic data in West Virginia}

The trends of ARMATs (alignment of residual magnetic anomaly terminations) were also summarized in rose diagram form (Figure 32). As in the case of the ARMAHLs, the trends in each region are shown, but no statistical evaluations were undertaken.

The main directional trend, shown in Figure 32, for the ARMATs within the northwestern region is $297^{\circ}$, with secondary trends of $285^{\circ}, 303^{\circ}, 320^{\circ}$. Across the NYAl, the combined ARMAT trends from the northeast and south are slightly different. Those lying northeast of the NY-Al trend between $283^{\circ}$ and $330^{\circ}$ with a main directional strike of $321^{\circ}$, and those southeast of the NY-Al trend between $280^{\circ}$ and $350^{\circ}$ with a main directional strike of $310^{\circ}$. 


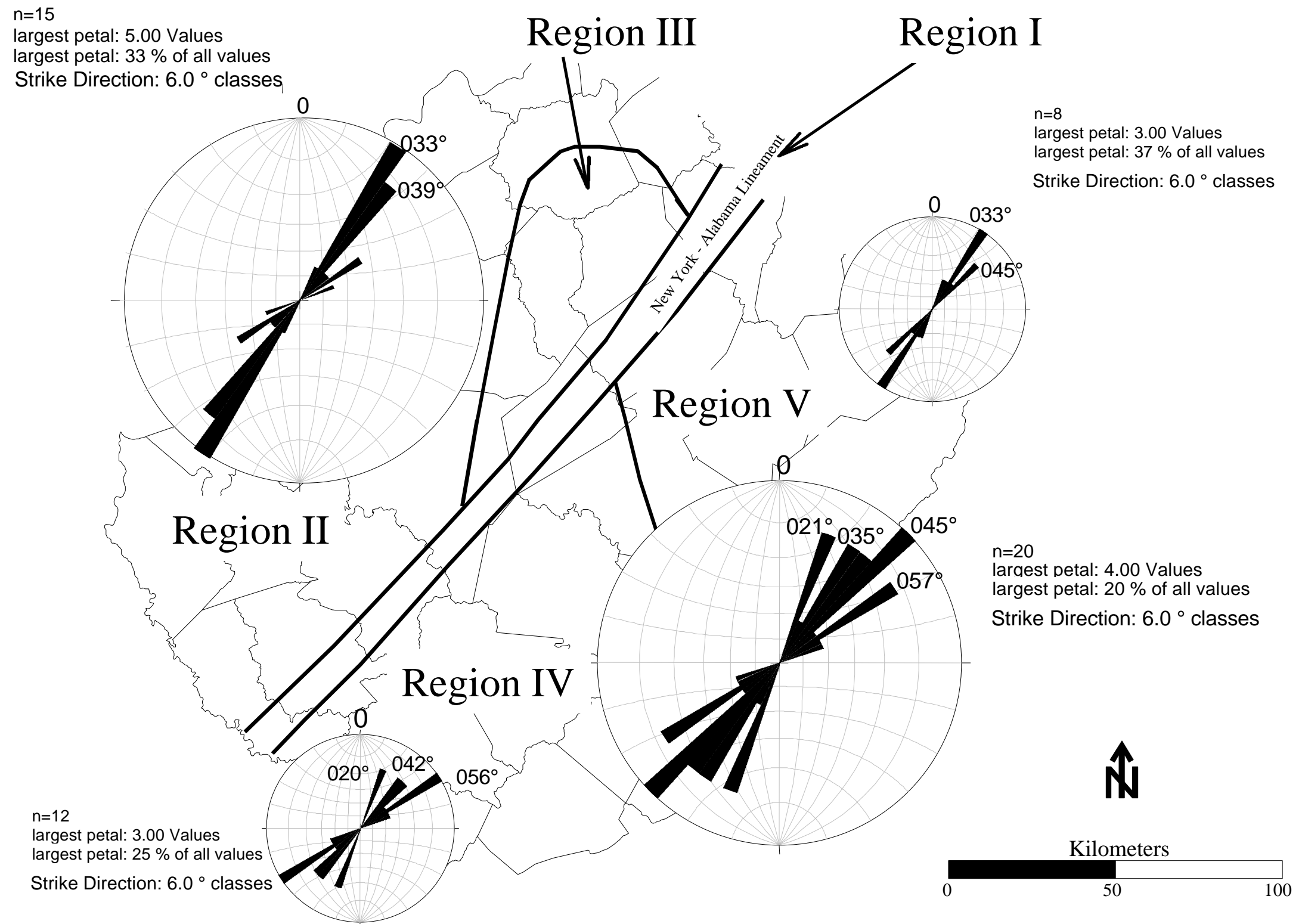

Figure 31: The directions of the ARMAHLs are summarized with rose diagrams according to magnetic regions 


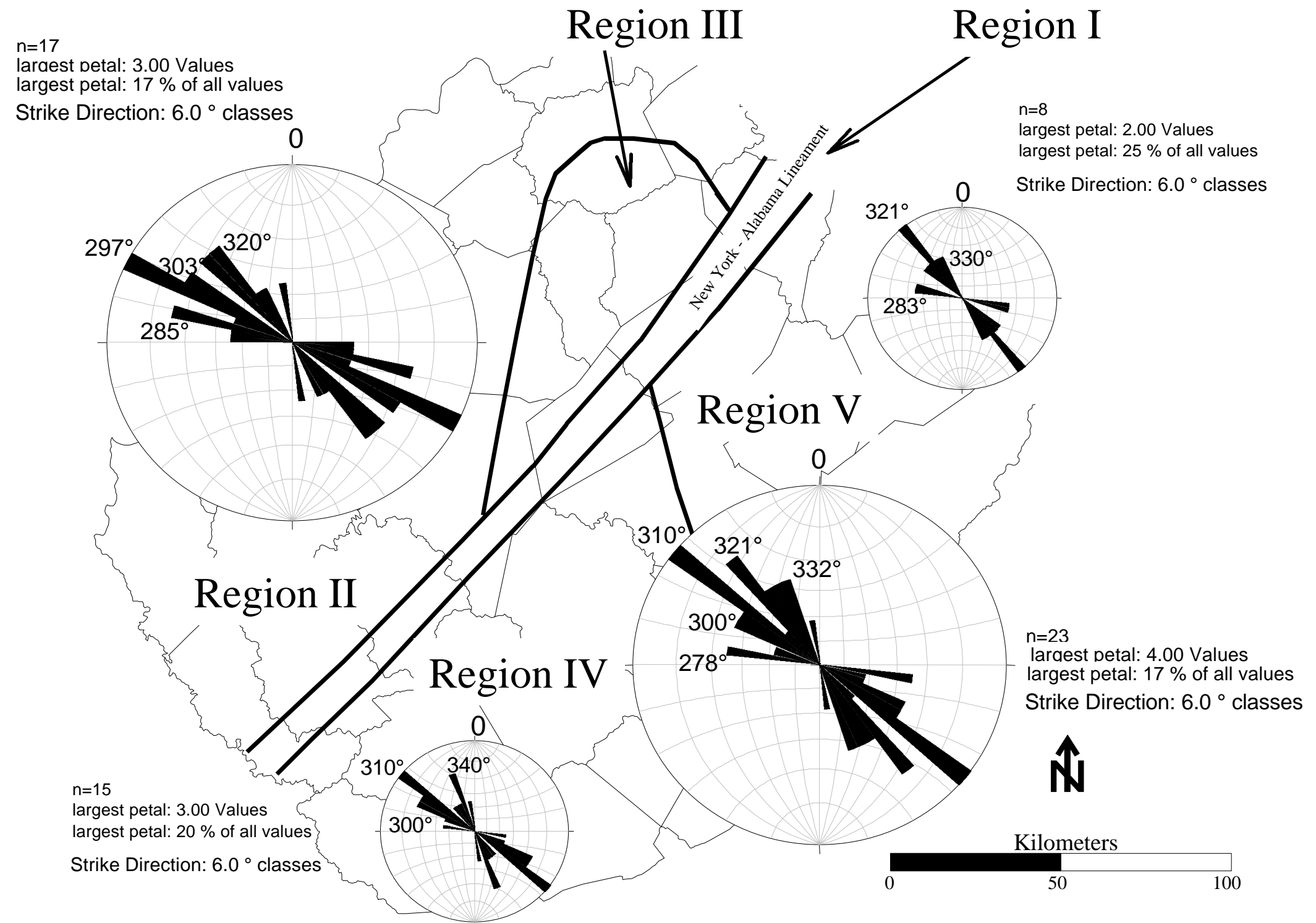

Figure 32: The directions of the ARMATs are summarized for each region in rose diagram form. 
4.2.3 Directional summary chart of ARMATs and ARMAHLs in southern West Virginia

Table 5: ARMAHL and ARMAT Directional Trends

\begin{tabular}{|c|c|c|c|c|}
\hline & $\begin{array}{c}\text { ARMAT } \\
\text { Main } \\
\text { Direction }\end{array}$ & $\begin{array}{c}\text { ARMAT } \\
\text { Secondary } \\
\text { Directions }\end{array}$ & $\begin{array}{l}\text { ARMAHL } \\
\text { Main } \\
\text { Directions }\end{array}$ & $\begin{array}{c}\text { ARMAHL } \\
\text { Secondary } \\
\text { Direction }\end{array}$ \\
\hline Region I & NA & NA & NA & NA \\
\hline Region II & $297^{\circ}$ & $\begin{array}{c}285^{\circ}, 303^{\circ}, \\
320^{\circ}\end{array}$ & $\mathbf{0 3 3}^{\circ}$ & $039^{\circ}$ \\
\hline Region III & NA & NA & NA & NA \\
\hline Region IV & $310^{\circ}$ & $300^{\circ}, 340^{\circ}$ & $056^{\circ}$ & $020^{\circ}, 042^{\circ}$ \\
\hline Region V & $321^{\circ}$ & $283^{\circ}, 330^{\circ}$ & $\mathbf{0 3 3}^{\circ}$ & $045^{\circ}$ \\
\hline $\begin{array}{l}\text { IV \& V } \\
\text { combined }\end{array}$ & $310^{\circ}$ & $\begin{array}{l}278^{\circ}, 300^{\circ}, \\
321^{\circ}, 332^{\circ}\end{array}$ & $045^{\circ}$ & $\begin{array}{c}021^{\circ}, 035^{\circ} \\
057^{\circ}\end{array}$ \\
\hline
\end{tabular}

\subsection{The Relationship of ARMATs and ARMAHLs to near surface structures}

The ARMAT and ARMAHL locations were superimposed upon maps of near surface structures on Figures 33 and 34. This comparison is undertaken to assess the possibility that the magnetic anomalies are associated with surface structural trends.

Presence of such association might suggest that the magnetic anomalies are associated with basement structures that may have been reactivated and influenced shallow sedimentary structural development. The direction and length trends of the ARMAHLs in West Virginia seem to be quite similar.

In addition, Yang (1998) has developed a basement sub-block map based stratigraphic anomalies. Features portrayed in Yang's map are also compared to the ARMAHLs and ARMATs from this study (figures 35 and 36). Sub-block 


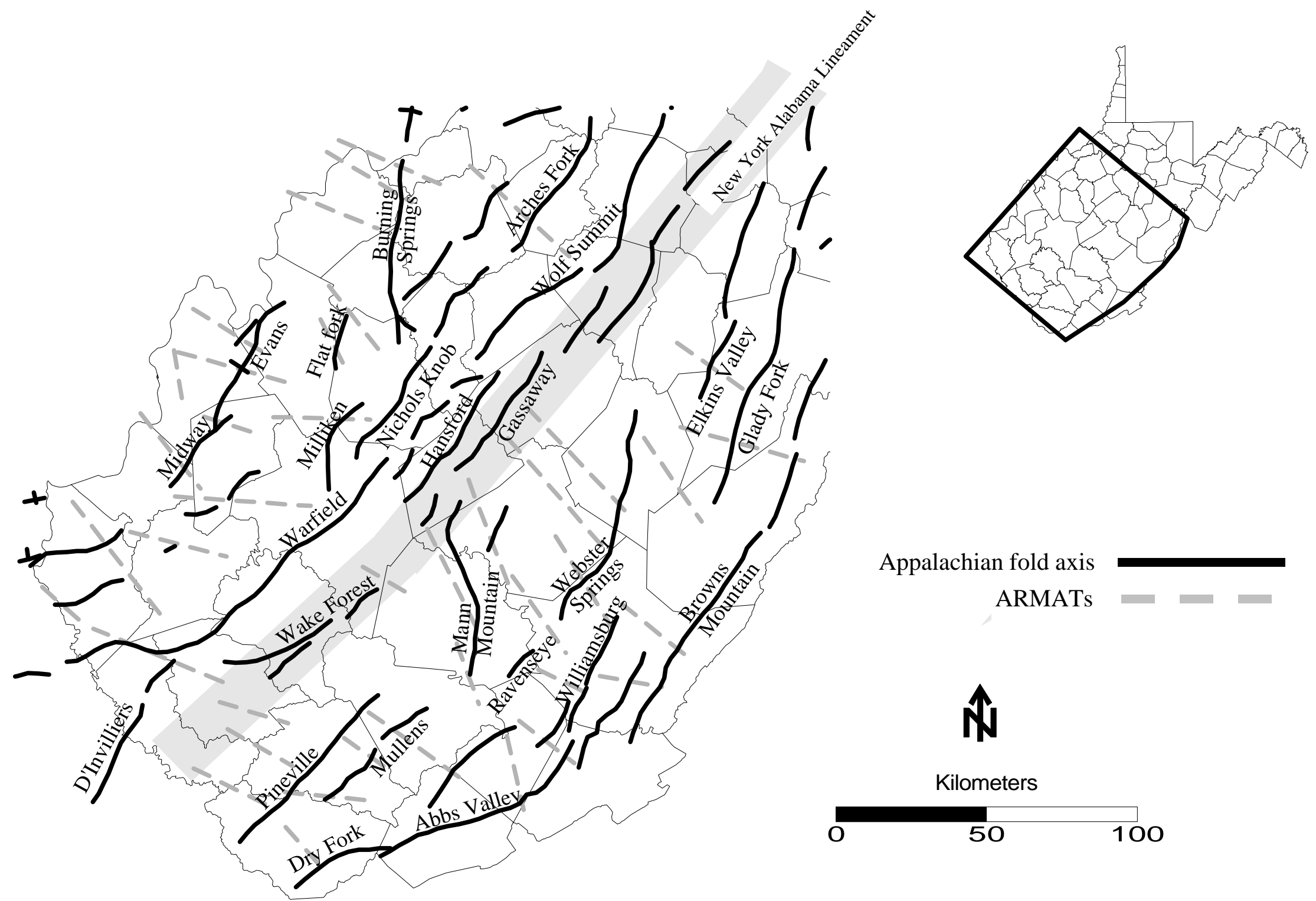

Figure 33: Major folds of the Appalachian foreland (Shumaker, 1996) are compared to the distribution of ARMATs in the study area. 


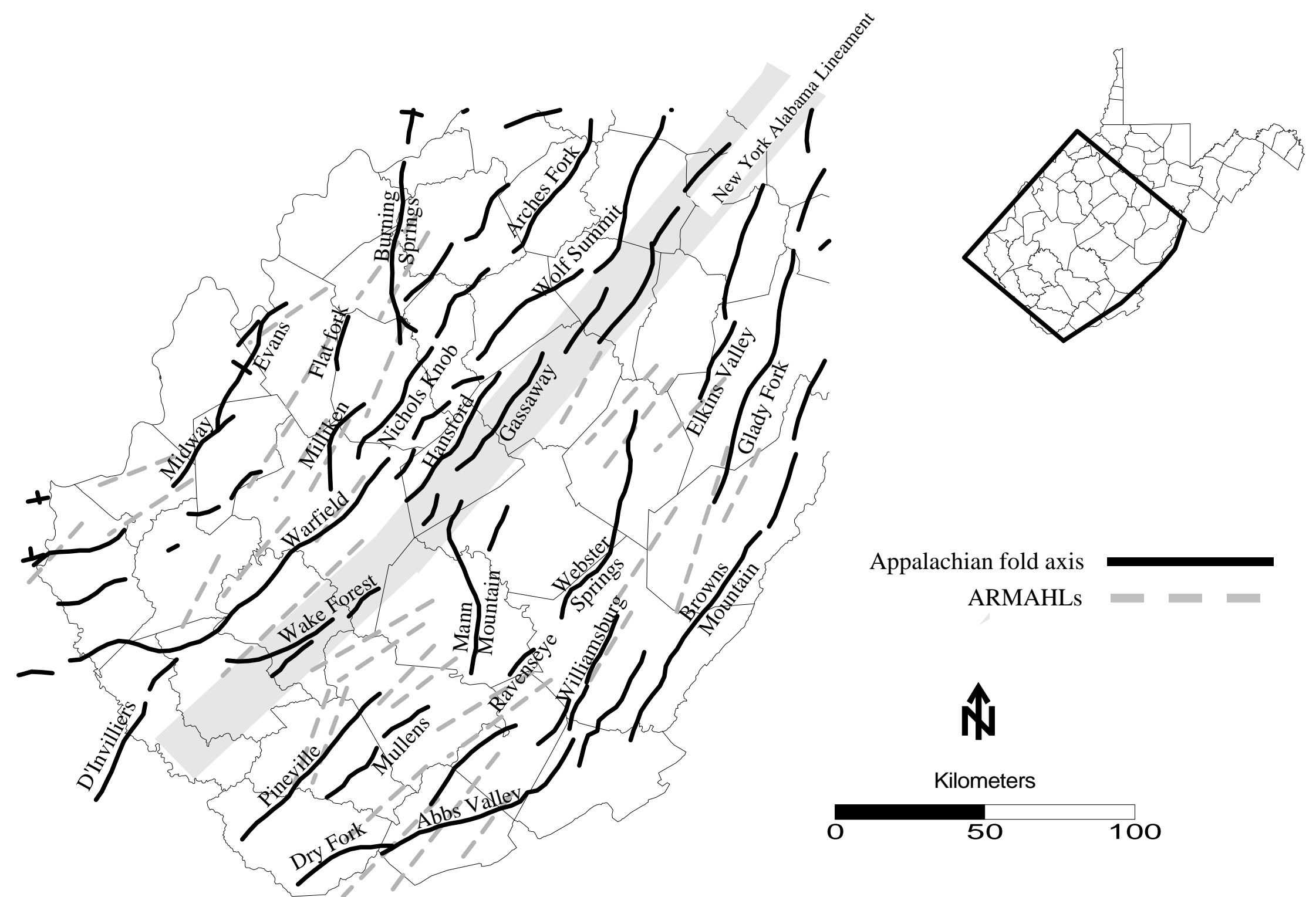

Figure 34: Major folds of the Appalachian foreland (Shumaker, 1996) are compared to the distribution of ARMAHLs in the study area 


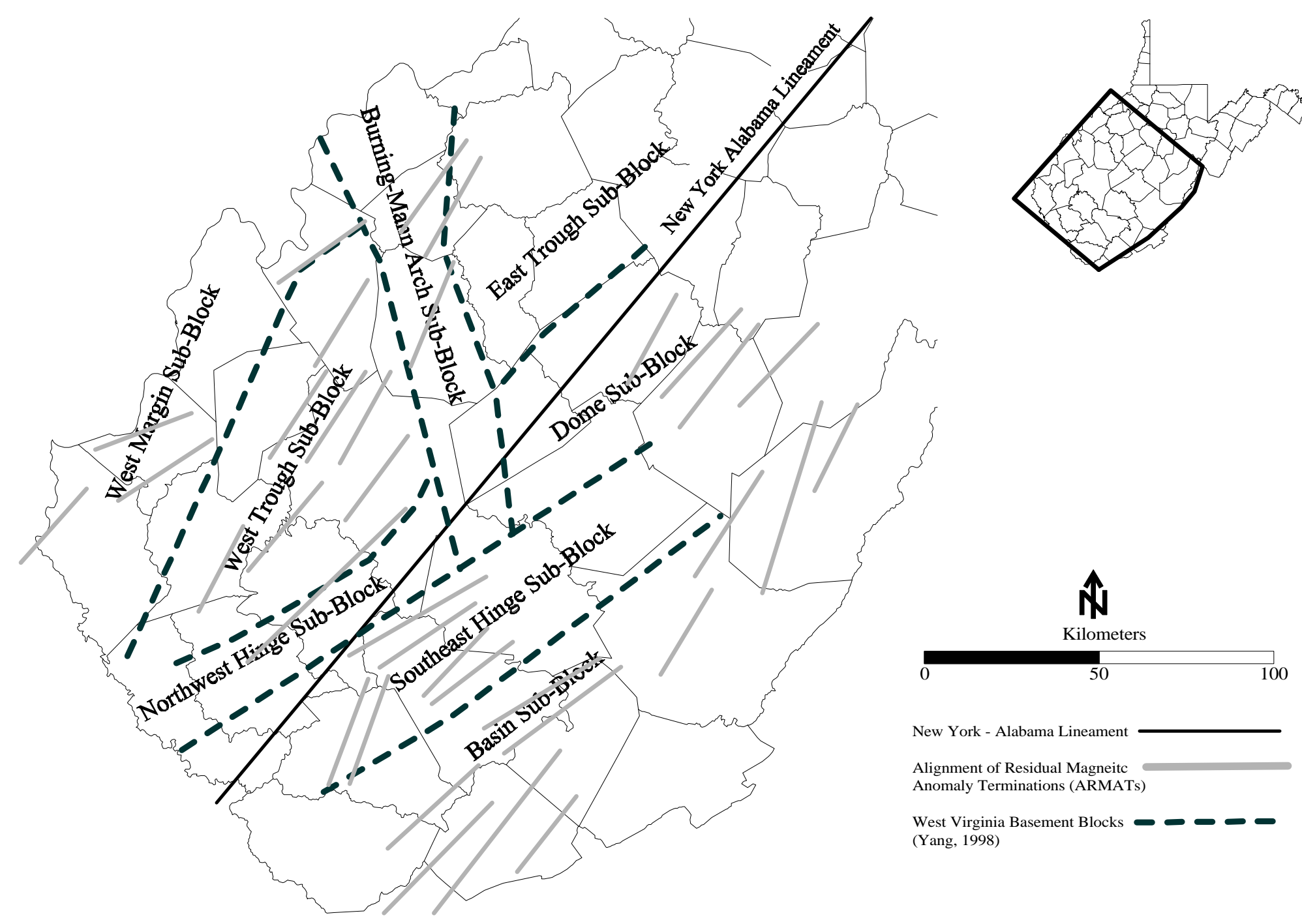

Figure 35: The basement of West Virginia was divided into smaller basement blocks called sub-blocks by Yang (1998) based on known and inferred basement structures and stratigraphic anomalies he observed. ARMATs along strike of the NY-Al are overlain the basement blocks. 


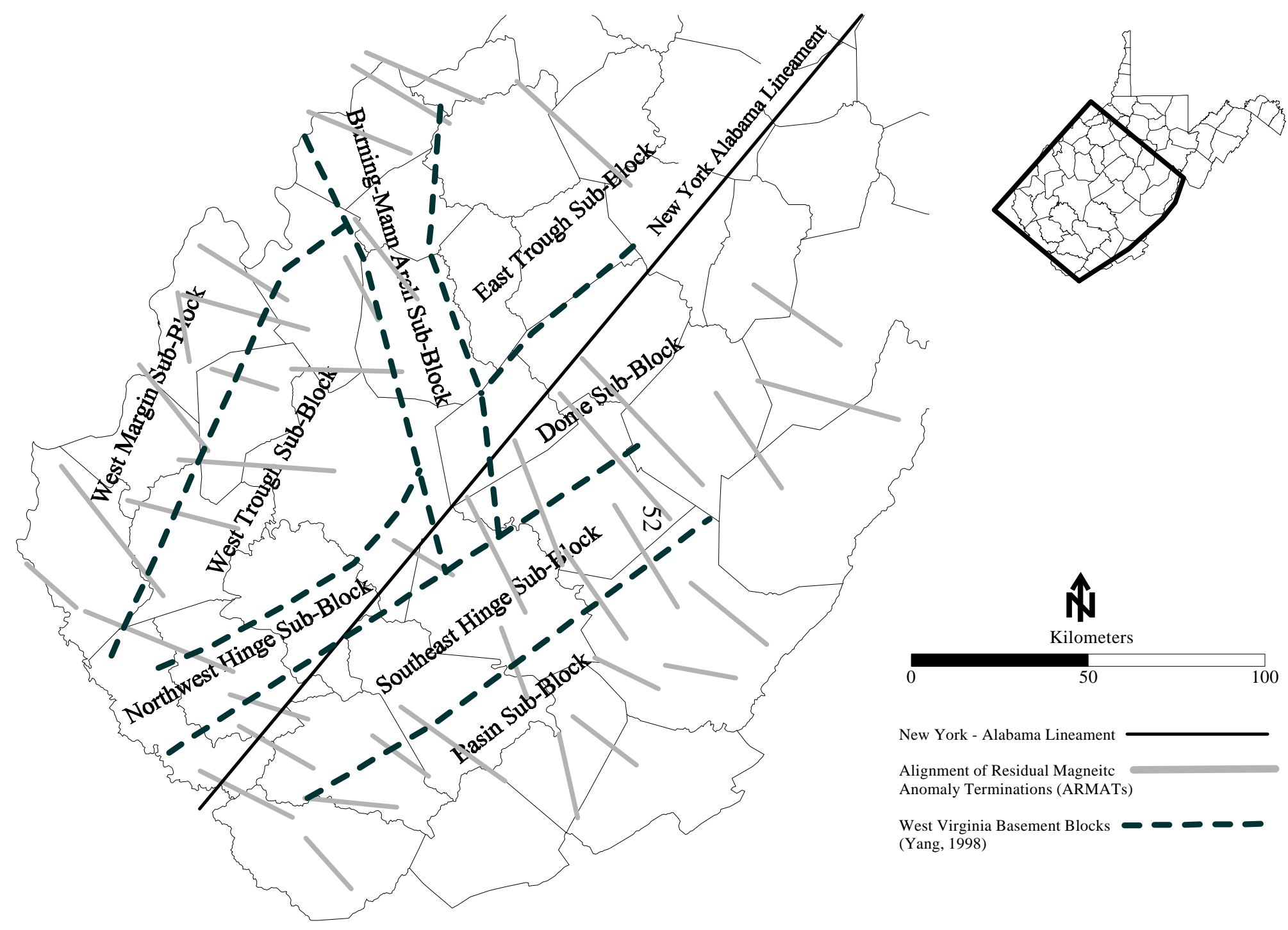

Figure 36: The basement of West Virginia was divided into smaller basement blocks called sub-blocks by Yang (1998) based on known and inferred basement structures and stratigraphic anomalies he observed. ARMAT directions can be compared to the basement orientations. 
orientations appear quite similar to the trends of the ARMAHLs shown Figure 35.

\subsection{ARMATs and ARMAHLs possible geological interpretations}

It is noteworthy, but not surprising that the ARMAHLs and the ARMATs have an orthogonal relationship to each other. In general, the ARMAHLs are aligned with the overall tectonic trend of both surface folds and basement faults in the region. While the ARMATs trend normal to regional strike. Many possible interpretations exist for the presence of these alignments of residual magnetic anomalies. Access to the residual aeromagnetic data contributed by AGI provides the first opportunity to make geological interpretations of this residual magnetic data.

\subsubsection{Possible geological interpretations of ARMATs}

Gay (personal communication) suggests that anomaly truncations (herein referred to as ARMATs) are associated with fault bounded grabens that interrupt regional structural trends. Figure 27 shows a pair of ARMATs directly southeast of the NY-Al, that Gay (personal communication) has interpreted to be normal basement faults. The ARMATs, according to Gay, are likely to be associated with faults in the basement that have the potential to be reactivated and cause the formation of shallow sedimentary structures. Smaller scale singular ARMATs (without a zone of low magnetic intensity between two terminations) may be associated with smaller scale deformation zones.

Another possible geological interpretation that will be explored in the next chapter is shown in Figure 37. In this framework, the basement topography surface is assumed to be flat, but is disrupted by deformation zones where intense faulting has created rubble zones, and disrupted the magnetic properties in the zone, giving it overall, 


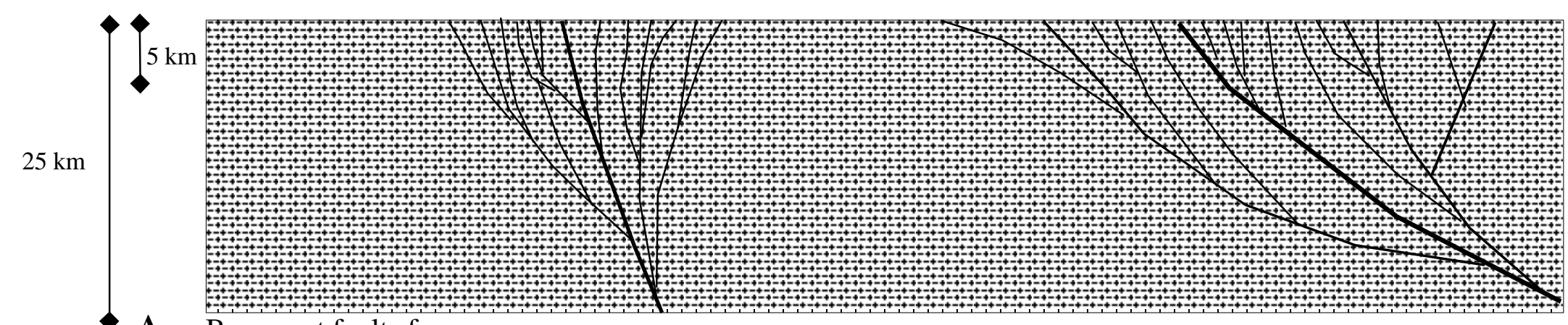

A. Basement faults form

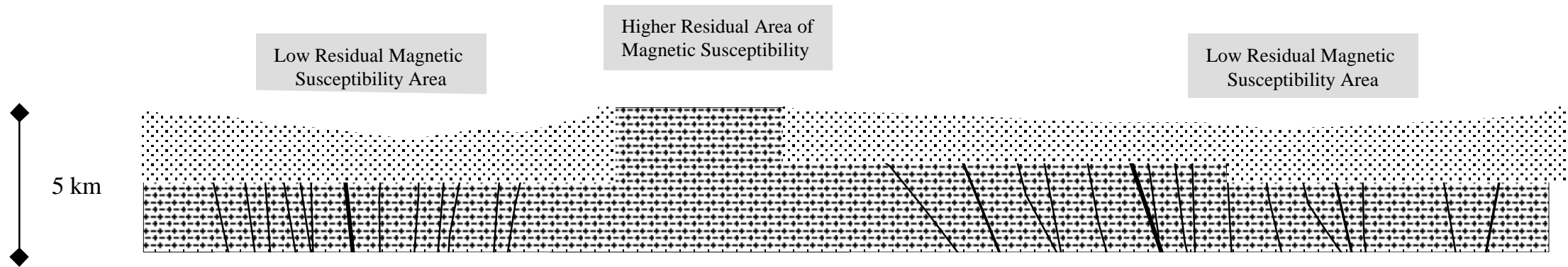

B. Basement deformation zone form at the fault tips

Figure 37: A) and B) show the formation of areas of low and high residual magnetic susceptibility on the basement surface as the result of basement faulting and weathering and erosion of the basement. These faults might be associated with extensive transform or normal fault zones in nature In B) the upper $5 \mathrm{~km}$ of the basement is shown. Intensely faulted areas may have been preferentially eroded as depicted in B) producing extensive low susceptibility zones across the basement surface. 
a lower susceptibility. It is also possible that the basement may have a slight amount of erosional topography imposed on it, if the fault zones were partially weathered and eroded prior to deposition of overlying sediments. These deformed zones, which may have an erosional topography, are tectonically significant in that these deformation zone could be antithetic shear zones to the theorized NY-Al transform fault system.

Another possible model for these ARMATs (and ARMAHLs) is an intruded basement situation. Basaltic or gabbro magma may have intruded along NY-Al and other faults of the NY-Al transform system. In this situation, the ARMAHLs may be basalt or gabbro intrusions themselves (shown as cylindrical bodies in Chapter 5, but not to scale), while the ARMATS would symbolize the termination or flanks of those intrusions.

\subsubsection{Possible geological interpretations of ARMAHLs}

ARMAHLs (alignments of residual magnetic highs or lows), in the residual magnetics through West Virginia, could arise through different geological processes. These alignments or zones can be interpreted to arise entirely from intruded fault zones as discussed in the above paragraph. High and low susceptibility lithologies could be arranged in such a way as to produce the features observed in the AGI data. 


\section{Chapter Five: Residual Magnetic Model Studies of the Appalachian Plateau, Rome Trough and Valley and Ridge Regions of West Virginia}

The purpose of this chapter is to discuss model studies of the residual magnetic data set provided for this study by AGI. Anomalous features in the residual magnetic data will be modeled over the Rome trough in central West Virginia, and areas to the east of the Rome trough within the Appalachian Plateau near the Valley and Ridge region (Nicholas and Fayette counties, see Figure 2).

\subsection{Magnetic Models near the Valley and Ridge Province of West Virginia}

Figure 38 shows four ARMATs (Alignment of Residual Magnetic Anomaly Terminations) that extend southeast of the NY-Al (New York - Alabama lineament) in central West Virginia defined by line segments AA' through DD'. Profiles 8 and 9 (Figure 38 and 39) are used to model the residual magnetics of the shallow basement across these four ARMATs. For orientation purposes, magnetic low zones $\mathrm{Y}$ and $\mathrm{Z}$ between the ARMATs (Figure 38), can also be seen in the magnetic profiles 8 and 9 featured on Figures 40 and 41. Also an additional low area, magnetic low X, on Figure 38 can be seen along profile 8 . These low intensity magnetic zones bounded by the ARMATs will be modeled to follow various geological scenarios, such as a deformation zone for example.

The models shown in figures 40 and 41 characterize the four ARMATs (Figure 36) that trend across regional strike just southeast of the NY-Al. These cross strike features extend from the NY-Al southeast through the Appalachian plateau toward the 


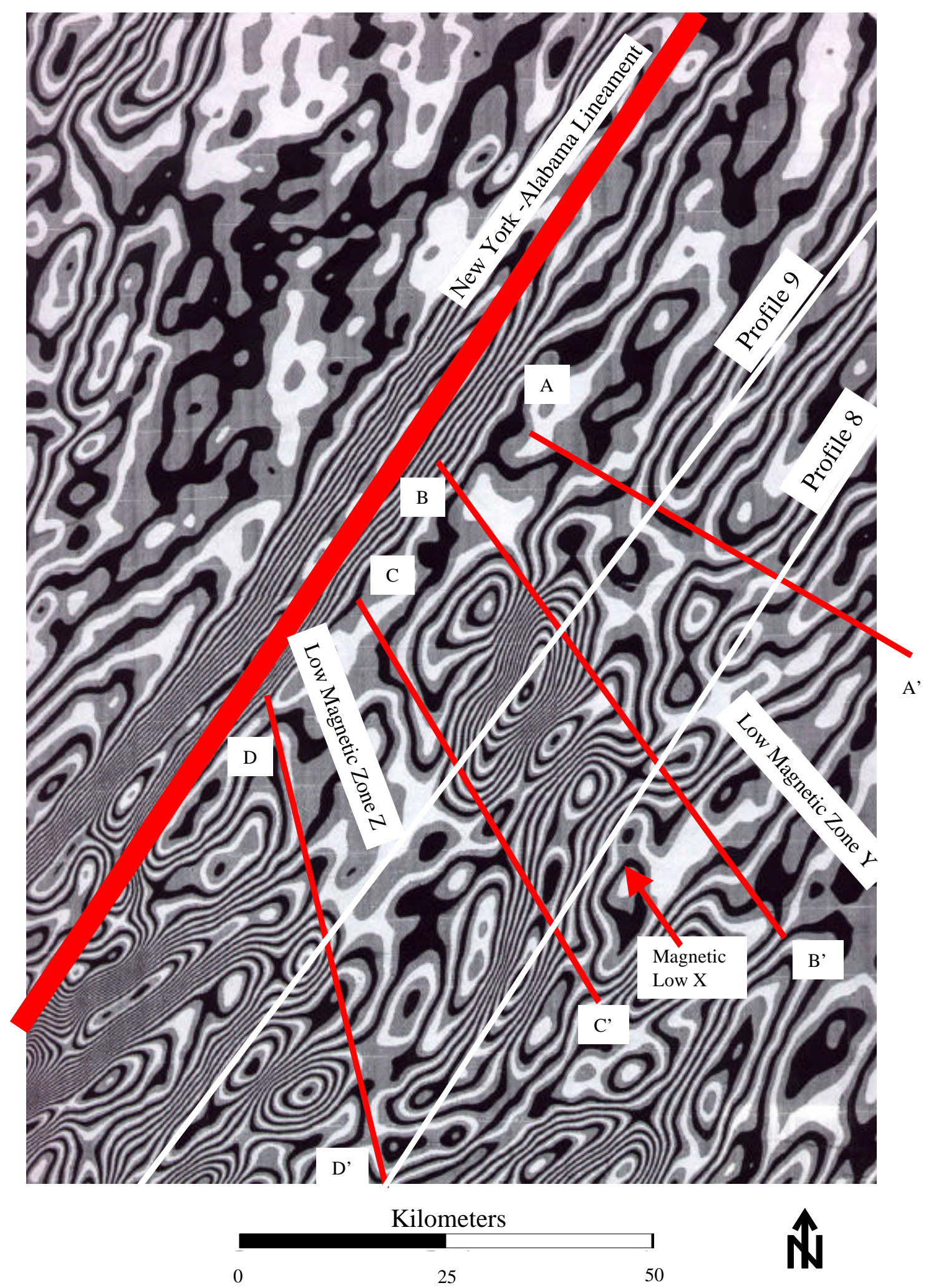

Figure 38: The Applied Geophysics Inc. (AGI) NewMag ${ }^{\circledR}$ residual map forms the basis for interpretation of possible basement patterns or structures on either side of the NY-Al. ARMATs (aeromagnetic residual magnetic anomaly terminations) are shown by line segments A through D. Magnetic profiles 8 and 9 supplied by AGI are shown by the white lines that trend parallel to the NY-Al. 


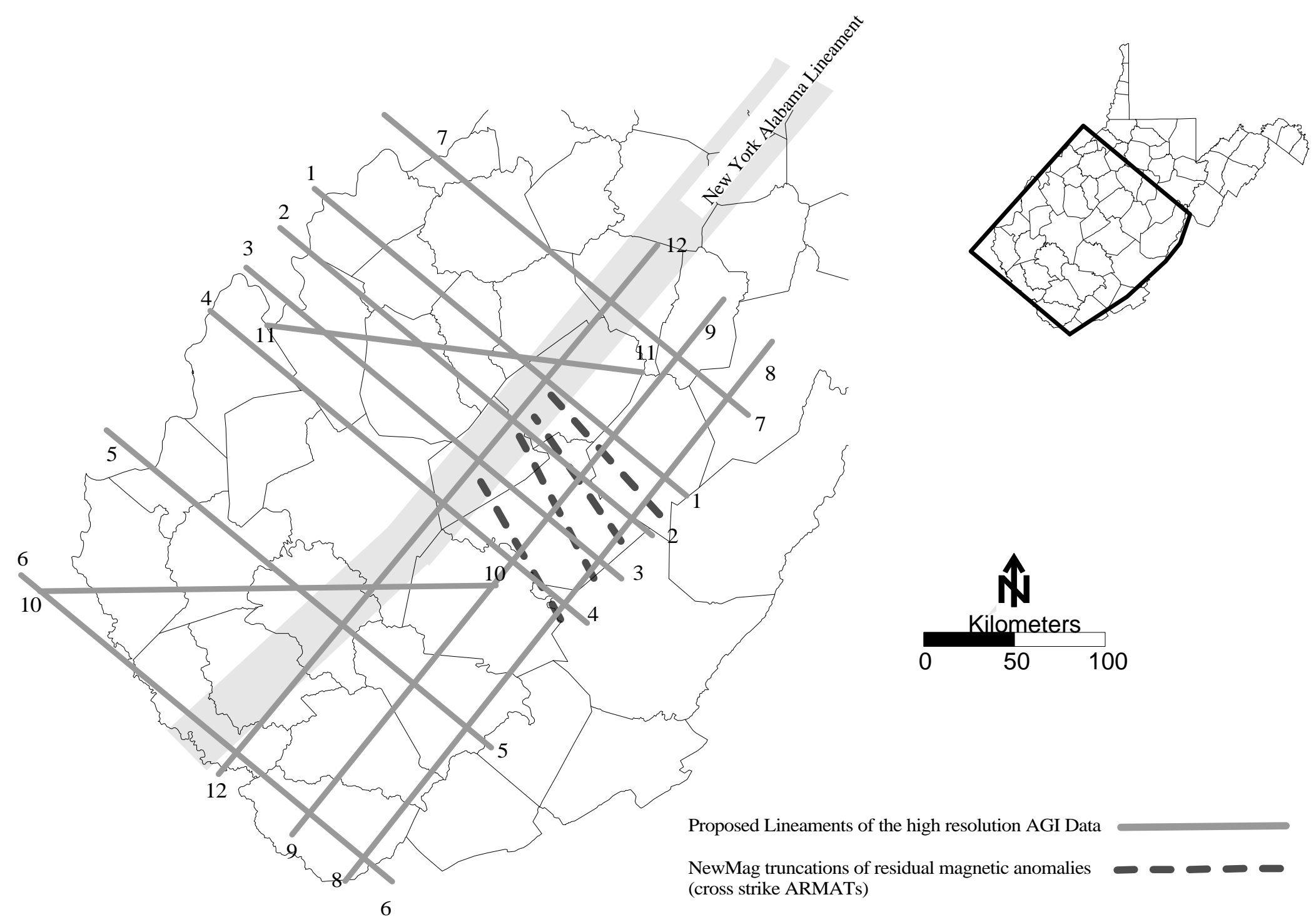

Figure 39: The location of transects provided by AGI are shown in solid lines. The dashed lines show the location of ARMATs modeled in Chapter 5. 

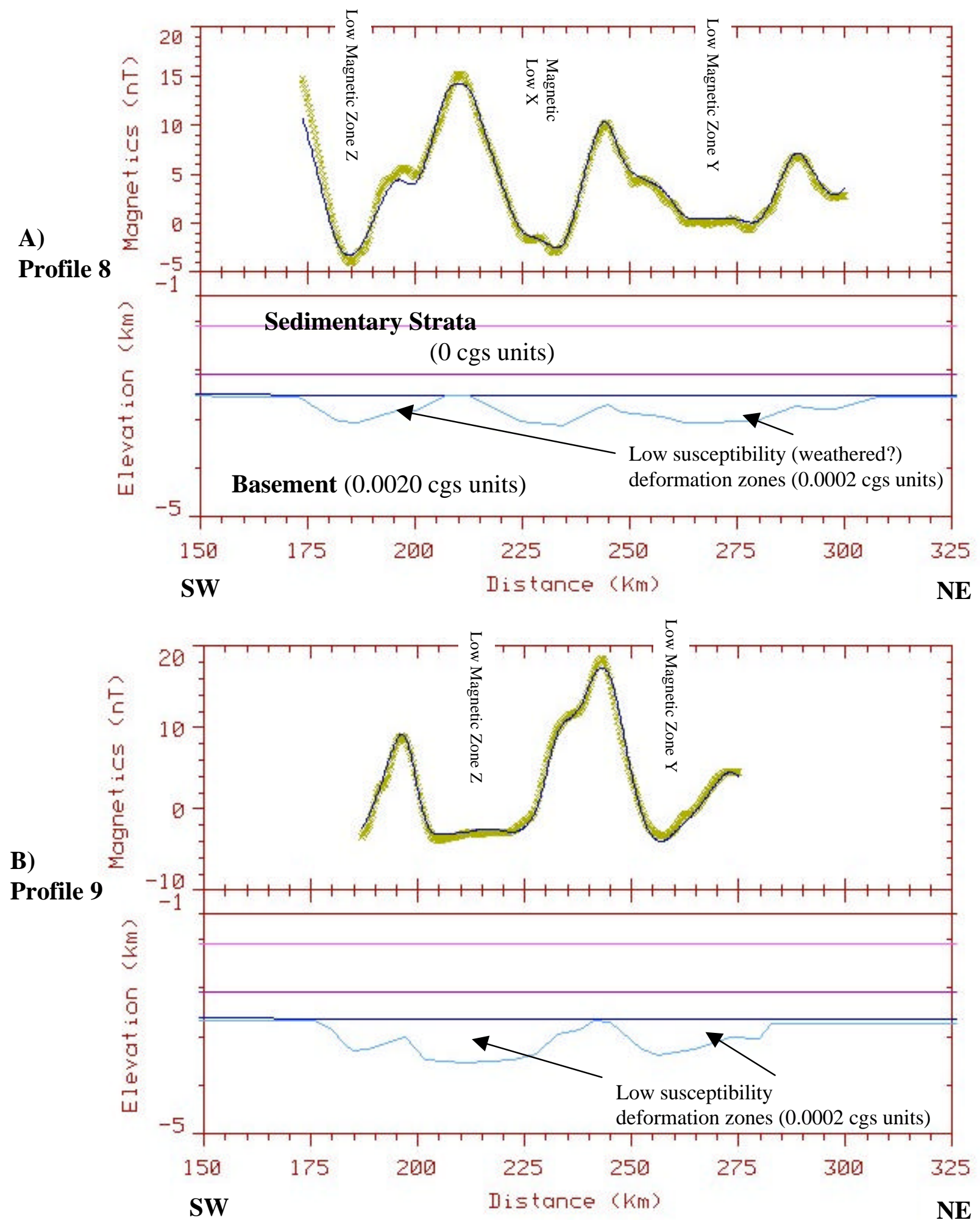

Figure 40: A) the residual anomalies along profile 8 are modeled as a relatively low susceptibility zone of variable thickness overlaying a deeper basement with a lightly higher susceptibility B) Results obtained along profile 9 incorporate the same susceptibilities. Both (A) and (B) models are exaggerated 10x vertically. Alternatively, these models can also be interpreted as a simple basement topography in filled with low susceptibility sediments. 

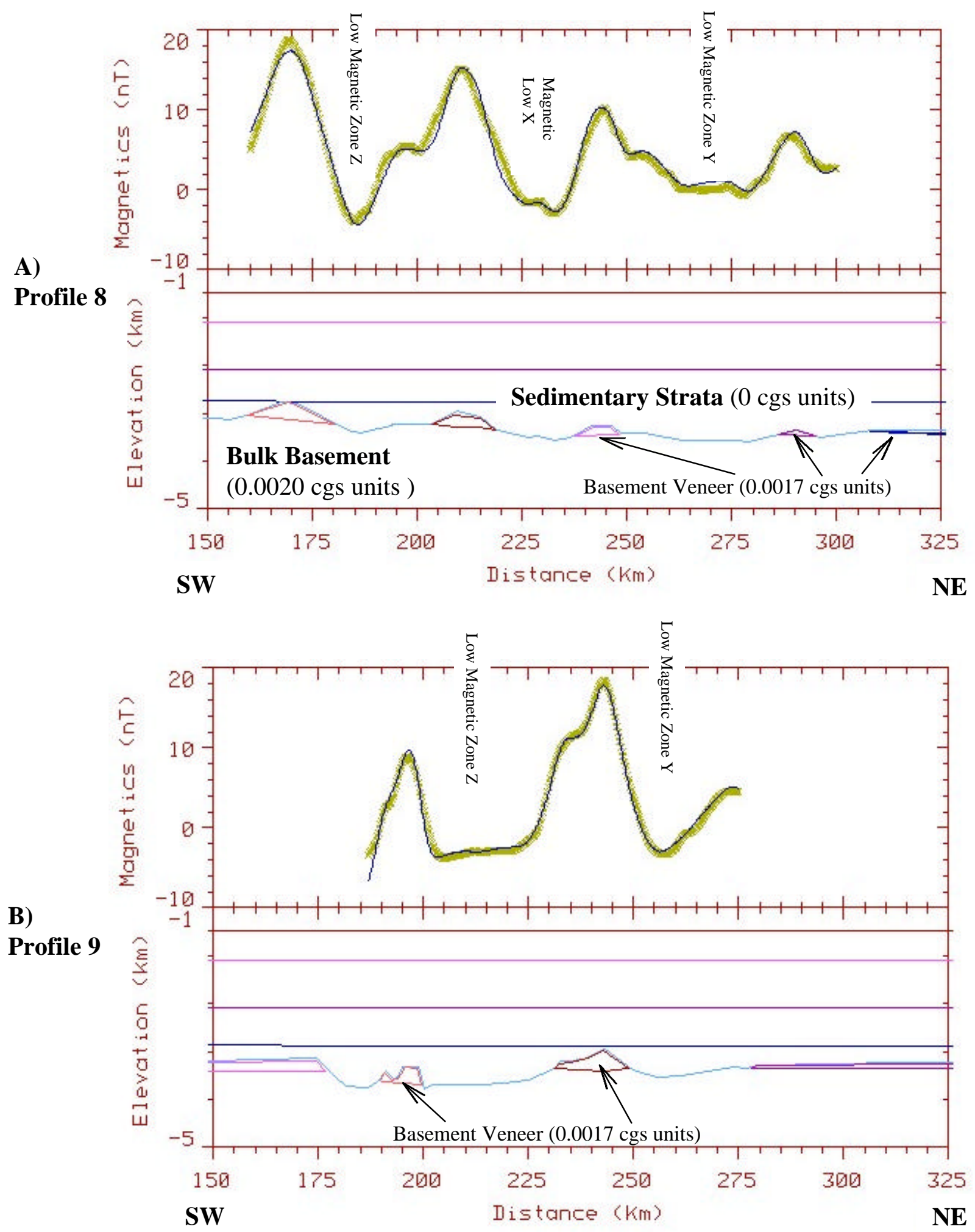

Figure 41 A) Profile 8 uses a combination of basement topography eroded into the low susceptibility veneer and deeper basement. B) Results obtained along Profile 9. Both (A) and (B) models are exaggerated 10x vertically. 
Valley and Ridge province. All models in this chapter have a basement susceptibility of 0.0020 cgs units.

Figure 40 models these basement zones as deep valley-like features associated with as weathered deformation zones o shown schematically on Figure 37 or a basement topography filled with low susceptibility sediments. In profile 8, Figure 40A and B, the bottom of the sedimentary cover is located 2.5 kilometers deep, and has no magnetic susceptibility. The basement adjacent these deformation zones has been given a constant magnetic susceptibility of $0.0020 \mathrm{cgs}$ units, this susceptibility is within the range of susceptibilities documented by King et al. (1998). This range also lies within the range of susceptibilities reported for both a granite and gneiss lithologies suggested by Telford et al (1976) and Boyd (1996). The basement deformation zones were given a susceptibility of $0.0002 \mathrm{cgs}$ units. Even though these zones are believed to have lost the overall magnetic intensity of the basement, they are assumed to have some net remnant magnetism.

Figure 40 A shows that three low intensity residual magnetic troughs are present along profile 8 . The two peaks shown in the middle of the Profile 8 merge toward the northwest to form one central residual peak on profile 9 (Figure 40 B). The minimum width of these model derived deformation zones is nearly 25 kilometers. The models also yield an approximate thickness of 1.5 to 2 kilometers as measured from an adjacent basement topographic high to low.

The models in Figure 41 A and B present a geological model interpretation where only a weathered basement causes the residual magnetic anomalies. Models shown in Figure $41 \mathrm{~A}$ and $\mathrm{B}$ also include a basement veneer preserved on the undeformed 
topography high areas of the basement. Basement susceptibility has been maintained at $0.0020 \mathrm{cgs}$ units. However, the thin veneer which is preserved on topographically high areas has a slightly lower magnetic susceptibility of $0.0017 \mathrm{cgs}$ units. This susceptibility is also consistent with the range of susceptibilities reported by King et al (1998). The valley lows in these models lie nearly 1 kilometer beneath the highs and have as much as 25 kilometers in lateral extent.

Figure $42 \mathrm{~A}$ and $\mathrm{B}$ are an attempt to simulate variability in the residual magnetic field by introducing an interval of varying magnetic susceptibility along profiles 8 and 9 , respectively. The models in Figure 42 produce a good fit with slight variations in basement lithology. These models suggest that the residual anomalies can be produced by a combination of effects including changes of lithology (symbolized with different susceptibilities) beneath the basement veneer combined with changes in the thickness of the veneer. Basement topography is also introduced into these models to improve the fit of the short wavelength anomalies present in the residual magnetic profiles 8 and 9. The large wavelength and amplitude anomalies are largely accounted by variation in basement lithology. The average susceptibility of the basement is maintained at 0.0020 cgs units, however, the roughly cylindrical bodies introduced into the basement have a different lithology that is represented by slight variations in their magnetic susceptibility (Figure 42). It should be noted, that the slightly more magnetic bodies are actually rectilinear sheets. Because of vertical exaggeration, the bodies appear to be roughly cylindrical in Figure 42, but they are actually rectilinear intrusive sheets. 


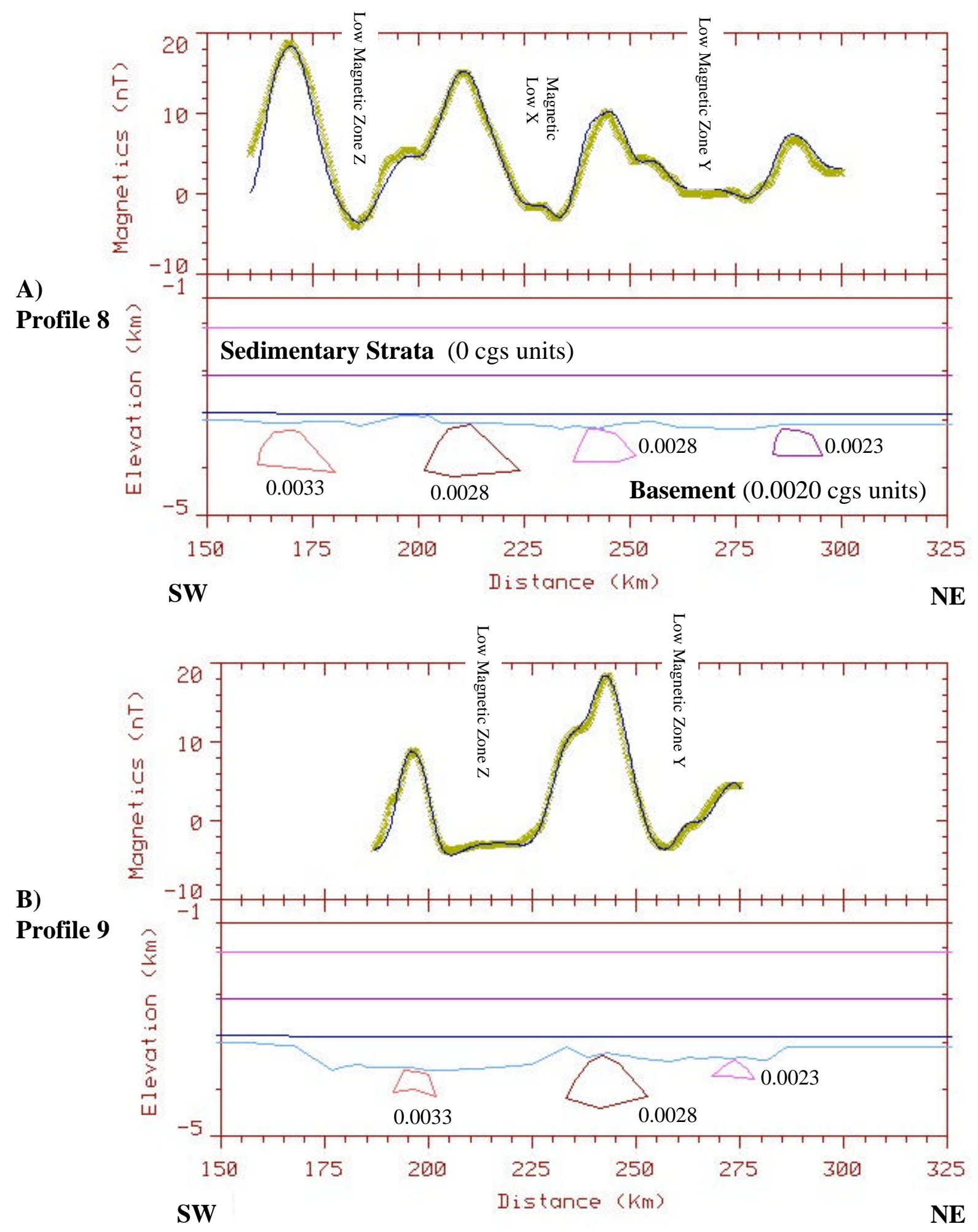

Figure 42: A) Variations in the residual magnetic field along Profile 8 are modeled using isolated rough cylindrical objects (actually flat sheets when restored to scale) of relatively high susceptibility. B) This approach is also used to simulate the variations in residual magnetic field observed along profile 9. Both (A) and (B) models are exaggerated 10x vertically. 


\subsection{Magnetic Models of the Appalachian Plateau Rome trough region in Central West Virginia}

Magnetic models over the Rome trough area in central West Virginia utilized profile lines 1, 2, and 3 (see Figure 39) along with profiles 10 and 11. In this area the east margin of the trough lies just northwest of the NY-Al. Profiles 1, 2 and 3 are orientated perpendicular to the NY-Al, whereas profiles 10 and 11 are orientated at an angle to the NY-Al.

\subsubsection{Incompatibility of Deformation Zone Models of the Rome trough}

Figure 43 shows a representation of the basement structure generalized from Morgan (1996). Variations in the AGI residual magnetic intensity are plotted along profile 1 on Figure 43. The basement (Figure 43) was assigned a constant magnetic susceptibility of $0.0020 \mathrm{cgs}$ units as in previous models. In this model (Figure 43), the possibility that the variations in the residual magnetic field can be attributed solely to structurally controlled relief across a magnetically homogeneous basement surface is tested. As can be seen on Figure 43, the calculated residual magnetic field variations across the trough alone do not produce the features observed in the residual magnetic field along the profile. 


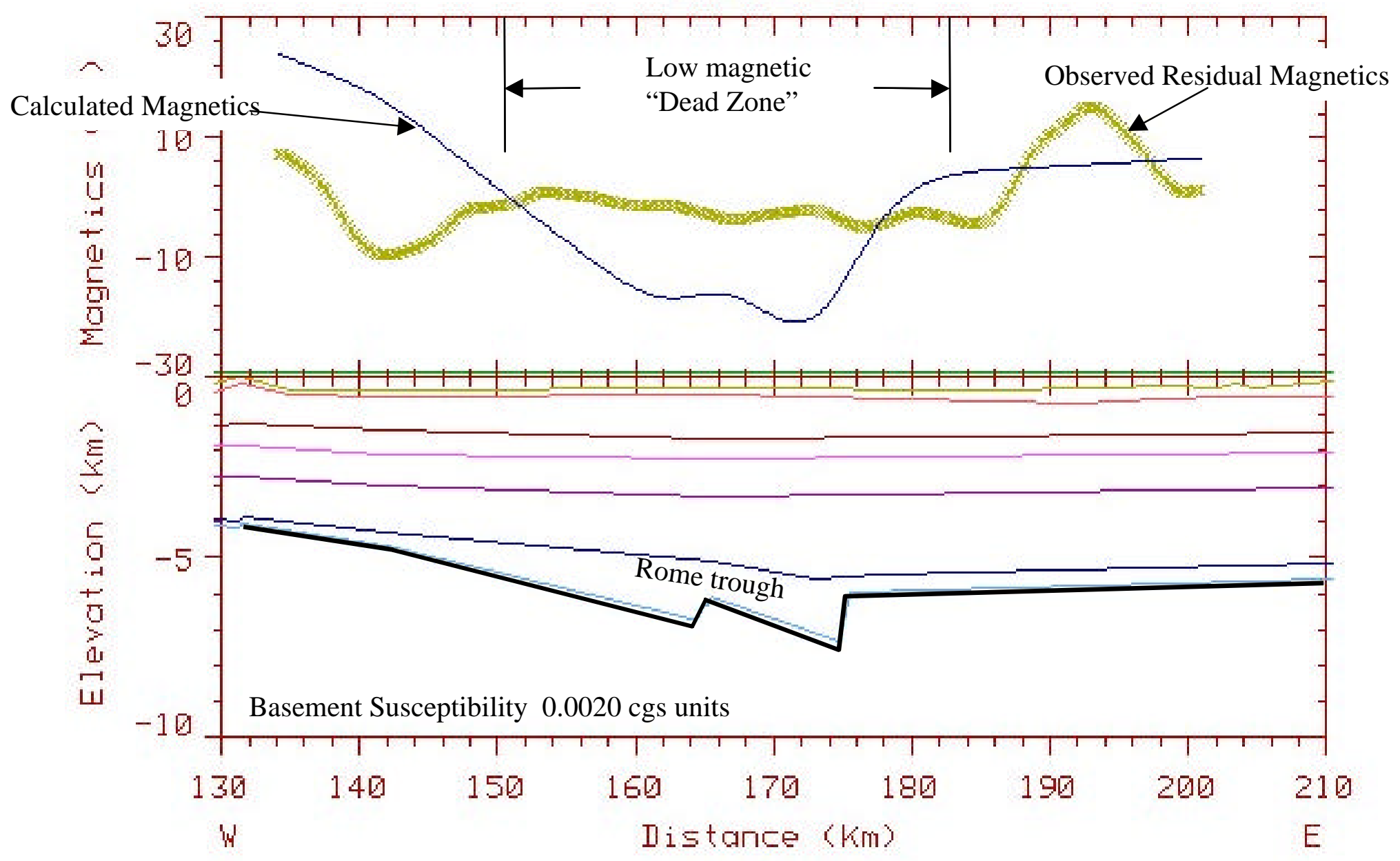

Figure 43: In this model developed along Profile 1 (see Figure 39 for location) the basement has been given a $0.0020 \mathrm{cgs}$ unit magnetic susceptibility in order to evaluate the calculated magnetic signature of the Rome trough exclusively 
To improve agreement between the calculated and observed residual magnetic intensities, a weathered deformation zone was introduced in an attempt to simulate the low amplitude and low wavelength magnetic zone (the dead zone) across the middle of profile 1 within Figure 44. Results show that the introduction of a low susceptibility weathering or deformation zone only accentuates the low magnetic intensity region that extends across the trough interior. In order to reduce the difference in residual magnetic field intensity observed across the trough, it is necessary to introduce low susceptibility material along the east and west flanks of the trough (Figure $44 \mathrm{C}$ ). Since the magnetic properties of the trough dead zone appear anomalously high with respect to the trough margin, another interpretation was developed that incorporates high susceptibility basalt flows within the low areas of the trough. Although no evidence is directly available to suggest this is possible, the distribution of deep wells does not preclude the existence of basalt flows in these areas. The possible existence of basalt flows in the Kentucky segment of the Rome trough (Ammerman and Keller, 1979) suggests that the Cambrian rifting event that gave rise to the trough, might have also included limited volcanic activity in the form of flood basalt within the West Virginia segment.

The extent of the low susceptibility regions (the dead zone of Region III, Figure 30) is also modeled along profile 1, 2 and 3 (Figure 45 A, B and C, respectively). The susceptibility of this veneer has been maintained at $0.0002 \mathrm{cgs}$ units in all three models shown on Figure 45. Additional objects were placed on the far eastern and western extents of models A and B to compensate for the large amplitude anomalies which may be associated with deeper objects (total intensity model bodies in chapters 2 and 3). 
Calculated Residual Magnetics

\begin{abstract}
A) Profile 1 with only Rome trough topography (no weathered or deformation zone)
\end{abstract}

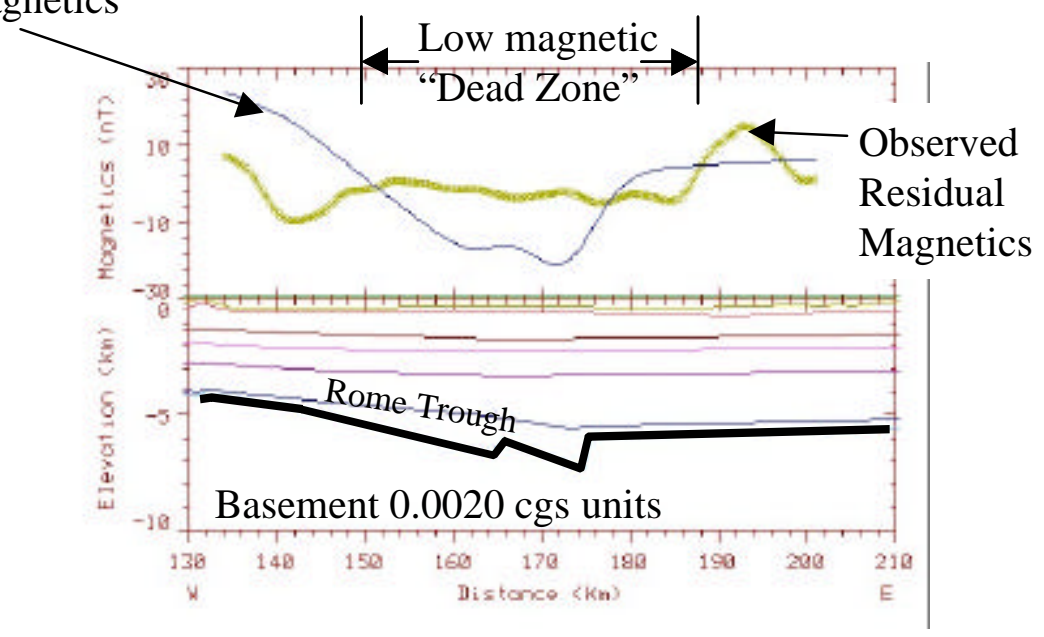

B) Profile 1 with a thick weathered or deformation zone around the Rome trough at the basement surface

C) Profile 1 with the thinnest deformation or weathered zone possible around the Rome trough at the basement surface

Low magnetic zone 0.0002 cgs units
Deformation Zone 0.0002 cgs units
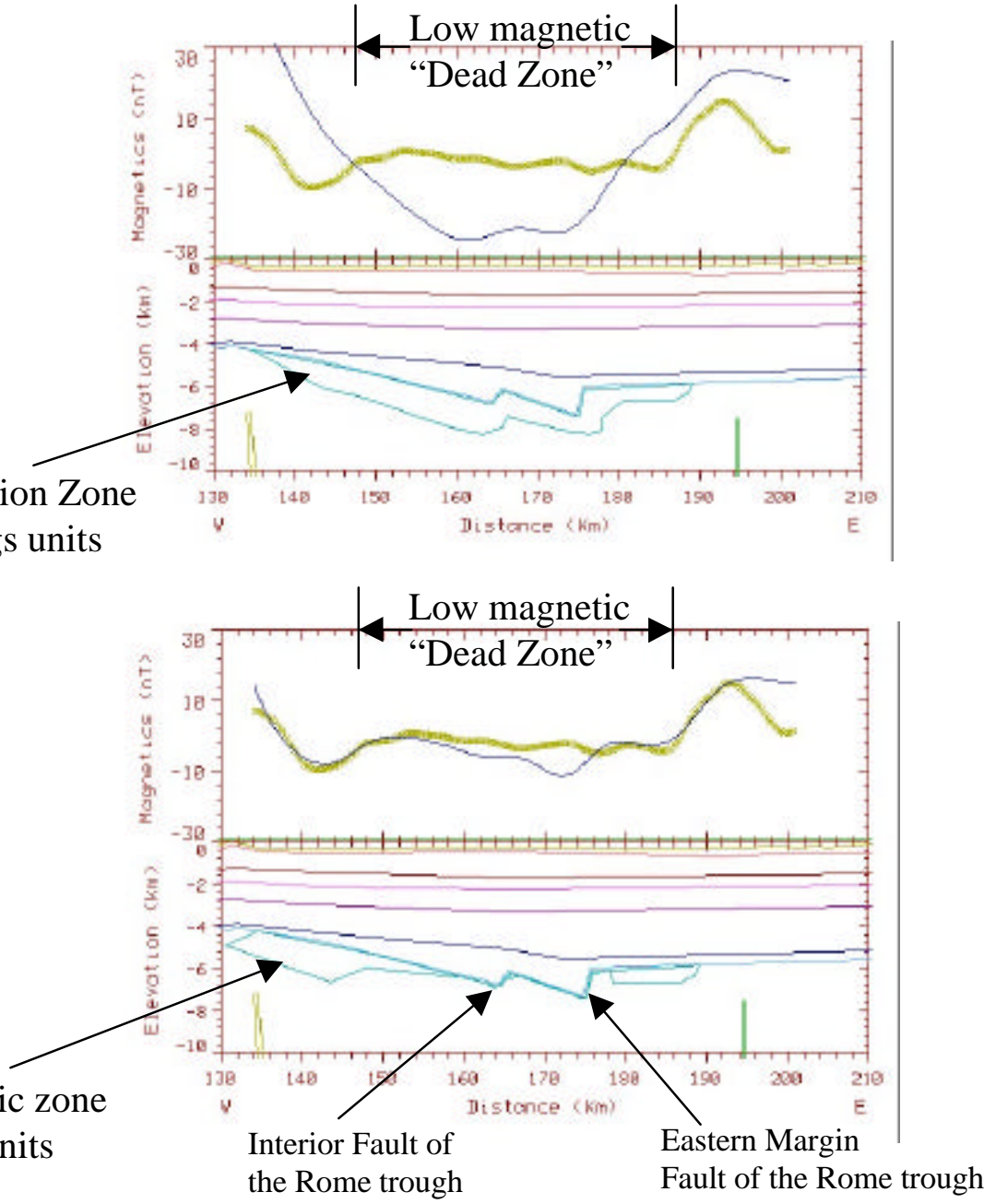

Figure 44: A) The basement has been given a $0.0020 \mathrm{cgs}$ unit magnetic susceptibility with no deformation zone B) and C) a zone of $0.0002 \mathrm{cgs}$ units has been added in order to evaluate the calculated magnetic signature of the Rome trough as a deformation zone 
A) Profile 1

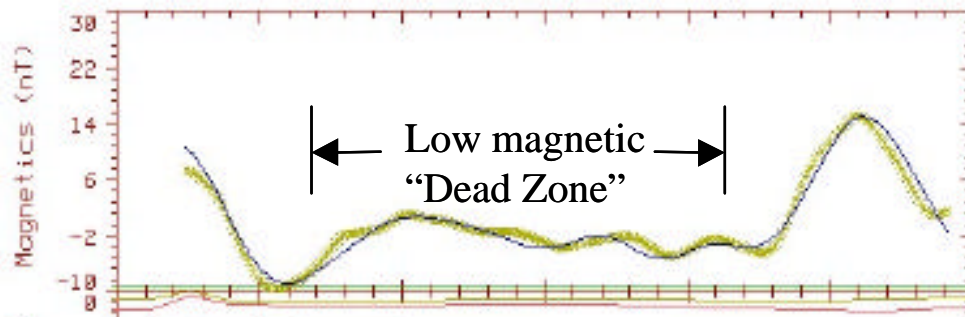

\section{Veneer Susceptibility
0.0002 cos units \\ Veneer Susceptibility
0.0002 cgs units}

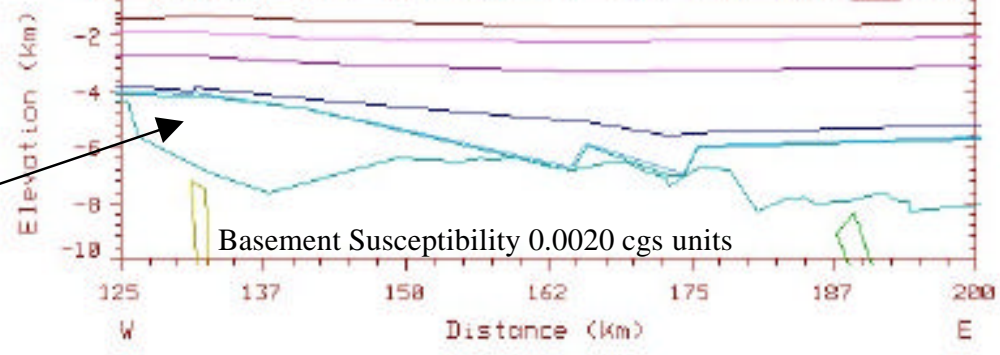

B) Profile 2

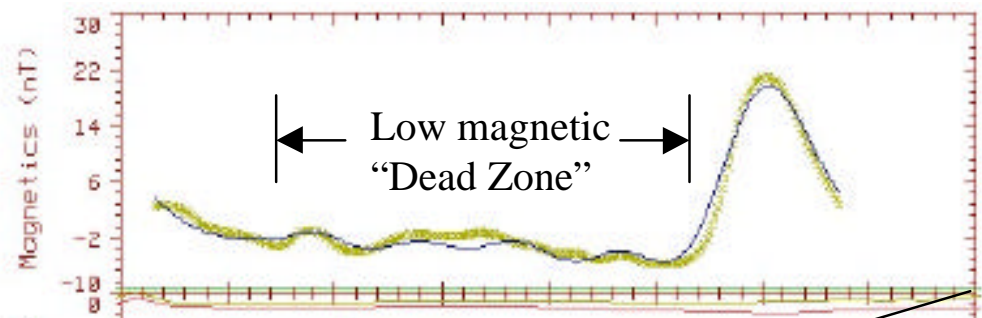

Bodies associated with deeper seated

opjects modeled in

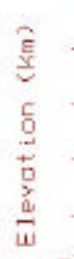
intensity anomalies (both 0.0030 cgs units)

C) Profile 3

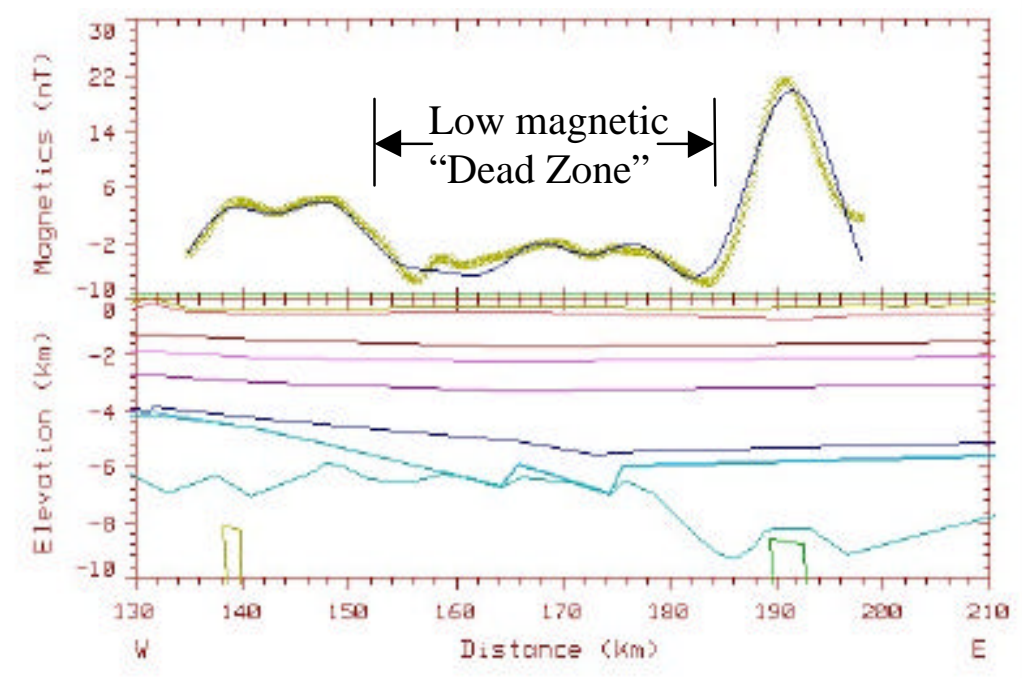

Figure 45: Models of profiles 1 (A), 2 (B), and 3 (B) are of a veneer layer on top of the basement. The veneer layer thins in the area of the dead zone. 


\subsubsection{Alternate models of the Rome trough of Central West Virginia}

Along profiles 1, 2, and 3 alternate models to the weathered or deformation zone models were developed over the Rome trough. In the basalt flow models (Figure 46) thin basalt bodies with a high magnetic susceptibility of $0.0035 \mathrm{cgs}$ units (within the range for basalt suggested by Boyd, 1996) have been intruded along the west flank of the trough and between the interior and east margin faults. Some dike "feeders" have also been included (Figure 46). The result may seem counterintuitive but is required to reduce the relative differences in the residual anomalies across the trough. Basement along the flanks of the trough must have relatively lower susceptibility than the basement within the interior of the trough. Figure $47 \mathrm{~A}$ and $\mathrm{B}$ are also basalt flow models along profiles 10 and 11. 
A) Profile 1

Basement Susceptibility

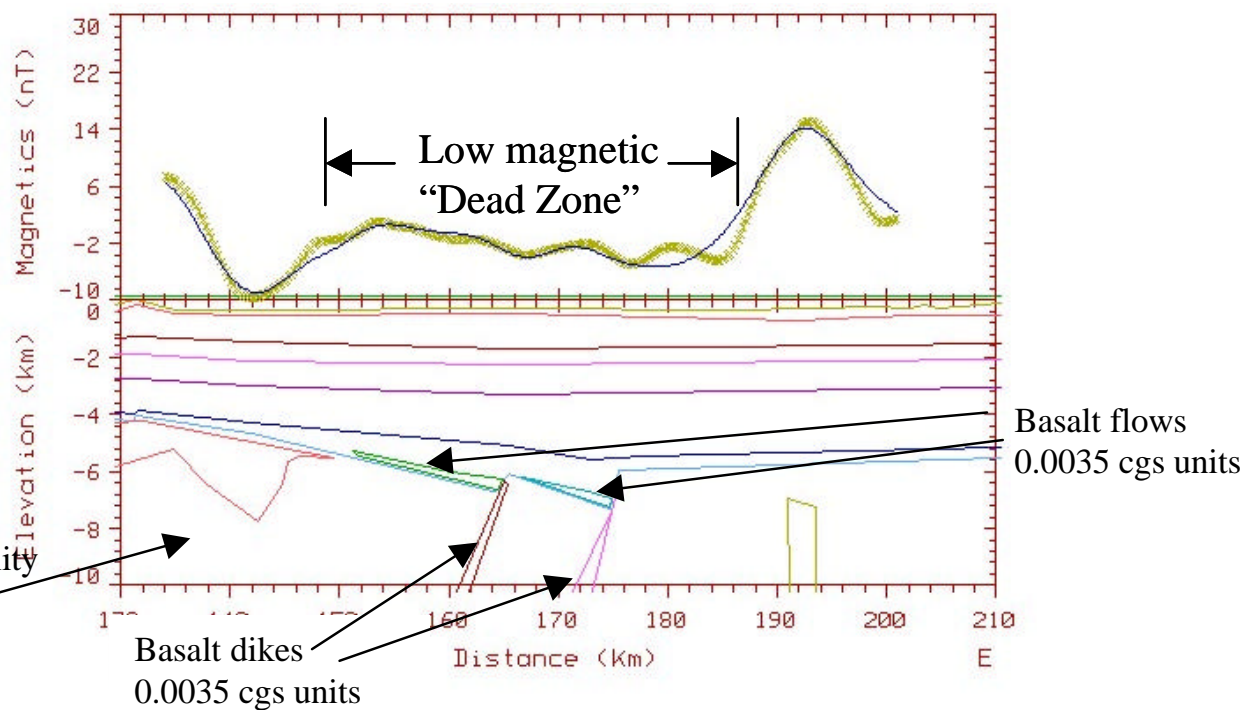

B) Profile 2

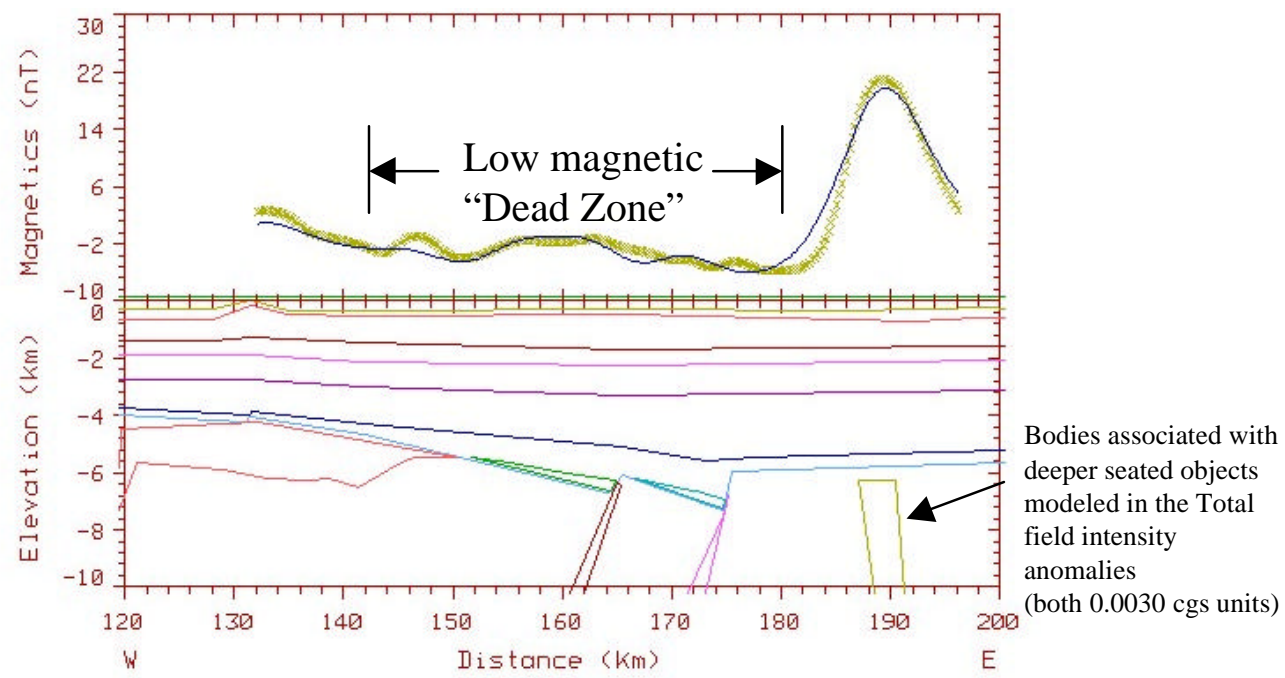

C) Profile 3

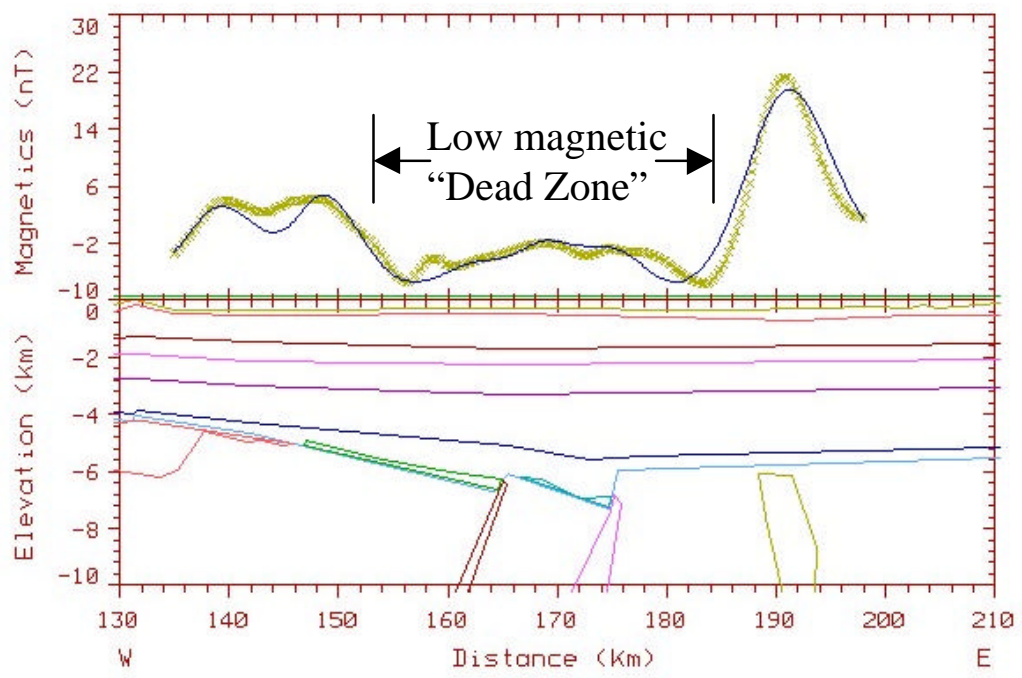

Figure 46: Models A) B) and C) are show the flow of basalt into the bottom of the Rome trough compensating for the low magnetic "Dead Zone". 


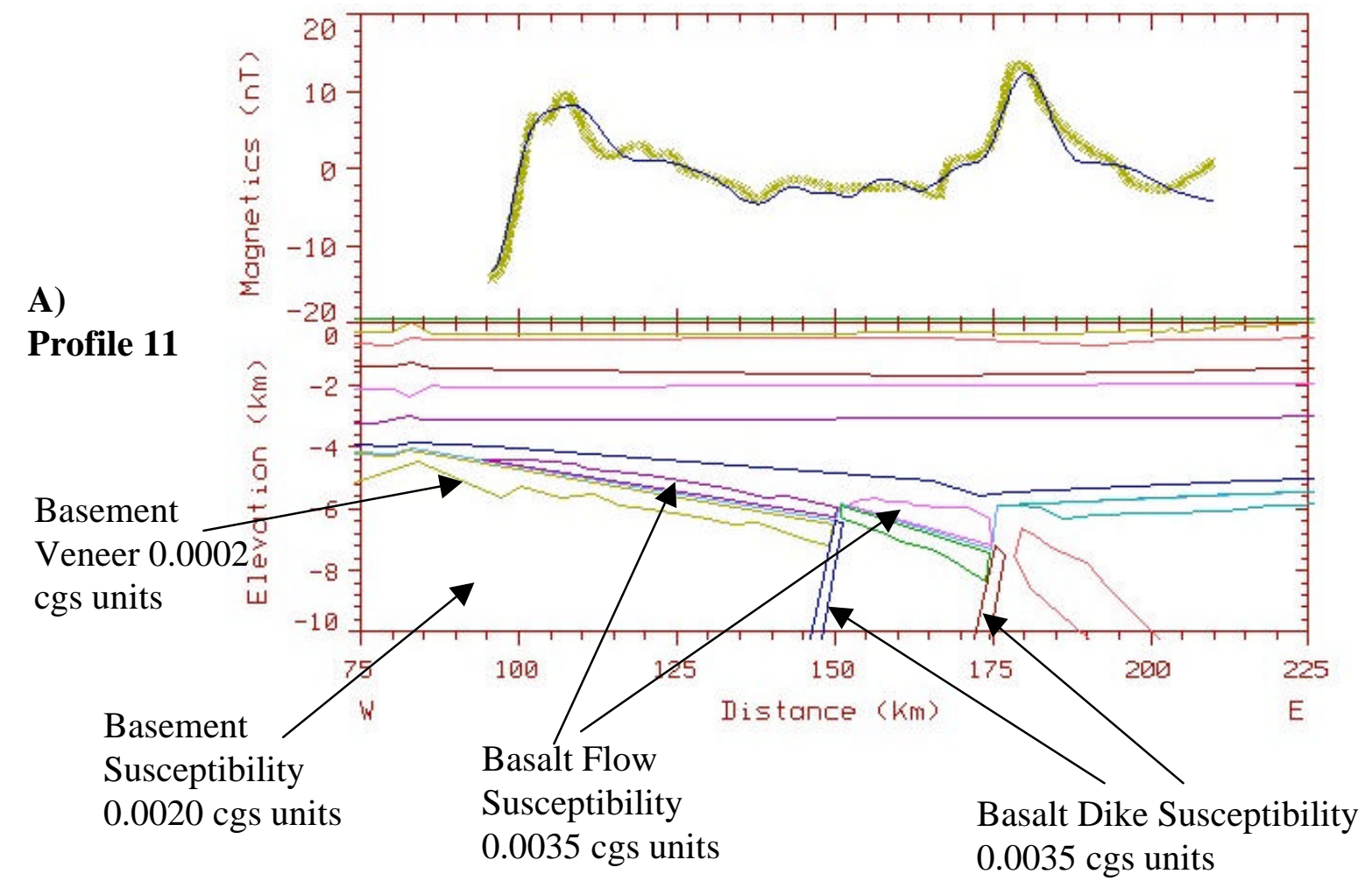

B)

Profile 10

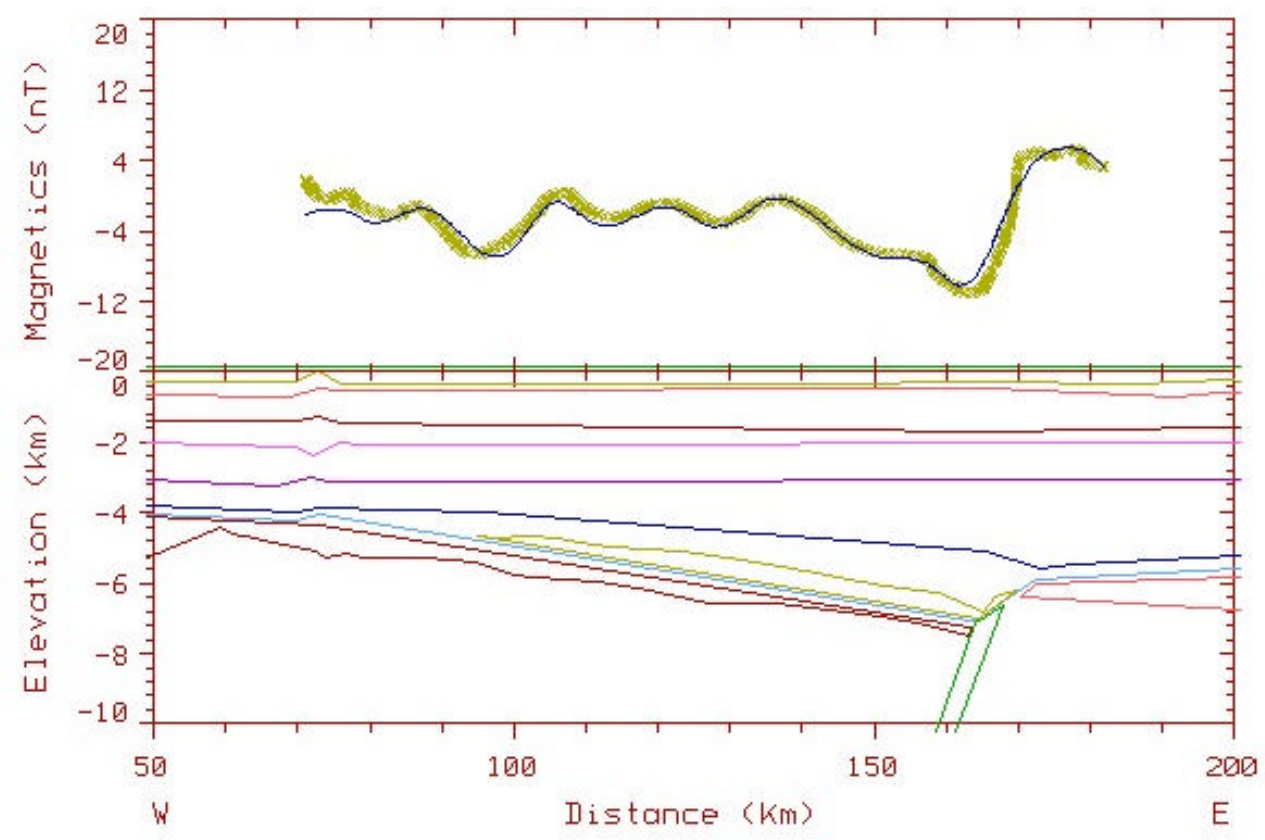

Figure 47: A) The residual magnetics along profile 11 are modeled with basalt flows into the Rome trough B) The basalt flow scenario into the Rome trough along profile 10 


\section{Chapter Six: Results and Conclusions}

This study was undertaken to evaluate the possible origins of the New York Alabama magnetic lineament (NY-Al) using total intensity aeromagnetic data. Other features in the total intensity data were also modeled. These features consisted of crossstrike zones in which the magnetic intensity is disrupted and lower than surrounding areas. Also, this study was undertaken to evaluate the subtler residual magnetic features of West Virginia.

The total intensity magnetic features of the NY-Al have been interpreted to be associated with a suture zone (King and Zietz 1978; and German 1985) or a strike slip zone (Gay, 1996). The possibility that either of these structural interpretations could produce such an anomaly were evaluated by modeling the NY-Al source object as a tabular zone of relatively high magnetic susceptibility. Various tests were undertaken to model the range of possible magnetic susceptibilities that might be associated with the NY-Al source object. These tests revealed that the range of susceptibility contrast is so great ( 0.0025 to $0.9 \mathrm{cgs}$ units) that just about any lithology could be used to model the NY-Al. The choice was made, however, to use a susceptibility contrast associated with known basic rock types (mainly basalt) which may result from the intrusion along a strike-slip (transform) zone. These models reveal that the maximum depth to the midpoint of the NY-Al source object can be no more than approximately 20 kilometers beneath current sea level, which corresponds to mid-crustal depths..

The model studies of the NY-Al reveal that the NY-Al source body can be simulated using a narrow tabular zone of constant susceptibility. This tabular shaped source body was oriented at various dip angles to simulate different tectonic 
interpretations. A near vertical dip was modeled to represent a strike slip or transform fault zone. Steep dips either to the southeast or northwest of the NY-Al were incorporated into the models to simulate possible subduction zone geometries. The dip of this zone could be varied between $32^{\circ} \mathrm{NW}$ to $27^{\circ} \mathrm{SE}$ so that it was not possible to discriminate between a northwest or a southeast dipping suture zone and vertical transform fault models.

Despite this limitation, the models make an important contribution. Previous models of the magnetic anomalies in the Appalachian region (German 1985; and Rice 1983) simulate variations in magnetic field intensity using crustal scale blocks of contrasting susceptibility. These blocks are usually bounded by vertical faults and represent tectonic interpretations very much unlike structures which are characteristic of extensional or compressional plate tectonic processes. Their models also do not honor what is currently known about basement structures in this area of the Rome trough. The models presented in this thesis take the important step of representing basement susceptibility contrasts in the form of plausible tectonic configurations. The New York Alabama lineament is considered by most (King et al. 1978; Gay, 1996) to be either a suture or strike-slip system. Since the NY-Al is an extremely straight feature through West Virginia, and because a vertical body best fits the observed total intensity magnetics, this study favors a transform fault system interpretation of the NY-Al. The east margin fault of the Rome trough does not lie along the NY-Al, however, it does lie within a few miles (4 - 8 miles) of the NY-Al. This suggests that the NY-Al source body may have influenced the location of the east margin fault of the Rome trough in West Virginia 
This study also undertakes modeling of more recent vintage higher resolution residual magnetic anomalies over the area provided by Applied Geophysics Inc. in Salt Lake City, Utah. This data reveal patterns of short wavelength anomalies that have general association with regional patterns of deformation in the basement surface and sedimentary cover. The potential significance of these anomalies was also explored in the form of various tectonic interpretations.

Previous interpretations of residual magnetic anomalies in the Appalachians and elsewhere (Gay, 1999) suggest they may arise from fault offset between regions of contrasting susceptibility. In this study, prominent features in the residual anomaly pattern where modeled as regions of extensively weathered deformation zones separated by relatively less deformed and weathered zones. These weathered zones were preferentially eroded producing topographic lows across the deformations zones. The model studies show that these are plausible scenarios. The attempt to model the low amplitude low wavelength anomalies over the Rome trough with preferentially weathered and eroded deformation zone was unsuccessful. An alternate model incorporated basalt flows of higher susceptibility material into the interior of the Rome trough provided a much better fit to the observed magnetics over the trough region.

Recent structural interpretations of the central Appalachian region (Shumaker and Wilson 1996; Wilson 2000) reveal that the reactivation of deeper basement rooted structures has played an important role in the development of structures in the Paleozoic sedimentary cover and in the localization of hydrocarbon reservoirs in the Appalachian foreland area. The magnetic model studies presented by Gay (1999) support an interrelationship of shallow sedimentary structures to variations in residual magnetic 
anomalies. The interpretations of Gay (1999) in the Powder River Basin, for example, suggest a tectonic relationship between trends in the residual magnetic anomalies and the distribution of hydrocarbon traps in that region. The model studies conducted in this thesis suggest that residual magnetic anomalies may have similar association to structures in the Appalachian foreland of West Virginia. 


\section{References Cited}

Ammerman, M.L., and G.R. Keller, 1979, Delineation of Rome Trough in Eastern Kentucky by Gravity and Deep Drilling Data: The American Association of Petroleum Geologists Bulletin, v. 63, no. 3, p. 341-353

Badger, R.L., and A.K. Sinha, 1988, Age and Sr isotopic signature of the Catoctin volcanic province: Implications for subcrustal mantle evolution, Geology, v.16, p. 692-695, August 1988

Bass, M.N., 1959, Basement rocks from the Sandhill well, Wood county, West Virginia. in Woodward, H.P., chm., A symposium on the Sandhill deep well, Wood County, West Virginia: West Virginia Geological Survey Report of Investigations 18 , p. 145-168.

Bass, M.N., 1960, Grenville boundary in Ohio; Journal of Geology, v. 68, no. 6, p.673677

Beardsley, R.W., and Cable, 1983, Overview of the Evolution of the Appalachian Basin, Northeastern Geology; v. 5, no. 3/4, p. 137-145

Boyd, T.M., 1996, Colorado School of Mines Online Notes: Introduction to Geophysical Exploration, web address:

http://www.mines.edu/fs_home/tboyd/GP311/MODULES/MAG/NOTES/rocksus $\underline{\text { html }}$

Burger, H.R., 1992, Exploration Geophysics of the Shallow Subsurface, Prentice Hall PTR, Englewood Cliffs, New Jersey, 489 p.

Dobrin, M.B., C.H. Savit, 1988, Introduction to Geophysical Prospecting, Fourth Edition, McGraw-Hill, Inc. New York, New York, 867 p.

Crowley, W.P., 1976, The Geology of the Crystalline rocks near Baltimore and its bearing on the evolution of the eastern Maryland Piedmont, Maryland Geological Survey; Report of Investigations No. 27

Gay, S.P. Jr., 1999, The Basement Fault Block Pattern: Its Importance in Petroleum Exploration, and Its Delineation with Residual Aeromagnetic Techniques, Special Paper for American Geophysical Institute

Gay, S.P., Jr., 1996, The Configuration of the Buried Southern Extension of the Grenville Province in the United States as Deduced from Aeromagnetic Data, Proterozoic Evolution in the North Atlantic Realm International Conference, Goose Bay, Labrador, Canada July $29^{\text {th }}-$ Aug. $2^{\text {nd }} 1996$, organized in part by IBTA (International Basement Tectonics Association) 
German, R.A., 1985, A Gravity and Magnetic Investigation of the New York-Alabama Lineament; M.S. Thesis; Purdue University, May 1985, 131 pp.

Gurshaw, E.A., 1995, Gravity Model Studies Across the Rome Trough of West-Central West Virginia, M.S. Project II; West Virginia University, May 1995, 48 pp.

Heald, M.T., 1981, Precambrian from Basement Well in Mingo County, West Virginia: The Association of American Petroleum Geologists Bulletin, April 1981, p. 749751

King, E.R., D.L. Daniels, W.F. Hanna, and S.L. Snyder, 1998, Magnetic and Gravity Anomaly Maps of West Virginia; USGS Miscellaneous Investigation Series Map $1-2346-\mathrm{H}$

King, E.R., and I. Zietz, 1978, The New York-Alabama lineament: Geophysical evidence for a major crustal break in the basement beneath the Appalachian basin; Geology, v. 6, p. 312-318

McGuire, W.H. and Howell, P., 1963, Oil and gas possibilities of the Cambrian and Lower Ordovician in Kentucky: Lexington, Spindletop Research Center (for Kentucky Department of Commerce), 216 p.

Rice, B.J., 1983, Major Crustal Lineaments and the Rome Trough in West Virginia, Pennsylvania State University Master's Thesis

Schwietering, J.F. and Roberts, P.A., 1988, Oil and gas report and maps of Cabell and Wayne Counties, West Virginia: West Virginia Geological and Economic Survey Bulletin B-42, 95 p., 6 pl.

Slichter, L.B., and H.H. Stearn, 1929, "Geophysical Prospecting," Am. Inst. Mining Met. Engrs., Trans.

Shumaker, R.C., 1996, Structural History of the Appalachian Basin: The Atlas of Major Appalachian Plays, West Virginia Geological and Economic Survey, Publication V-25

Shumaker, R.C., T.H. Wilson, 1996, Basement structure of the Appalachain foreland in West Virginia: Its style and effect of sedimentation: Geolgical Society of America Special Paper 308, p. 139-154.

Summerson, C.H., 1962, Precambrian in Ohio and adjoining areas: Ohio Division Geological Survey Report of Investigations 44, 16 p.

Telford, W.M., L.P. Geldart, R.E. Sheriff, D.A. Keys, 1976, Applied Geophysics, Press Syndicate of the University of Cambridge, New York, New York, 860 p. 
Turner, F.J, J. Verhoogen, 1960, Igneous and Metamorphic Petrology, International Series in the Earth Sciences, McGraw-Hill Book Company, Inc. New York, NY, $694 \mathrm{p}$.

Viso, R.F., 1999, Sequential Development of the Gassaway Structure in Braxton County, West Virginia, West Virginia University Master's Thesis, Web Address http://157.182.199.25/etd/templates/showETD.cfm?recnum=681

Wilson, T.H., 2000, Seismic Evaluation of Differential Tectonic Subsidence, Compaction, and Loading in an Interior Basin, AAPG Bulletin, Volume 84, No. 3, March 2000, p. 376

West Virginia Geological and Economic Survey (WVGES) and West Virginia Oil and Gas Conservation Commission, 1978, Aeromagnetic Map of West Virginia, contour interval 50 gammas, scale 1:250,000

Yang, C., 1998, High-Resolution Sequence Stratigraphy Approach to Basin Analysis of the Carboniferous Strata in Central and Southern West Virginia: Morgantown, WV, West Virginia Univerisity, Ph.D. Dissertation. 